\title{
Environmental Analysis and Prediction of Transmission Loss in the Region of the New England Shelfbreak
}

By

\author{
Heather René Hornick
}

B.S., University of South Carolina, 2002

Submitted in partial fulfillment of the requirements for the degree of

Master of Science

at the

\section{MASSACHUSETTS INSTITUTE OF TECHNOLOGY \\ and the \\ WOODS HOLE OCEANOGRAPHIC INSTITUTION}

September 2009

(C) 2009 Heather René Hornick. All rights reserved.

The author hereby grants to the United States Government, MIT and WHOI permission to reproduce and to distribute publicly paper and electronic copies of this thesis document in whole or in part in any medium now known or hereafter created.

Joint Program in Oceanography/Applied Ocean Science and Engineering

Massachusetts Institute of Technology

and Woods Hole Oceanographic Institution

Certified by




\title{
Environmental Analysis and Prediction of Transmission Loss in the Region of the New England Shelfbreak
}

\author{
by Heather René Hornick \\ Submitted to the Massachusetts Institute of Technology/ \\ Woods Hole Oceanographic Institution \\ Joint Program in Oceanography/ Applied Ocean Science and Engineering \\ on August 12, 2009, in partial fulfillment of the requirements \\ for the Degree of Master of Science in Oceanographic Engineering
}

\begin{abstract}
A confluence of several coastal oceanographic features creates an acoustically interesting region with high variability along the New England Shelfbreak.

Determining the effect of the variability on acoustic propagation is critical for sonar systems. In the Nantucket Shoals area of the Middle Atlantic Bight, two experiments, the New England Shelfbreak Tests (NEST), were conducted in May and June, 2007 and 2008, to study this variability. A comprehensive climatology of the region along with the experimental data provided detailed information about the variability of the water column, particularly the temperature and sound speed fields. Empirical orthogonal function (EOF) analysis of the ocean sound speed field defined a set of perturbations to the background sound speed field for each of the NEST Scanfish surveys.
\end{abstract}

Attenuation due to bottom sediments is the major contributor of transmission loss in the ocean. In shallow water, available propagation paths most often include bottom interaction. Perturbations in the ocean sound speed field can cause changes in the angle of incidence of sound rays with the bottom, which can result in changes to the amount of sound energy lost to the bottom. In lieu of complex transmission loss models, the loss/bounce model provides a simpler way to predict transmission loss changes due to perturbations in the background sound speed field in the ocean. Using an acoustic wavenumber perturbation method, sound speed perturbations, defined by the ocean EOF modes, are translated into a change in the horizontal wavenumber, which in turn changes the modal angle of incidence. The loss/bounce model calculates the loss of sound energy $(\mathrm{dB})$ per bottom bounce over a given distance based on the change in angle of incidence. Evaluated using experimental data from NEST, the loss/bounce model provided accurate predictions of changes to transmission loss due to perturbations of the background sound speed field.

Thesis Supervisor: Dr. James Lynch

Woods Hole Oceanographic Institution 


\section{Acknowledgements}

First, I want to thank my thesis advisor, Dr. Jim Lynch for his advisement and tireless support. Even before officially becoming my advisor, Jim provided me with invaluable guidance. I am grateful for Jim's direction and ability to keep me grounded and focused when I needed it most. Working with Jim has been a wonderful experience from start to finish, and I truly look forward to continuing to work together in the future. I also want to thank Dr. Glen Gawarkiewicz who unofficially co-advised me through the physical oceanography work. In addition to his careful revisions, Glen provided exceptional advice and always made time for insightful discussion. I truly enjoyed our afternoons pouring over satellite imagery and questioning the processes of the shelfbreak. I am deeply grateful to Arthur Newhall and Ying Tsong Lin for their unwavering support and patient answers to my endless questions. I would like to thank Frank Bahr for his preparation of and assistance working with the NEST Scanfish data.

I would like to give a special thanks to all of the participants of the NEST experiments and the crew of the R/V Hugh R. Sharp for the pleasure of working with them at sea.

Thanks to the wonderful WHOI Academic Programs Office, and Ronni Schwartz at MIT, who work daily to make sure that the Joint Program is a unique and outstanding experience.

To my fellow engineering students, particularly Jeff Kaeli, Wu-Jung Lee and Toby Schneider for helping me adjust to the academic rigors of our program and keeping me motivated from the beginning. The teamwork and support you have shown me are unforgettable. To all my fellow Joint Program students, the collective passion and drive among you inspires me daily. I would like to extend a special thanks to Jordan Stanway who was my sounding board throughout this process.

Ultimately, none of this would have been possible without the continuous support and dedication of my parents, Mark and Betty. Your steadfast encouragement is enough to carry me through the toughest moments and remind me that if it were easy, everyone would do it.

Finally, I would like to thank the United States Navy for funding provided through the Civilian Institutions Program. 


\section{Contents}

Table of Contents

$\begin{array}{ll}\text { List of Tables } & 7\end{array}$

$\begin{array}{lr}\text { List of Figures } & 8\end{array}$

$1 \quad$ Background $\quad 13$

$\begin{array}{ll}1.1 \text { Introduction } & 13\end{array}$

$\begin{array}{ll}\text { 1.2 Environmental Variability } & 15\end{array}$

1.3 Acoustic Uncertainty 30

1.4 Approach 36

$2 \quad$ The Environment $\quad 38$

$\begin{array}{ll}2.1 \text { Climatology } & 38\end{array}$

2.2 The NEST Experiments 43

$\begin{array}{ll}2.3 \text { NEST I } & 50\end{array}$

2.3.1 Scanfish Surveys $\quad 50$

2.3.2 Mooring Data $\quad 59$

2.3.3 NEST I Summary $\quad 64$

2.4 NEST II $\quad 66$

2.4.1 Scanfish Surveys $\quad 66$

$\begin{array}{ll}\text { 2.4.2 Mooring Data } & 77\end{array}$

$\begin{array}{ll}\text { 2.4.3 NEST II Summary } & 80\end{array}$

2.5 Mesoscale Analysis of the New England Shelf 81

2.6 Summary of the NEST Environment $\quad 87$

$3 \quad$ Acoustics $\quad 92$

3.1 Basic Acoustics of the Middle Atlantic Bight 92 
3.2 Simple Acoustic Sound Speed Profile Models 99

3.3 Quantifying the Effects of Sound Speed Perturbations 100

3.3.1 Horizontal Wavenumber Perturbation Method 105

3.3.2 Ray Theory Method 107

$\begin{array}{ll}\text { 3.3.3 Method Comparison } & 108\end{array}$

$\begin{array}{lr}3.4 \text { Experimental Results } & 123\end{array}$

4 Conclusions $\quad 130$

$\begin{array}{lr}\text { 4.1 Summary } & 130\end{array}$

$\begin{array}{ll}4.2 \text { Environment } & 131\end{array}$

$\begin{array}{ll}4.3 \text { Acoustics } & 134\end{array}$

$\begin{array}{lr}\text { 4.4 Future Work } & 138\end{array}$

$\begin{array}{ll}\text { Bibliography } & 140\end{array}$ 


\section{List of Tables}

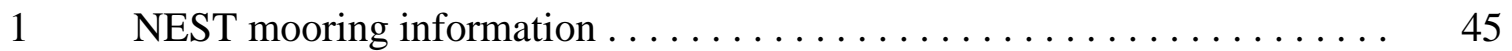

$2 \quad$ NEST I internal wave characteristics $\ldots \ldots \ldots \ldots \ldots \ldots \ldots \ldots . \ldots 6$

$3 \quad$ NEST II internal wave characteristics $\ldots \ldots \ldots \ldots \ldots \ldots \ldots \ldots . \quad 80$

$4 \quad$ Perturbation profile characteristics for method comparison. .......... 117

$5 \quad$ NEST I loss/bounce results. . . . . . . . . . . . . . . . . . . 125

$6 \quad$ NEST II loss/bounce results. . . . . . . . . . . . . . . . . . 126

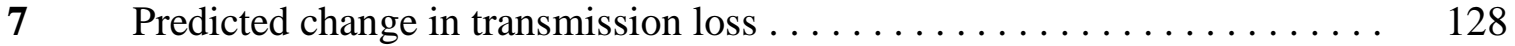

$8 \quad$ Predicted vs. calculated transmission loss . . . . . . . . . . . . . . . 129 


\section{List of Figures}

1 The Middle Atlantic Bight, from Linder and Gawarkiewicz (1998) . . . . . 15

2 SAR image of the New England Shelf. . . . . . . . . . . . . . . . . . 19

$3 \quad$ NEST I Mooring C 24-hr temperature time series. . . . . . . . . . 21

4 Climatology cross-shelf spring potential temperature $\ldots \ldots \ldots \ldots \ldots \ldots$

$5 \quad$ Climatology cross-shelf spring salinity $\ldots \ldots \ldots \ldots \ldots \ldots \ldots \ldots \ldots$

$6 \quad$ SST image of the northern Middle Atlantic Bight, May 27, 2007. . . . . . 25

$7 \quad$ Ray paths showing the afternoon effect $\ldots \ldots \ldots \ldots \ldots \ldots \ldots \ldots$

$8 \quad$ Mid-depth salinity for the Middle Atlantic Bight from Linder, et al. (2006) 29

9 Temperature profiles for transmission loss example $\ldots \ldots \ldots \ldots \ldots \ldots$

10 Sound speed profiles for transmission loss example $\ldots \ldots \ldots \ldots \ldots \ldots \ldots$

11 Transmission loss in a $10 \mathrm{~m}$ mixed layer environment $\ldots \ldots \ldots \ldots \ldots$

12 Transmission loss in a 50m mixed layer environment $\ldots \ldots \ldots \ldots \ldots \ldots$

13 Change in transmission loss from $10 \mathrm{~m}$ to $50 \mathrm{~m}$ mixed layer environment .. 35

14 Transmission loss between source and variable depth receiver . . . . . . 35

15 Climatology seasonal potential temperature . . . . . . . . . . . . . . 39

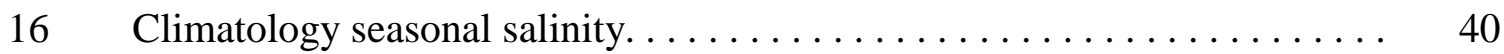

17 Climatology spring potential temperature profiles............. 41

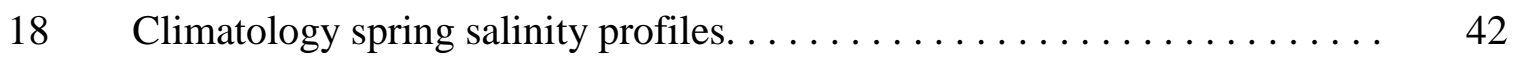

19 Climatology spring sound speed profiles. . . . . . . . . . . . 42

$20 \quad$ NEST test area, May-June, $2007-2008 \ldots \ldots \ldots \ldots \ldots \ldots \ldots \ldots \ldots$

$21 \quad$ NEST vertical profile locations. . . . . . . . . . . . . . . 45



$23 \quad$ NEST I CTD profiles $\ldots \ldots \ldots \ldots \ldots \ldots \ldots \ldots \ldots \ldots \ldots \ldots \ldots \ldots \ldots$ 


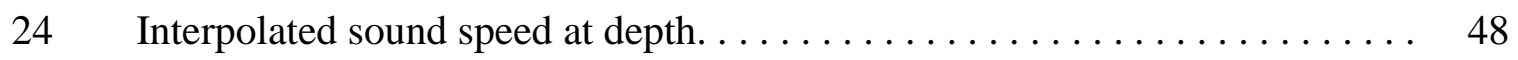

$25 \quad$ NEST I Scan 1 temperature, salinity, and sound speed profiles. . . . . . . . 52

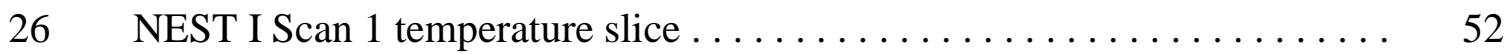

27 NEST I Scan 2 temperature, salinity, and sound speed profiles. . . . . . . . 54

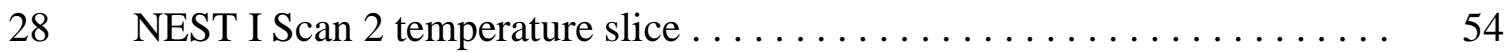

29 NEST I Scan 3 temperature, salinity, and sound speed profiles. . . . . . . 56

$30 \quad$ NEST I Scan 4 temperature, salinity, and sound speed profiles. . . . . . . 57

$31 \quad$ NEST I Scan 4 temperature slice $\ldots \ldots \ldots \ldots \ldots \ldots \ldots \ldots \ldots \ldots$

$32 \quad$ NEST I Scan 5 temperature, salinity, and sound speed profiles. . . . . . . 58

$33 \quad$ NEST I Mooring $\mathrm{C}$ temperature time series. . . . . . . . . . 61

$34 \quad$ NEST I Mooring C 24-hr temperature time series. . . . . . . . . . . 61

$35 \quad$ NEST I Mooring $\mathrm{C}$ individual thermistor time series $\ldots \ldots \ldots \ldots \ldots \ldots$

$36 \quad$ NEST I Mooring A temperature time series . . . . . . . . . . . 60

37 SST image of the Middle Atlantic Bight, May 29, 2008. . . . . . . . . 67

$38 \quad$ NEST II Scan 1 temperature, salinity, and sound speed profiles. . . . . . . 68

$39 \quad$ NEST II Scan 1 temperature slice $\ldots \ldots \ldots \ldots \ldots \ldots \ldots \ldots \ldots \ldots \ldots$

$40 \quad$ NEST II Scan 2 temperature, salinity, and sound speed profiles. . . . . . . 70

$41 \quad$ NEST II Scan 3 temperature, salinity, and sound speed profiles. . . . . . . 71

42 Comparison of NEST II Scan 3 profiles. . . . . . . . . . . . . 72

$43 \quad$ NEST II Scan 3 temperature slice. . . . . . . . . . . . . . 72

$44 \quad$ NEST II Scan 4 temperature, salinity, and sound speed profiles . . . . . . . 74

$45 \quad$ NEST II Scan 4 temperature slice. . . . . . . . . . . . . . 74

$46 \quad$ NEST II Scan 5 temperature, salinity, and sound speed profiles . . . . . . 76

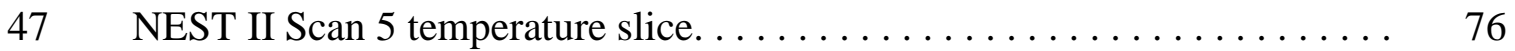


$48 \quad$ NEST II Mooring $\mathrm{C}$ temperature time series $\ldots \ldots \ldots \ldots \ldots \ldots \ldots$

$49 \quad$ NEST II Mooring B temperature time series $\ldots \ldots \ldots \ldots \ldots \ldots \ldots$

$50 \quad$ NEST II Mooring B individual thermistor time series. . . . . . . . . . 79

$51 \quad$ SST image for the Middle Atlantic Bight, May 26, 2007. . . . . . . 83

$52 \quad$ SST image for the northern Middle Atlantic Bight, May 26, $2007 \ldots \ldots$. . . 84

$53 \quad$ SST image for the Middle Atlantic Bight, May 30, 2007. . . . . . . . . 84

$54 \quad$ SST image for the northern Middle Atlantic Bight, May 30, $2007 \ldots \ldots \ldots$

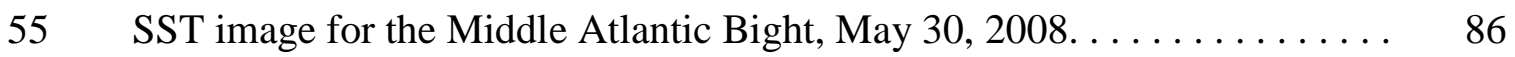

$56 \quad$ SST image for the northern Middle Atlantic Bight, May 30, $2008 \ldots \ldots \ldots$

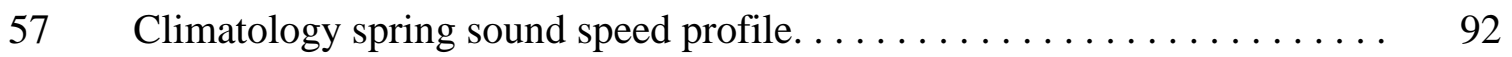

58 Cross-front transmission loss $\ldots \ldots \ldots \ldots \ldots \ldots \ldots \ldots \ldots \ldots \ldots \ldots$

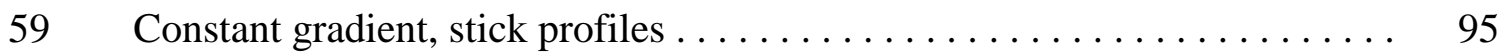



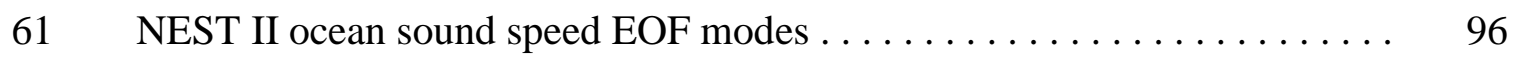

$62 \quad$ Simple acoustic vertical sound speed profile models. . . . . . . . . . . . 97

63 Magnitude of the reflection coefficient .................. 104

64 Mean climatology cross-front isovelocity profiles. . . . . . . . . . . . 110

65 Transmission loss for cross-front isovelocity profiles . . . . . . . . . 111

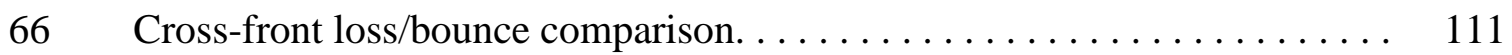

67 Perturbation profiles $(\min / \max )$ for method comparison. . . . . . . . . 114

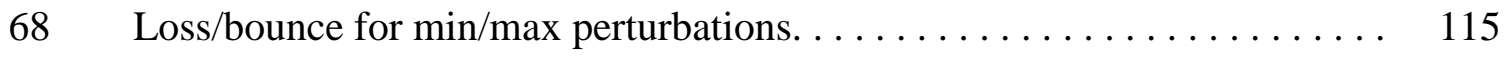

69 Loss/bounce for $\min / \max$ perturbations $\left(0-45^{\circ}\right) \ldots \ldots \ldots \ldots \ldots \ldots$

$70 \quad$ Loss/bounce for $\min / \max$ perturbations $\left(45-65^{\circ}\right) \ldots \ldots \ldots \ldots \ldots \ldots$

71 Perturbation profiles $( \pm 5 \mathrm{~m} / \mathrm{s})$ for method comparison $\ldots \ldots \ldots \ldots \ldots \ldots$ 
72 Loss/bounce for $\pm 5 \mathrm{~m} / \mathrm{s}$ perturbations $\left(0-45^{\circ}\right) \ldots \ldots \ldots \ldots \ldots \ldots \ldots$

$73 \quad$ Loss $/$ bounce for $\pm 5 \mathrm{~m} / \mathrm{s}$ perturbations $\left(45-65^{\circ}\right) \ldots \ldots \ldots \ldots \ldots \ldots \ldots$

74 Transmission loss from wavenumber perturbation method . . . . . . . . 121

75 Transmission loss from ray theory method. . . . . . . . . . . 121

$76 \quad$ NEST I Scan 1 ocean sound speed EOF modes . . . . . . . . . . . . . . 124

77 Perturbation profiles from NEST I Scan 1 EOF modes . . . . . . . . . . 124

78 Typical shallow water ocean sound speed EOF modes . . . . . . . . 127 


\section{Chapter 1: Background}

\subsection{Introduction}

It has long been understood that the ocean is a highly variable environment. For many decades, oceanographers have studied the various features of the ocean, trying to measure and predict their nature. Oceanographic features and processes exist on a variety of spatial and temporal scales. Frequently, several processes interact to form a complex environment across multiple scales.

Varying sound propagation in the ocean is directly correlated to changes in the water column and seafloor, due to the effect of these characteristics on the speed of sound. These changes can sometimes be offset or exploited, with a priori knowledge, or by selection and placement of sensors for a specific purpose.

Uncertainty is a measure of unknown variability which leads us to question the accuracy of specific acoustic propagation predictions. For instance, how well does a transmission loss (TL) model accurately predict transmission loss in the real ocean? Is the predicted TL reliable for a given purpose in this environment? How quickly will the environment change and make this prediction invalid? These are practical questions which drive us to improve our understanding of uncertainty.

Uncertainty in ocean model predictions can come from several sources including the governing equations of the model, field resolution, and input parameters. We are not interested in updating existing transmission loss models. Instead, we seek to fully 
understand the variability of the input parameters, which are commonly water column properties and sediment characteristics, and the ocean processes which affect them. A better understanding of these parameters and their associated variability will lead to a greater understanding of the inherent uncertainty of acoustic propagation conditions.

The area of focus is the Middle Atlantic Bight (MAB), a geographic region from Cape Hatteras, NC, to Cape Cod, MA, encompassing waters from the coastline to the edge of the continental shelf. Two experiments, the New England Shelfbreak Tests (NEST), took place within the Nantucket Shoals region of the MAB, in 2007 and 2008 (Figure 1). The waters of the MAB are a great resource to commercial fisheries, oceanographers studying the dynamic processes of the shelfbreak region, and recently as a potential site for a renewable wind energy farm. The dynamic environment of the $\mathrm{MAB}$ is a result of the intersection of two water masses from the continental shelf and slope. Cool, fresh water flows from the north and over the continental shelf. Warm, saline slope water originates from the Gulf Stream western boundary current. The shelfbreak front separates the water masses and is a dominant feature within the region. Often, as a result of the shifting front, shelf water creates a mid-depth layer of cool, fresh water referred to as the Cold Pool or (acoustically) the Cold Pool duct. The interaction of water masses along the varying topography of the shelfbreak creates an exciting area on which to focus our study. 


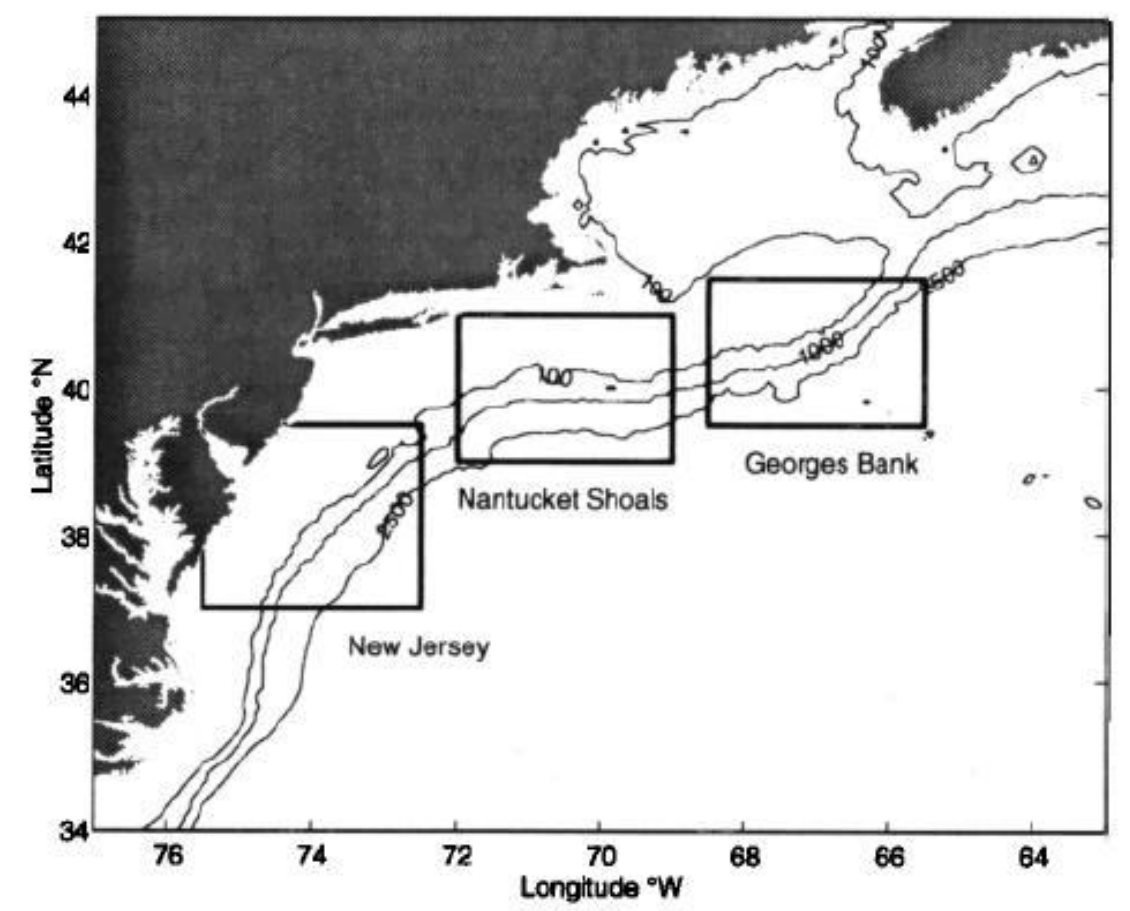

Figure 1. Map of the Middle Atlantic Bight, showing the location of the Nantucket Shoals (Linder and Gawarkiewicz, 1998).

\subsection{Environmental Variability}

Variability of the ocean leads to perturbations in the ocean sound speed field.

When the oceanographic variability is not well quantified, it translates to uncertainty in our acoustic predictions. However, if we are able to provide a measure of the environmental variability, through sampling and statistics, we can convert that quantity into a defined measure of the variability and uncertainty of acoustic predictions. Quantifying acoustic uncertainty provides the operator with a measure of confidence about the prediction and can lead to better exploitation of the receiver operator characteristic (ROC) curves. 
There are a seemingly unlimited number of features and processes of the ocean that demonstrate variability. These include tides, ocean fronts, currents, internal waves, internal tides, the surface mixed layer, diurnal heating, biomass, sea surface roughness, wind generated transport, evaporation, and ice cover. Each of these mechanisms can have an effect on temperature, salinity, density, and water phase, and thus on acoustic propagation, although not all are relevant in every scenario. Our focus will be on those features and processes which are relevant to the MAB continental shelf and shelfbreak region. To begin to quantify the variability of the ocean, we must understand the range of spatial and temporal scales over which these mechanisms vary. Ocean features and processes are often categorized by basin, meso- and micro- scale. The basin scale generally refers to the global ocean and monthly time scales or longer. Included are basin scale circulations such as gyres and western boundary currents, large scale ocean interior waves, and seasonal fluctuations. Mesoscale features are generally on the order of 10$100 \mathrm{~km}$ and vary temporally from days to months. Examples of mesoscale features are many fronts and currents, warm and cold core eddies, and tides. Microscale features have much shorter spatial and temporal scales on the order of $10 \mathrm{~m}$ to $10 \mathrm{~km}$, and minutes to hours. Microscale features include the surface mixed layer and internal waves. Depending on location, these features vary in strength and therefore in their magnitude of effect on acoustic propagation.

One of our goals is to determine the relative strength of these meso- and microscale features to one another, in order to determine the key contributors to acoustic variability within a particular region. Some features are well understood, well predicted, 
and although they may be highly variable, contribute little to the overall acoustic uncertainty due to water column processes. However, many other features which are not well sampled or understood may be a major source of environmentally generated uncertainty. Common meso- and micro- scale features which dominate the shelfbreak region include the tidal cycle, internal waves, the shelfbreak front and both offshore and shelfbreak eddies.

Tides vary regionally in their magnitude and frequency. Generally, barotropic tidal cycles are well understood, and surface elevations in particular are reasonably well predicted. The time scale of the barotropic tidal cycle is predominantly diurnal or semidiurnal with some areas having mixed tides. The MAB experiences primarily semidiurnal barotropic tides. The lunar cycle also affects the relative strength of these tides, creating maximum spring and neap tides which provide additional variability. Since tidal changes have the most effect closest to shore, the effect of the tides on acoustic propagation is not of primary concern in the open ocean. However, even in coastal waters such as the MAB shelf and shelfbreak, the effects of barotropic tides are generally not the dominating factor in changing propagation conditions for transmission loss.

Baroclinic tides, or internal tides, are another source of variability in the ocean. They can result from well-defined water column stratification and the interaction of barotropic tides with bathymetric features causing mixing and non-uniform vertical velocities. Unlike barotropic tides, baroclinic tides are highly variable and not so easily predicted. Along the New England shelf, variability of baroclinic tides results from 
seasonal changes in stratification and movement of the shelfbreak front (Shearman \& Lentz, 2004). The effects of baroclinic tides on acoustic propagation are mainly dependent upon the internal waves created by them and their magnitude.

Internal waves are a ubiquitous feature of the shelfbreak region, common when irregular topography, intense water column stratification, and strong tidal influences combine to create baroclinic tides. Important because they can propagate long distances, sometimes up to several hundred kilometers, and transport significant mass and momentum, internal waves are difficult to model and predict. Furthermore, the variability of internal waves can significantly alter the acoustic field as they propagate through an area, irregularly displacing the pycnocline. Several studies have been conducted highlighting the common presence of internal waves along the New England shelf (Apel \& Jackson, 2002; Colosi, et al., 2001; Jackson, 2004; Lynch, Lin, Duda, Newhall, \& Gawarkiewicz, 2009; Tang, et al., 2006).

Internal waves generated at the shelfbreak are often soliton like, non-linear waves. Although these waves travel in the interior of a fluid, they also cause some local modulation of surface wave height. The complex structure of an internal wave train begins with a soliton as the leading edge of a bore, a series of decaying oscillations, followed by a depression of the pycnocline and flattening of the sea surface. Because the effects of internal waves may be detected on the surface, synthetic aperture radar (SAR) imagery has been a primary sensor for detecting internal waves. The train of oscillations, often referred to as the soliton packet, followed by the decreased surface energy is 
sometimes apparent in SAR images. Figure 2 shows a SAR image of the New England shelf from August 8, 1996, in which several internal wave packets are visible.

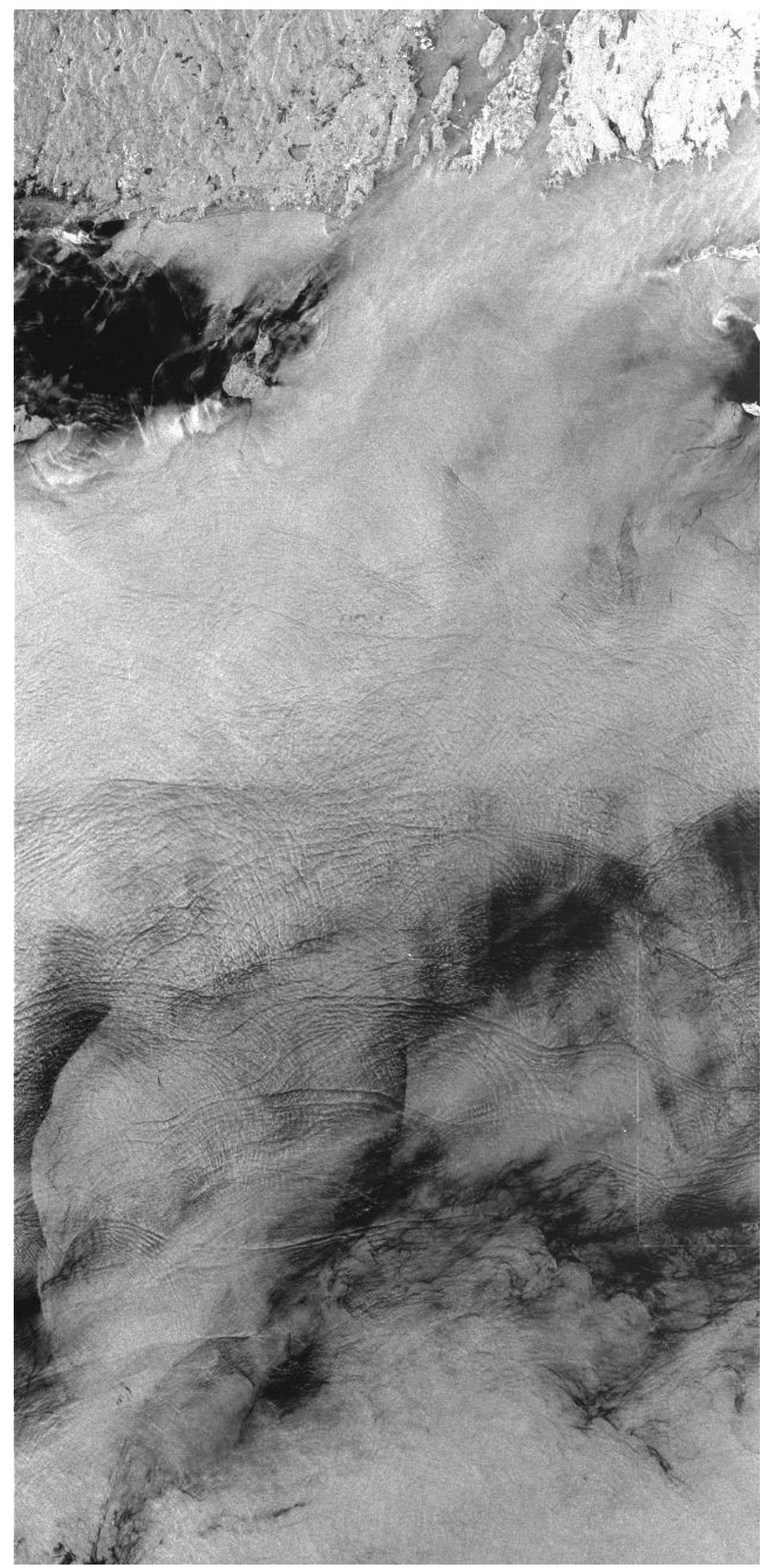

Figure 2. SAR image of the New England shelf on August 8,1996 shows the surface signature of internal solitons propagating shoreward from the continental shelfbreak. (ERS-2, C-Band, VV) CESA 1996. 
Soliton packets are generally formed by barotropic tides interacting with the shelfbreak. The packets can vary in number of oscillations from a few to several dozen. The number of oscillations within a packet usually increases as the wave propagates away from the generation point and ages. In general, the packets are nonsinusoidal and rank ordered. The amplitude, wavelength, and crest length of individual oscillations decreases from the front to the back of the soliton packet. Common length scales for the New England shelf are 1-10km packet length, 5-25m amplitude, and $0.5-1.0 \mathrm{~m} / \mathrm{s}$ long wave speed (Apel \& Jackson, 2002).

Generation, propagation, and dissipation of internal waves are not completely understood. Apel \& Jackson (2002) provides two theories for the generation phase. First, internal waves are created by the formation of a lee wave down current of a steep change in bathymetry, such as the shelfbreak. Second, the barotropic tide causes direct production of rank ordered solitons by shear flow instabilities just up current of the shelfbreak. Internal waves then propagate away from the generation point. The propagation phase is on the order of the semi-diurnal tidal period. Dissipation of internal waves occurs due to shoaling bathymetry which slows the speed of advance and erodes the amplitudes of oscillation.

Internal waves may be nonlinear and difficult to capture in ocean modeling, but their strength and frequent presence inshore of the shelfbreak make them an important feature of our analysis. Figure 3 shows a 24-hr time series of temperature measurements from a $152 \mathrm{~m}$ isobath mooring which measured the passage of internal waves in the 
Nantucket Shoals on the New England continental shelf. Several models have been developed which show the structure and propagation characteristics of soliton packets very well, however, prediction of the location and frequency of internal waves is not yet available. The effects of internal waves on the acoustic field can be quite significant and therefore must be included when estimating the environmental variability of the shelfbreak region.

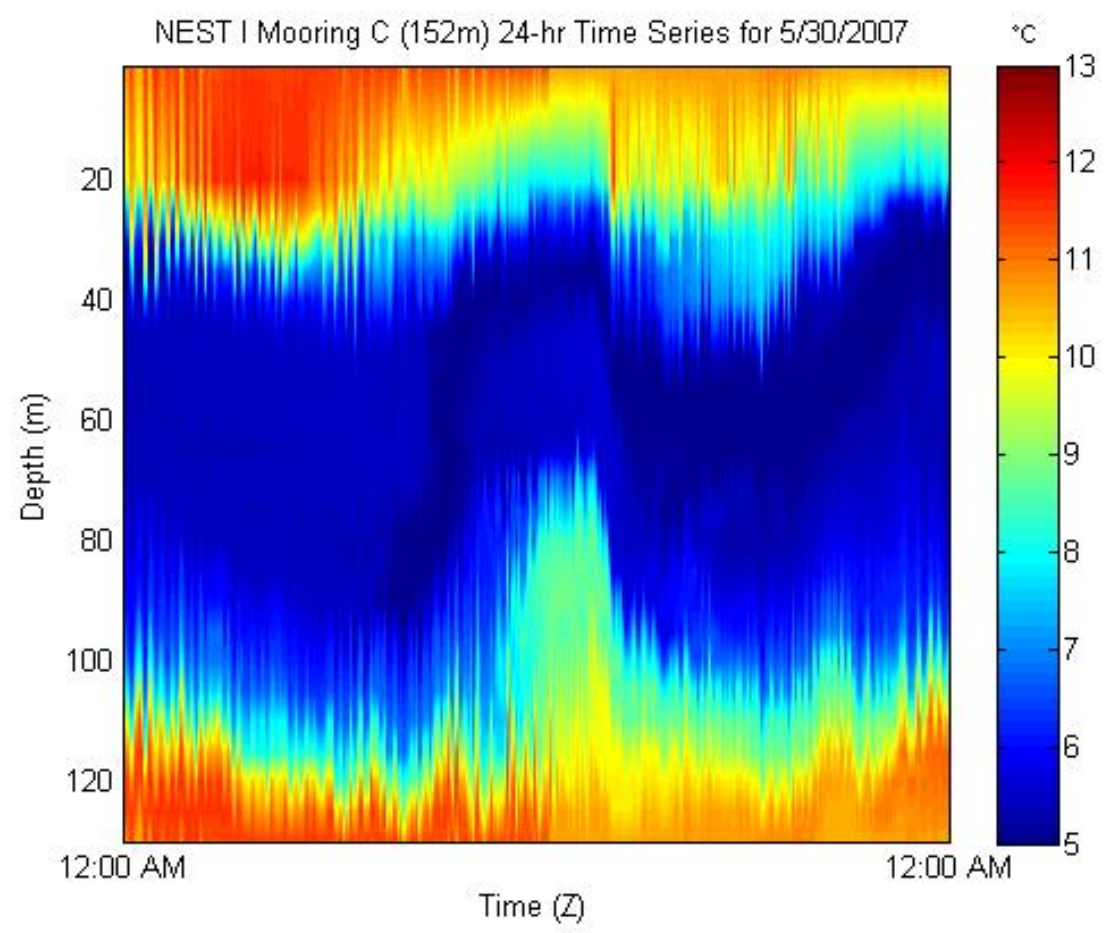

Figure 3. NEST I 24-hr temperature $\left({ }^{\circ} \mathrm{C}\right)$ time series from Mooring C (152m isobath) showing internal wave activity.

The two main water masses in the northern MAB are shelf water and slope water. Shelf water is a result of cold, fresh Scotian Shelf water and warm, saline continental slope water mixing in the Gulf of Maine (Mountain, 2003). The mixed water flows around Georges Bank, through Nantucket Shoals, and further into the MAB. Inter-annual 
salinity variability is driven by both the fresh water content from the Scotian Shelf water and fresh water river runoff directly into the MAB (Linder \& Gawarkiewicz, 1998). Shelf water is approximately $4-13^{\circ} \mathrm{C}$ and $32 \mathrm{PSU}$, although Mountain (2003) defines shelf water as less than 34 PSU. In contrast, slope water is warm and saline, with a temperature range of $13-18^{\circ} \mathrm{C}$ and a salinity of $35.5 \mathrm{PSU}$. Slope water flows from the outer edge of the Gulf Stream current to the continental slope throughout the entire MAB. In some areas of the MAB, the mixing of shelf water and slope water make it difficult to identify the characteristic water masses. However, in the northern MAB, the shelfbreak front usually creates a well-defined boundary between the water masses.

Along the shelfbreak in the northern MAB, the shelfbreak front defines the boundary between cold, fresh shelf water and warm, saline slope water. The scale of the front is generally $20 \mathrm{~km}$ across shelf with a horizontal temperature variation of roughly $5^{\circ} \mathrm{C}$ (Figure 4) and salinity variation of roughly 2 practical salinity units (PSU) (Figure 5). Previous characterizations of the shelfbreak front have used the $10^{\circ} \mathrm{C}$ isotherm or the $26.5 \mathrm{~kg} / \mathrm{m}^{3}$ isopycnal to define the front. Here we will define the front by the 34.5 PSU isohaline (Beardsley \& Flagg, 1976; Linder \& Gawarkiewicz, 1998). The foot of the front, where the 34.5 PSU isohaline intersects the bottom, is usually located within $10 \mathrm{~km}$ of the $100 \mathrm{~m}$ isobath, while the location of the surface outcrop is much more variable. The front is generally vertical with increased subsurface structure in the spring, summer and fall, which can be described by two characteristic slopes; a lower region of relatively constant slope, and an upper region with a seasonally variably slope. The dominant feature of the shelfbreak front is the baroclinic frontal jet which varies 
seasonally in strength, width, and location. In Nantucket Shoals, the mean jet location is $5 \mathrm{~km}$ offshore of the $100 \mathrm{~m}$ isobath, while seasonally the jet varies from $3 \mathrm{~km}$ onshore to $12 \mathrm{~km}$ offshore, in Oct-Nov and Dec-Jan, respectively. The core velocity of the jet ranges from $0.17-0.30 \mathrm{~m} / \mathrm{s}$, with the strongest flow occurring in the spring. The jet is $60 \mathrm{~m}$ deep year round, with a horizontal width of $15-20 \mathrm{~km}$, with exception of Dec-Jan, when the width of the jet increases up to $40 \mathrm{~km}$ (Linder \& Gawarkiewicz, 1998). The jet is located close to the shelfbreak near the foot of the front, rather than near the surface outcrop. The shape and strength of the shelfbreak front, and associated jet, are important factors in determining how acoustic propagation is affected as sound crosses the shelfbreak.

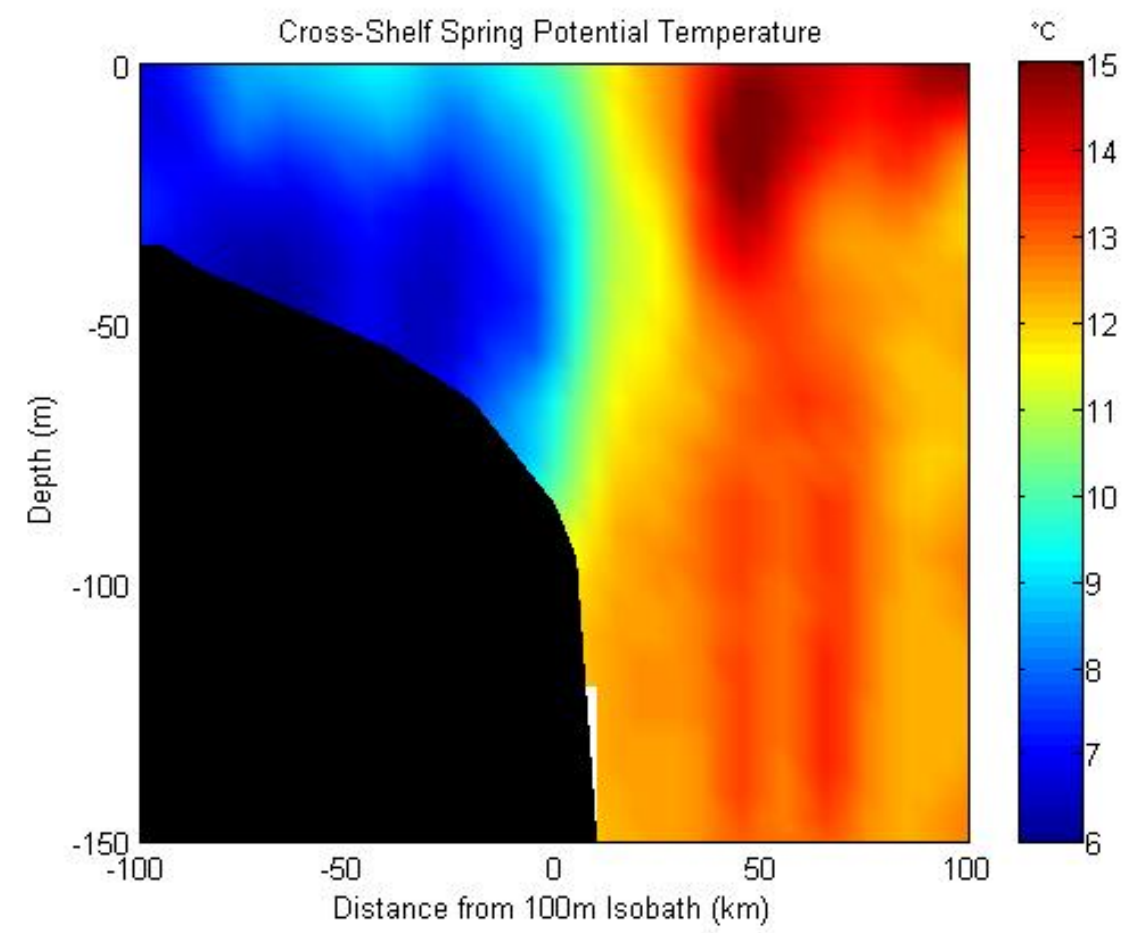

Figure 4. Nantucket Shoals spring potential temperature $\left({ }^{\circ} \mathrm{C}\right)$ cross-shelf section as compiled in Linder, et al. (2006). 


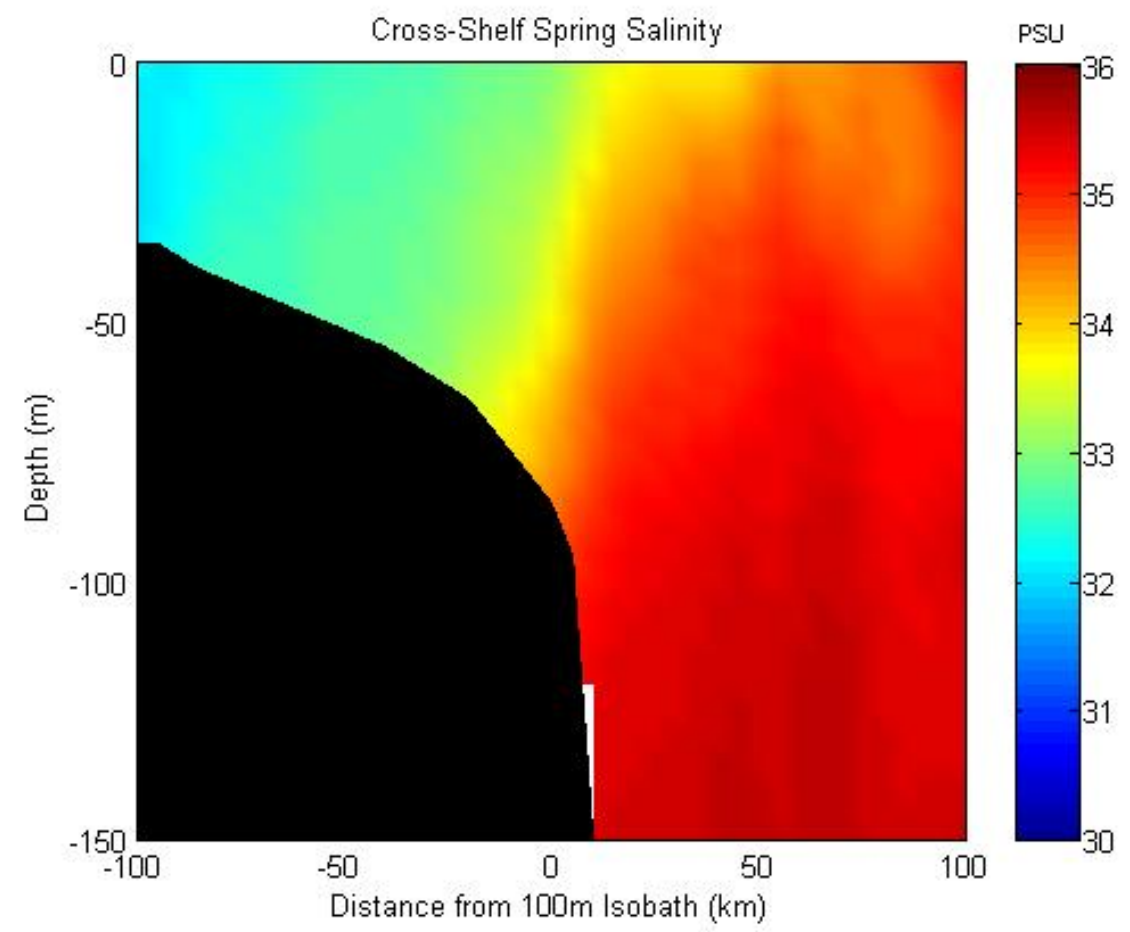

Figure 5. Nantucket Shoals spring salinity (PSU) cross-shelf section as compiled in Linder, et al. (2006).

Mesoscale eddies, or rings, formed from western boundary currents, such as the Gulf Stream, are dynamic ocean features that can have significant impacts on acoustic propagation conditions. An anomalous water mass separated from the main body of the current due to a meander is called a ring, in order to differentiate it from the small-scale eddies which spawn from the main current or the perimeter of the large eddies (Joyce, 1984). The Gulf Stream commonly sheds warm core rings consisting of warm Sargasso Sea water and cold core rings of relatively colder slope water. At any given time, cyclonic (cold core) rings cover $15 \%$ of the Sargasso Sea, and anti-cyclonic (warm core) rings cover $40 \%$ of the Western Atlantic continental margin (Colling, 1989). The typical scale of these rings is $100-150 \mathrm{~km}$, with cold core rings usually larger than warm core rings. A composite sea surface temperature (SST) satellite image from May 27, 2007 
shows the presence of warm and cold core rings off of the Gulf Stream western boundary current (Figure 6).

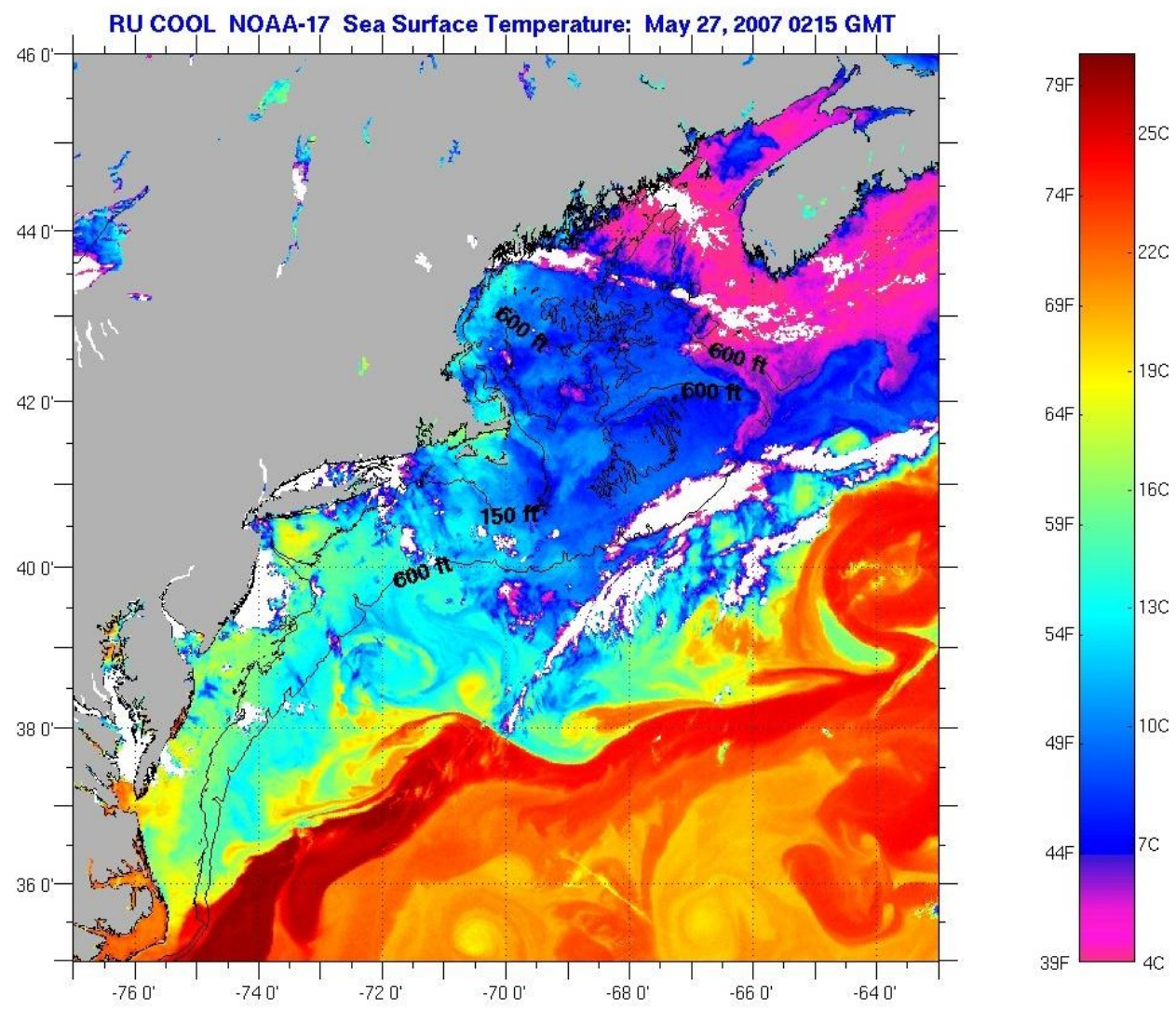

Figure 6. Satellite sea surface temperature composite showing the presence of Gulf Stream warm and cold core rings in the northern Middle Atlantic Bight. Image from Rutgers University Coastal Ocean Observation Lab (http://marine.rutgers.edu/mrs/sat_data/).

Warm core rings are an important feature of the MAB because once generated they move toward the North Atlantic shelf and often interfere with the structure of the shelfbreak front (Csanady, 1979). Formed to the north of the Gulf Stream, warm core rings generally move west at $3-5 \mathrm{~m} / \mathrm{s}$, with internal currents up to $2 \mathrm{~m} / \mathrm{s}$, and remain for 68 months before mixing with surrounding waters or being reabsorbed back into the Gulf Stream (Joyce, 1984). Warm core rings begin to form when a parcel of anomalous water is isolated from the main current, usually due to a large meander pinching off of the main 
body. The less dense warm water spreads out over the surface at a velocity proportional to the available potential energy. As the water spreads, it is deflected by the Coriolis force, creating rotation of up to $2 \mathrm{~m} / \mathrm{s}$. If the original parcel of warm water is large enough to prohibit disintegration during the generation process, geostrophic balance is established and the warm core ring can persist, self-contained. Due to friction and entrainment of surrounding waters, the geostrophic current, which contains the ring, slows down. The warm water in the core begins to spread and the Coriolis force again restores the tangential velocity. This continues until the core water is thin enough to be mixed into the surface layer or the ring is reabsorbed in the main current (Csanady, 1979). Particularly in the MAB, warm core rings, due to their structure, movement, and potential interaction with the shelfbreak, can create exciting and variable effects on the acoustic field.

Ocean temperature changes on a variety of scales. Latitudinal and seasonal changes in water temperature are due to the Earth's position relative to the sun. Similar to seasonal changes on land, the Earth's rotation affects the amount of surface heating causing the ocean to experience seasonal variations throughout the year. Within the water column, temperature generally decreases with depth, mainly driven by density gradients which cause cooler, denser water to sink below warmer, less dense water. Locally, depth-temperature changes depend on circulation and local water masses. Along the shelf, the horizontal scale of temperature changes can vary from $10 \mathrm{~m}$ to $100 \mathrm{~km}$, while the vertical scale can be less than $1 \mathrm{~m}$. 
Daily temperature changes are caused by the Earth's rotation about its axis and have a considerable effect on the vertical temperature profile. The ocean surface experiences diurnal heating, which is local heating due to the sun's radiation during the day and local cooling at night. A relevant example of this phenomenon is referred to as the "afternoon effect", in which the vertical temperature profile changes drastically in the afternoon due to the sun's radiation creating a very warm surface layer with a strong sound speed gradient leading to very rapid changes in acoustic propagation conditions (Figure 7). This effect was first noted when ships using hull mounted sonar arrays would notice significant degradation in the performance of their sonar equipment every afternoon when sound from a source would be refracted before reaching the hull mounted array in the warm surface layer. Temperature profiles provide a "first look" at the vertical water column structure. However, without accurate 3-D environmental information, it is difficult to fully utilize features such as the surface layer and exploit the environment to maximum effect. 


\section{Comparison of ray paths when surface heats up $3^{\circ} \mathrm{C}$}
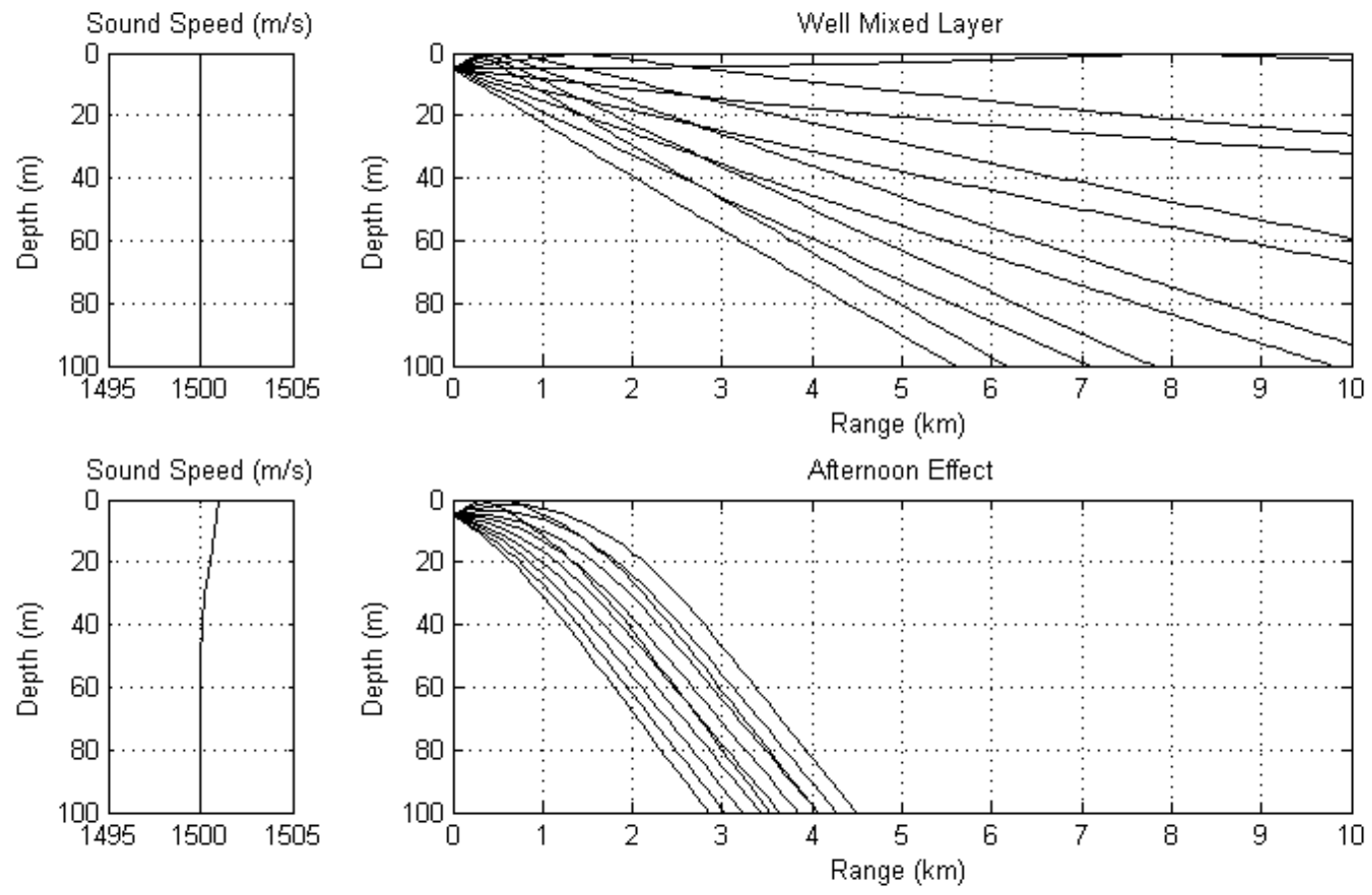

Figure 7. Comparison of ray paths when surface temperature increases by $3^{\circ} \mathrm{C}$ in the afternoon. Figure courtesy of A. Newhall.

Salinity is fairly constant in the global ocean. The average ocean salinity is 34.7 parts per thousand (\%) with a range of approximately $33-37 \%$, except in extreme locations such as the polar oceans or confined seas (Garrison, 2005). In many areas of the ocean, salinity is not highly variable. However, the MAB, particularly along the shelfbreak, often sees dramatic changes in salinity (Figure 8). On average, the water over the continental shelf is low salinity, 32 PSU, while the slope water has higher salinity, 35.5 PSU. The shelfbreak front is defined by the 34.5 PSU isohaline, but extremes in the salinity contrast can be as great as 3 PSU within $5 \mathrm{~km}$. The error in direct conversion between parts per thousand and PSU is generally accepted to be negligible. PSU will be used throughout this study. 

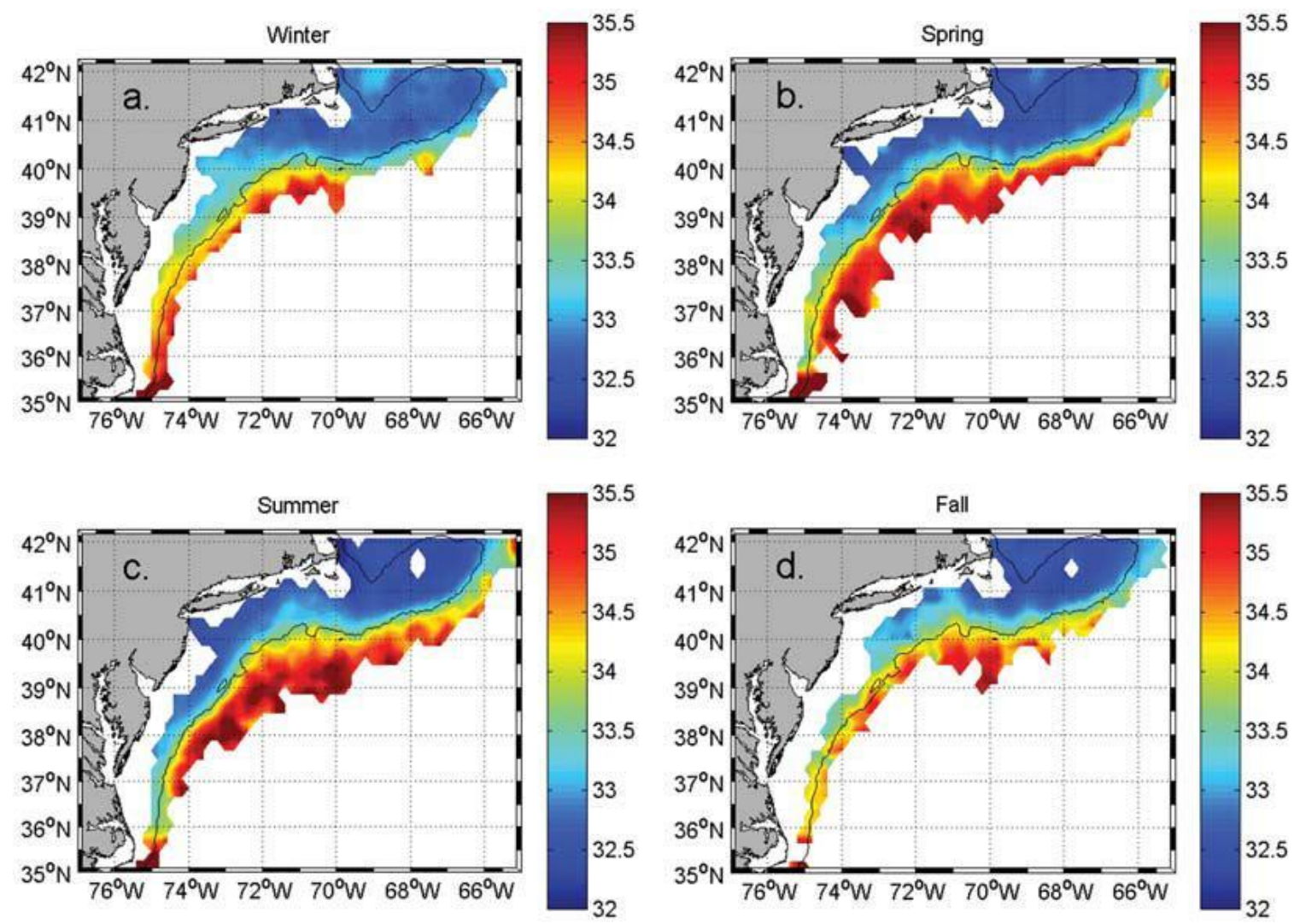

Figure 8. Middle Atlantic Bight mid-depth (40-55 m) mean salinity for (a) winter, (b) spring, (c) summer, and (d) fall. From Linder, et al. (2006).

Density gradients are driven by changes in salinity and temperature. The effects

of density are important in overturning water masses, creating geostrophic currents, and lead to the stability of global ocean circulation. On the scales of interest to shallow water acoustic propagation, less than $100 \mathrm{~km}$, density changes are most affected by temperature. Often, in areas where the local variability in salinity is small, temperature trends represent the dominant changes to the water column. As we have noted, the MAB is a region of increased salinity variability due to the two main water masses which converge at the shelfbreak. Although salinity is important in this region, the variation of the 
density gradients, especially seasonally, tend to follow changes in temperature (Linder \& Gawarkiewicz, 1998).

In addition to ocean features and processes, seabed characteristics are also of great importance to acoustics. Although these characteristics cannot be grouped into the same scale categories, understanding their variability is equally important. Seabed characteristics, such as sediment type and thickness, vary spatially depending on geological history, but generally have geological temporal scales much greater than the scope of our acoustic predictions and so can be considered locally constant. Spatially, however, seabed characteristics can vary sharply, particularly in dynamic areas such as

the shelfbreak. Several studies have been conducted on the geoacoustic properties of the seabed along the northern MAB shelfbreak. Specific composition of the surface layer varies depending on location along the shelf or slope. However, the seafloor in the NEST study area generally consists of fine to medium grained sands and clays (Potty, Miller, Lynch, \& Smith, 2000). Unfortunately, geoacoustic data is relatively sparse and boundaries in bottom type are often difficult to define.

\subsection{Acoustic Uncertainty}

Understanding the variability of the ocean is important when using sonar systems because small changes in the ocean can lead to significant changes in acoustic propagation. In some situations, these changes can lead to an increase in transmission loss of 10-15dB, which can easily be the difference between success and failure in detection, localization, tracking, communication, etc. Mapping the fully 3-D ocean 
environment instantaneously would allow us to exploit these changes in order to maximize acoustic performance. However, there is currently no way to have such an instantaneous picture of a large coastal area, nor do we envision such a thing anytime soon. Our best chance at exploiting the environment is to sample the ocean to the best of our ability, quantify the variability, and predict the acoustic propagation, using a measure of uncertainty to give error bounds to our prediction.

To begin looking at acoustic issues, imagine a surface ship with a passive variable depth sonar array being towed at an arbitrary depth in $200 \mathrm{~m}$ of water. There is a sound source located at a depth of $100 \mathrm{~m}$. Figure 9 a shows a temperature profile with a $10 \mathrm{~m}$ mixed layer, and a nearly isothermal profile extending to the bottom. Figure $9 \mathrm{~b}$ shows a similar environment with a 50m mixed layer. Figure 10 shows the corresponding sound speed profiles creating downward refraction in the lower half of the water column. If we were trying to hear the source at $100 \mathrm{~m}$ depth with a surface ship towed sonar, knowledge of the mixed layer depth (MLD) and placement of the receiver would be critical. 

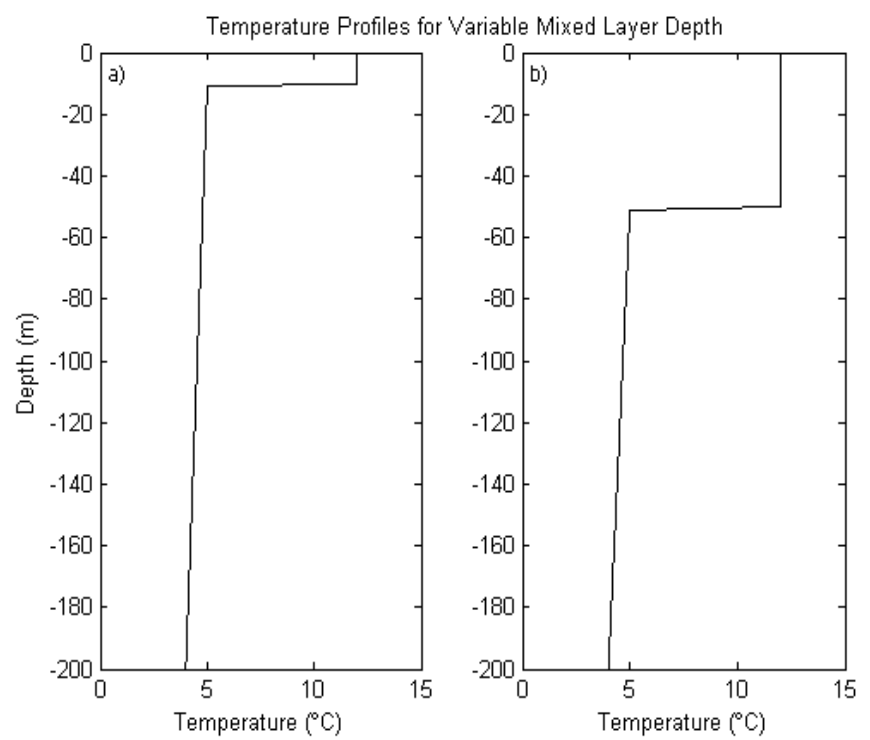

Figure 9. Temperature $\left({ }^{\circ} \mathrm{C}\right)$ profiles for a $200 \mathrm{~m}$ water column with a) a $10 \mathrm{~m}$ mixed layer, and b) a $50 \mathrm{~m}$ mixed layer.

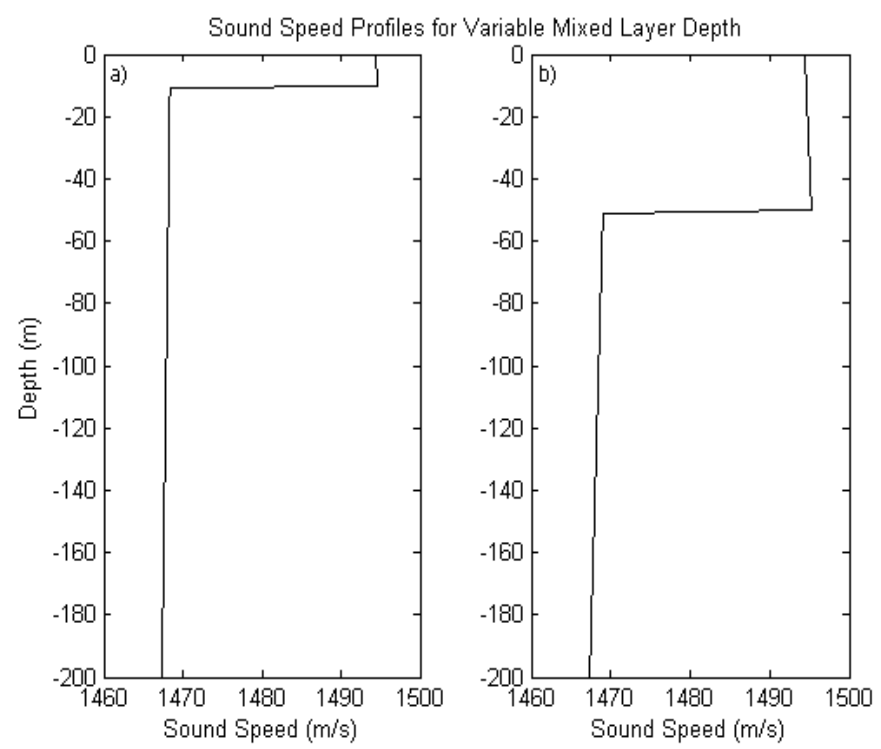

Figure 10. Sound speed $(\mathrm{m} / \mathrm{s})$ profiles for a $200 \mathrm{~m}$ water column with a) a $10 \mathrm{~m}$ mixed layer, and b) a $50 \mathrm{~m}$ mixed layer.

TL fields were calculated for both environments using the Range-dependent

Acoustic Model (RAM). The TL field resulting from the first sound speed profile with a $10 \mathrm{~m}$ mixed layer is shown in Figure 11. At high angles and short ranges, acoustic energy 
penetrates the mixed layer. However, at longer ranges, lower angle rays are reflected off the bottom of the mixed layer, leading to increased TL above the layer. As the mixed layer develops and deepens to 50m, some high angle rays which penetrate into the mixed layer become trapped and propagate for a short distance within the layer. Lower angle rays are still reflected from the bottom of the mixed layer and there is, again, increased TL above 50m (Figure 12). Figure 13 shows the point by point change in TL ( $\Delta \mathrm{TL}$ ) between the fields created by each profile. Positive $\Delta \mathrm{TL}$ indicates that the 50m MLD TL is greater than the $10 \mathrm{~m}$ MLD TL. Primarily, the large positive $\Delta \mathrm{TL}$ is concentrated above the MLD, indicating that TL increases above the layer as the layer depth deepens, for a source below the layer. Figure 14 shows the transmission loss between the source at $100 \mathrm{~m}$ depth and a receiver at a range of $10 \mathrm{~km}$. When the towed array is below the layer, the predicted TL is similar in both environments $(-72-76 \mathrm{~dB})$. However, in the same environment (50m MLD), changing the depth of the receiver from above the layer (40m) to below the layer $(70 \mathrm{~m})$ would result in an improvement in $\mathrm{TL}$ of $+14 \mathrm{~dB}$, which is great enough to significantly improve signal excess. Source detection, localization, etc. are of course much more complex than this simple example. Many environmental and engineering variables contribute to the problem, but to first order, this example illustrates how being unaware of the state of the environment can lead to uninformed decisions in sensor placement and thus a decrease in sonar performance. 


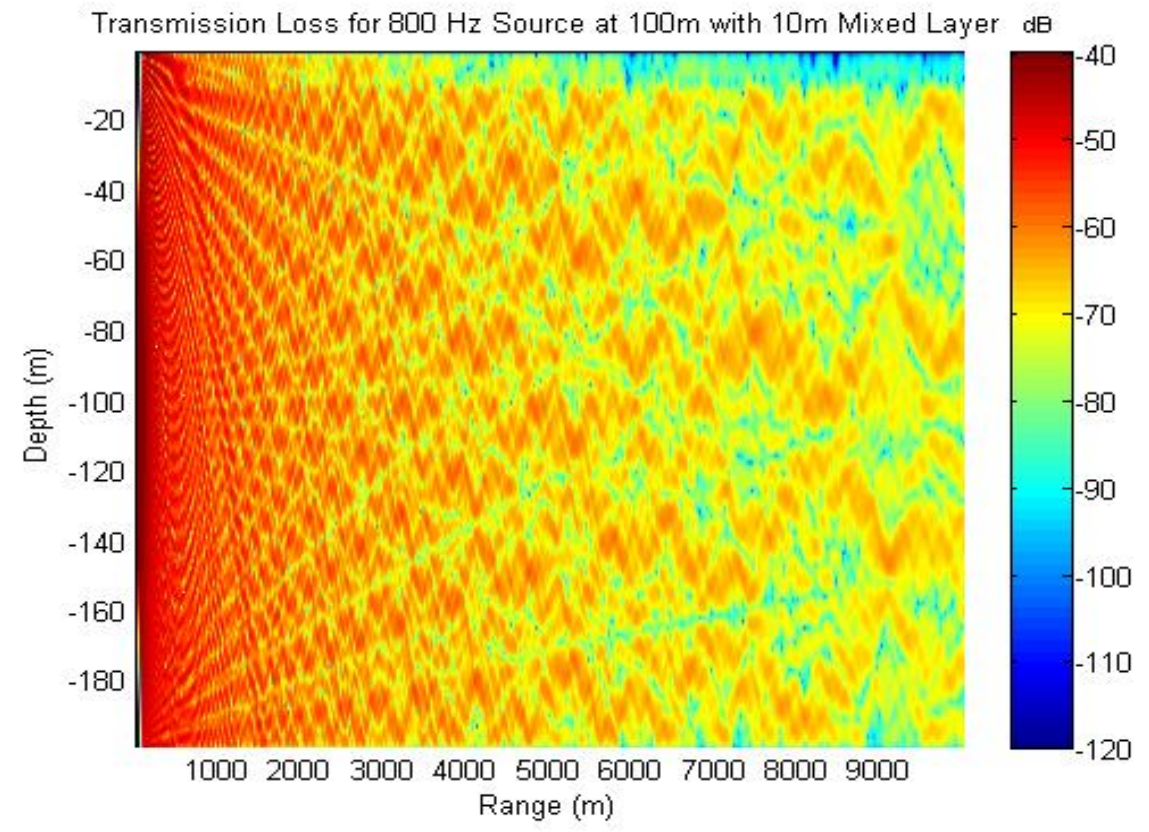

Figure 11. Transmission loss $(\mathrm{dB})$ from a source at $100 \mathrm{~m}$ in a $10 \mathrm{~m}$ mixed layer environment.

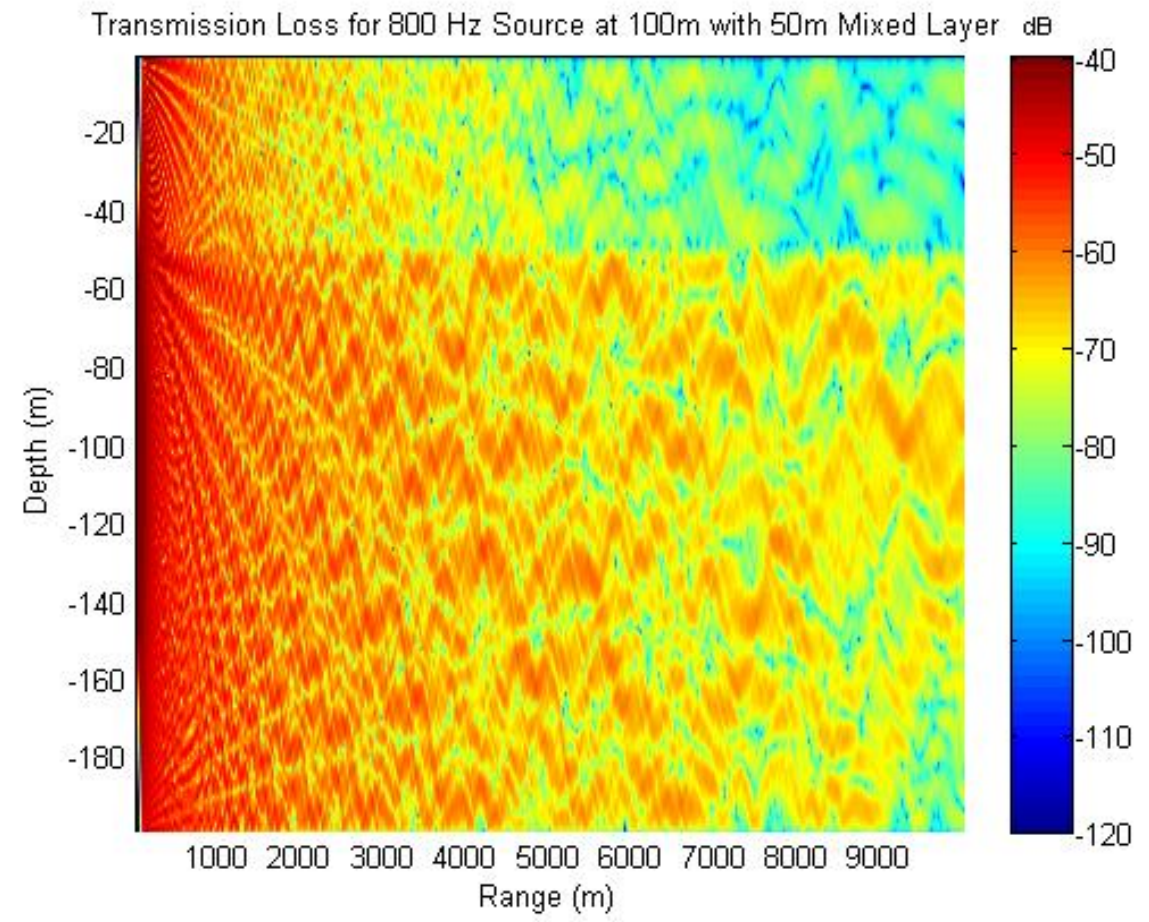

Figure 12. Transmission loss $(\mathrm{dB})$ from a source at $100 \mathrm{~m}$ in a $50 \mathrm{~m}$ mixed layer environment. 


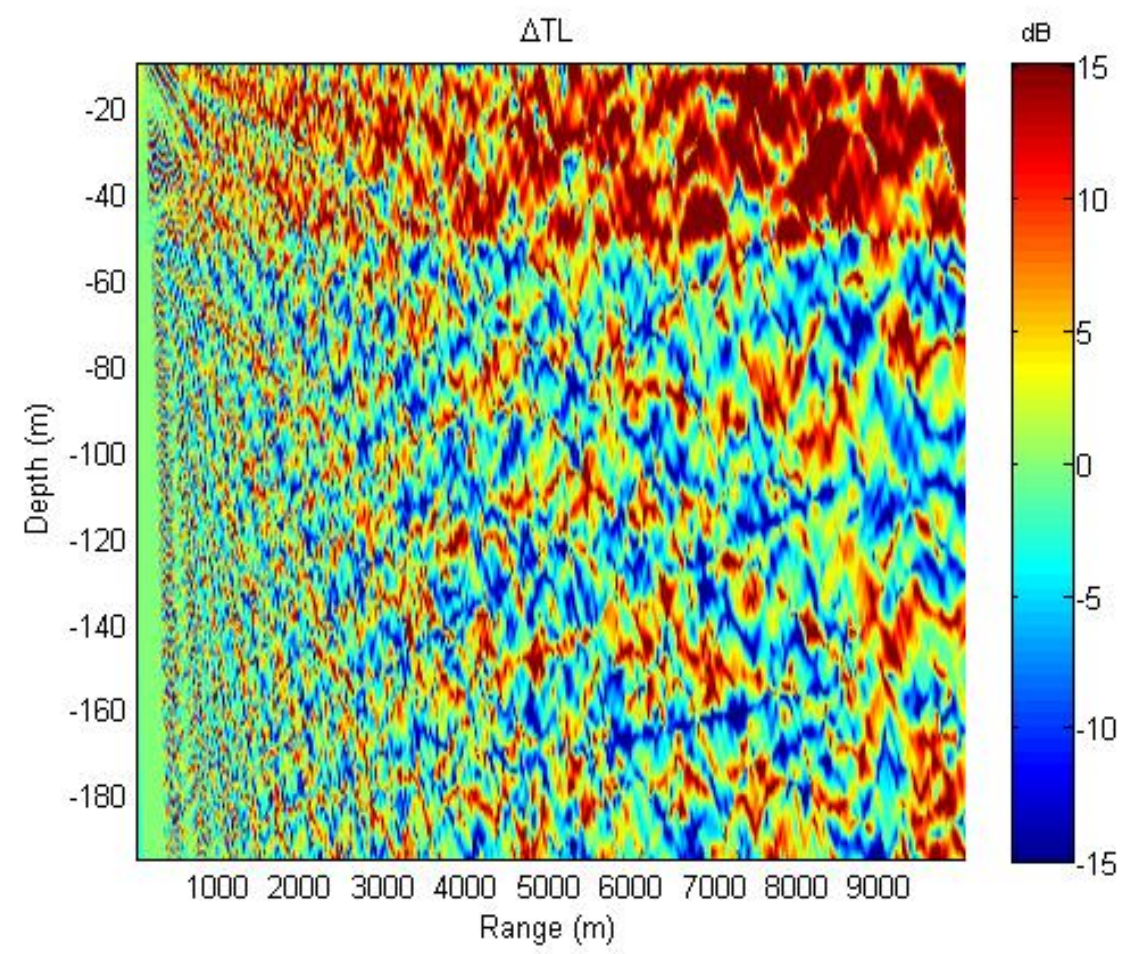

Figure 13. Change in transmission loss (dB) from TL field with a $10 \mathrm{~m}$ mixed layer to TL field with a 50m mixed layer.

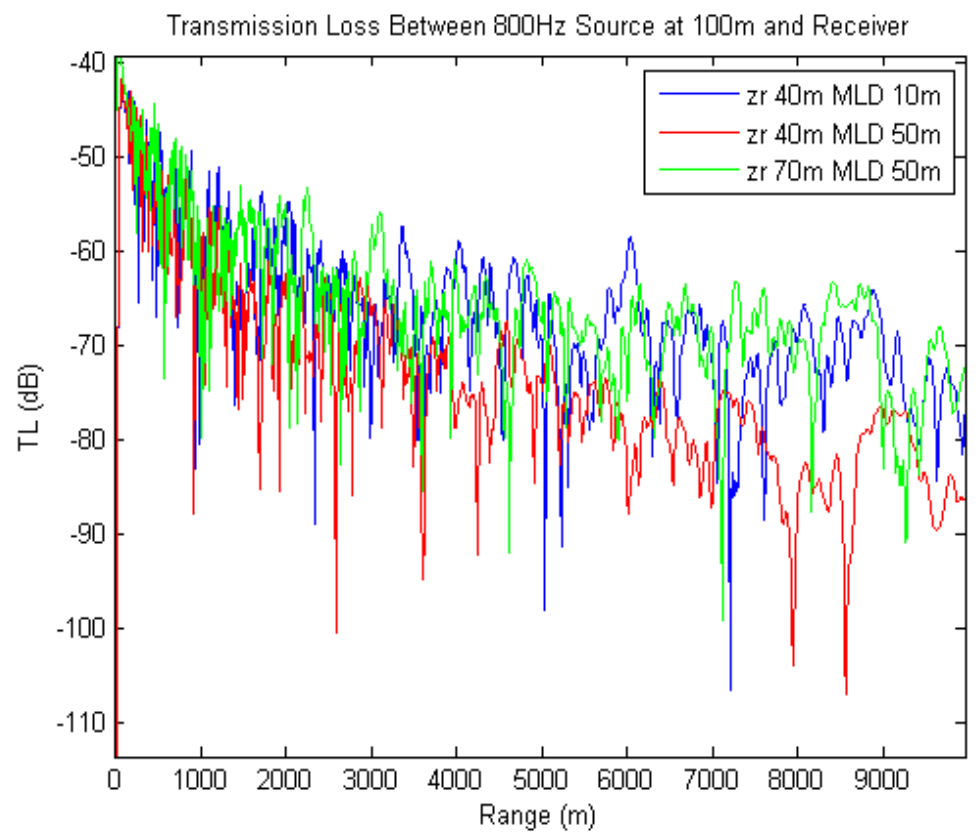

Figure 14. Transmission loss $(\mathrm{dB})$ between an $800 \mathrm{~Hz}$ source at $100 \mathrm{~m}$ and a receiver at $10 \mathrm{~km}$. 


\subsection{Approach}

Our approach to quantifying uncertainty is as follows. First, it is important to identify which of the parameters affecting acoustic propagation are the most critical within the area of interest. Second, we will determine the variability of these parameters, with respect to the experimental data. Finally, we will present a method for predicting changes to TL based on sound speed perturbations.

The NEST experiments were conducted in the waters of the MAB, specifically within the Nantucket Shoals. Dominant features which are thought to contribute greatly to the changes in acoustic propagation within this region are the surface mixed layer, the shelfbreak front, and internal waves. Within these features, several parameters have been identified as critical keys to anticipate changes in acoustic propagation between source and receiver. These parameters are the mixed layer depth, the depth of the Cold Pool duct, the thickness of the middle layer, the cross shelf position of the foot of the shelfbreak front, and the height and period of the internal waves.

In order to determine the variability of the critical keys, we will evaluate the observations taken during NEST I and II and the comprehensive climatology for the area that has been presented in Linder, Gawarkiewicz, \& Taylor (2006). Environmental statistics, particularly the mean and variance of the water column properties, can provide us with details on the background state of the temperature, salinity, and sound speed fields and their fluctuations. However, when the number of observations is limited, this is not a reliable measure. Empirical orthogonal function (EOF) analysis of the sound 
speed field will provide a comparison of this background state and the variability of the collected data. Using a combination of environmental statistics and simple waveguide models, we will determine the effects of the critical parameters and identify which ones have a significant effect on changing TL.

Several approaches have been used to understand and quantify uncertainty. These methods include using environmental statistics, probability density functions and estimating parameter sensitivity. As discussed above, environmental statistics provide a first look at the environmental variability and can lead to inferences about the acoustic uncertainty. Another method using probability density functions (pdf) and comparing the mean TL $\left(\mu_{\mathrm{TL}}\right)$ to the standard deviation of TL $\left(\sigma_{\mathrm{TL}}\right)$ was described in Abbot, Dyer, \& Emerson (2006). Dosso has presented a method for determining sensitivity based on an environmental uncertainty distribution (Dosso, 2008). Here, we will present a method which combines wavenumber perturbation theory with the effects of bottom attenuation to predict changes in transmission loss. 


\section{Chapter 2: The Environment}

\subsection{Climatology}

Important for its dynamic oceanography, relatively benign topography, and role in commercial fisheries, the MAB has been the site of numerous experiments and long term data collection efforts. Due to the abundance of data available for this area, an extensive climatology has been created (Linder \& Gawarkiewicz, 1998) and updated using methods described in Linder, et al. (2006). This climatology was created from a wide collection of oceanographic data including the HydroBase2 global database, Shelf Edge Exchange Processes (SEEP) hydrographic data, and National Oceanographic and Atmospheric Administration (NOAA) National Marine Fisheries (NMF) hydrographic data (19902001). The spring climatology, which includes observations from April 1-June 30, comprises $30 \%$ of the total observations and covers the season of interest in this study (Linder, et al., 2006). While this climatology is the most extensive collection of data for the MAB, the spatial gradients in the data can appear smoothed due to the averaging of data over broad time frames, large along shelf distances, and a wide variety of processes.

Seasonal variation is most evident in the temperature gradients where the contrast varies from $2-6^{\circ} \mathrm{C}$ (Figure 15). The location of the front is often identified by the $10^{\circ} \mathrm{C}$ isotherm; however, during the summer and fall, mixing has eliminated a clear definition of the Cold $\mathrm{Pool}$ and the $10^{\circ} \mathrm{C}$ isotherm is not even present within the domain of Figure 15. It is due to this large movement in the $10^{\circ} \mathrm{C}$ isotherm that the $34.5 \mathrm{PSU}$ isohaline is considered a better locator of the position of the front. The largest cross-shelf 
temperature gradients are located near the $100 \mathrm{~m}$ isobath, generally coinciding with the position of the shelfbreak front, and are strongest during the spring.
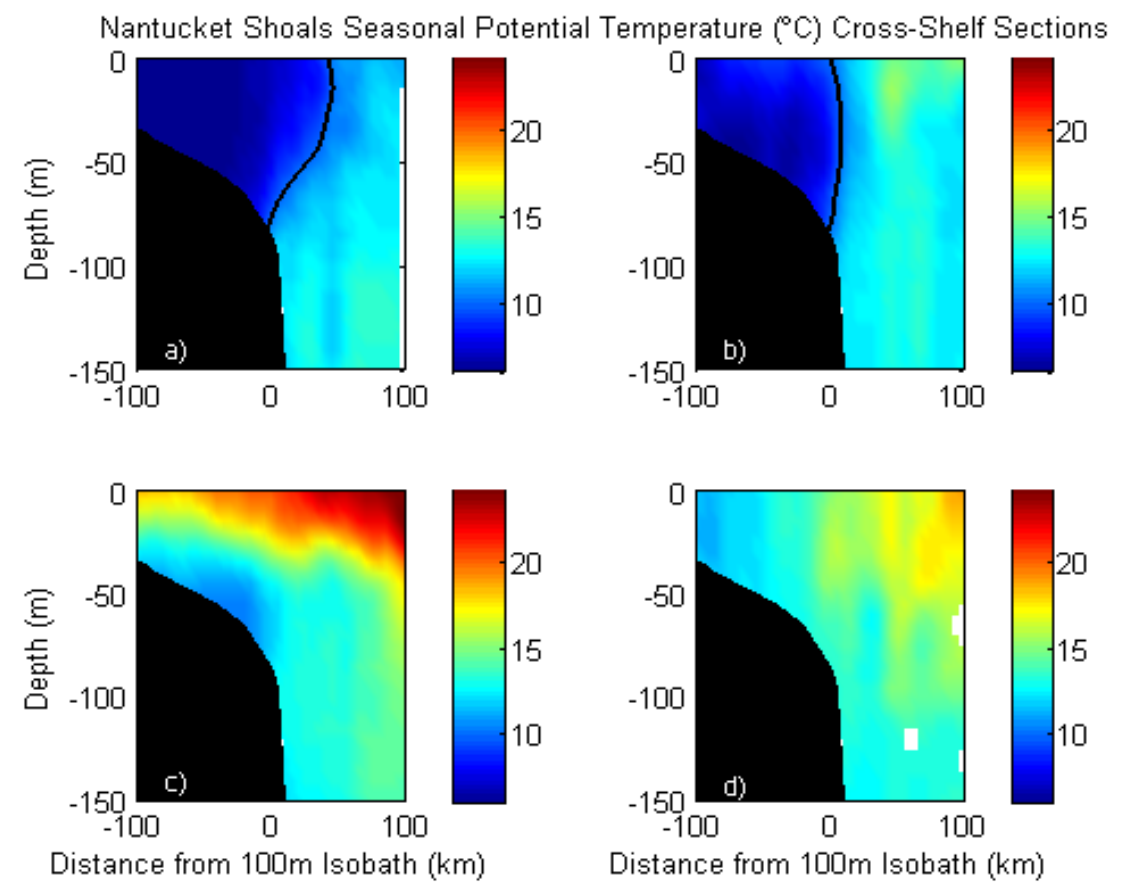

Figure 15. Nantucket Shoals seasonal potential temperature $\left({ }^{\circ} \mathrm{C}\right)$ cross-shelf sections for a) winter, $b$ ) spring, c) summer, d) fall from climatology (Linder, et al., 2006). Solid line shows the $10^{\circ} \mathrm{C}$ isotherm.

Salinity shows less seasonal variation throughout the year, with the exception of spring (Figure 16). In winter, summer, and fall, the salinity fields are similar to each other, with a standard deviation of only 0.75 to 1 PSU. There is increased sub-surface structure to the front itself during summer and fall, as denoted by the 34.5 PSU isohaline. However, during the spring, increased freshwater input from the Gulf of Maine and offshore wind-driven transport results in increased variability in the vicinity of the shelfbreak front, with a standard deviation of 4.5 PSU (Linder, et al., 2006). Inter-annual variation may be caused by salinity intrusions which have been observed throughout the MAB, but are not considered here because there was little inter-annual salinity variation 
from NEST I to NEST II. The 34.5 PSU isohaline defines the core of the front and closely follows the $100 \mathrm{~m}$ isobath near the seafloor. The intersection of the $34.5 \mathrm{PSU}$ isohaline with the bottom defines the foot of the front, which shows little seasonal or annual variation, remaining within $10 \mathrm{~km}$ of the $100 \mathrm{~m}$ isobath. At mid-depth, the front is slightly more offshore, approximately $20 \mathrm{~km}$ seaward of the $100 \mathrm{~m}$ isobath, with a $3^{\circ}$ frontal slope. The maximum salinity variance coincides with the mean position of the front.
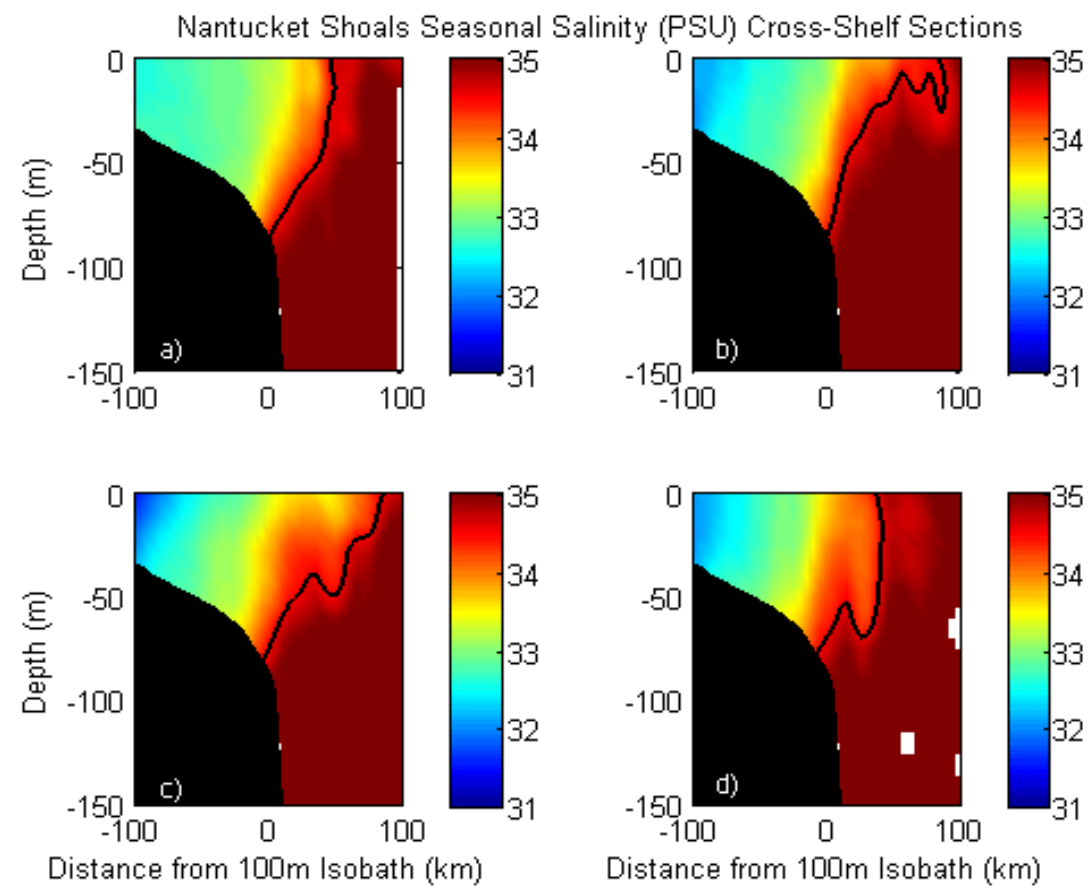

Figure 16. Nantucket Shoals seasonal salinity (PSU) cross-shelf sections for a) winter, b) spring, c) summer, d) fall from climatology (Linder, et al., 2006). Solid line shows the 34.5 PSU isohaline.

Cross-shelf sections of spring potential temperature and salinity were shown in Figure 4 and Figure 5, respectively. Profiles within the Nantucket Shoals region were extracted from the climatology to provide a background environment for this investigation. For the spring season (April 1-June 30), the climatology shows a warm 
surface layer, a temperature minimum at approximately $30-40 \mathrm{~m}$, and a warm bottom layer (Figure 17). The saline and fresh water masses are clearly defined by the front. Individual salinity profiles show a general trend of increasing salinity from the surface to the bottom (Figure 18). The corresponding sound speed cross-shelf section shows a weakly defined duct with a sound speed minimum between $30-40 \mathrm{~m}$ which weakens with passage through the shelfbreak front (Figure 19). Although bottom interaction is generally a large source of attenuation in shallow water environments, it may not be a dominant factor just shoreward of the shelfbreak because the majority of the sound speed profiles there are upward refracting. From the criterion established in Linder, et al. (2006), ducting conditions existed in $41 \%$ of spring casts. With the intensification of stratification from spring to summer, the likelihood of strong ducting increases throughout the season.

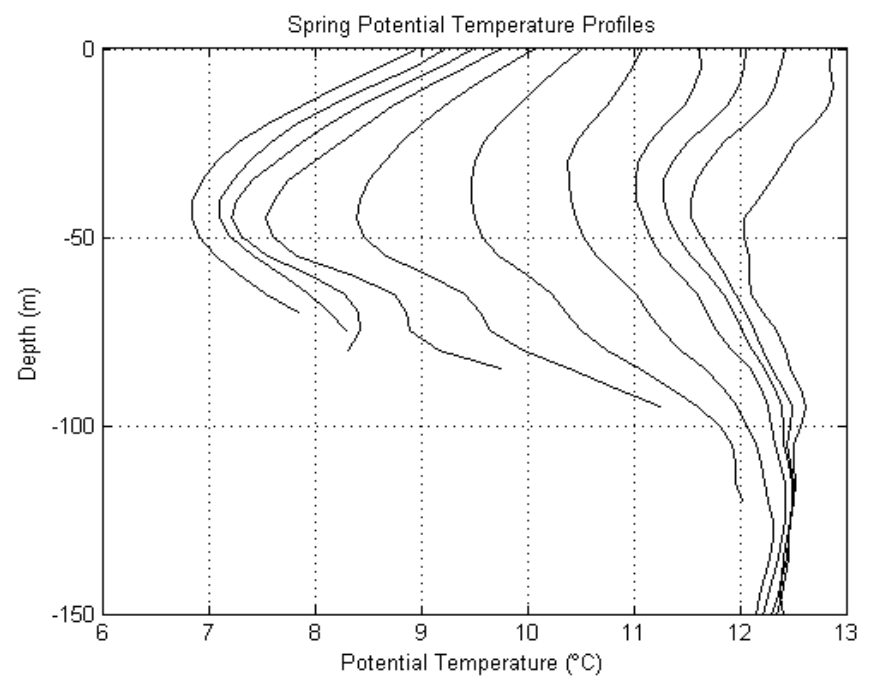

Figure 17. Spring potential temperature profiles $\left({ }^{\circ} \mathrm{C}\right)$ crossing the front within the Nantucket Shoals region, extracted from climatology (Linder, et al., 2006). 


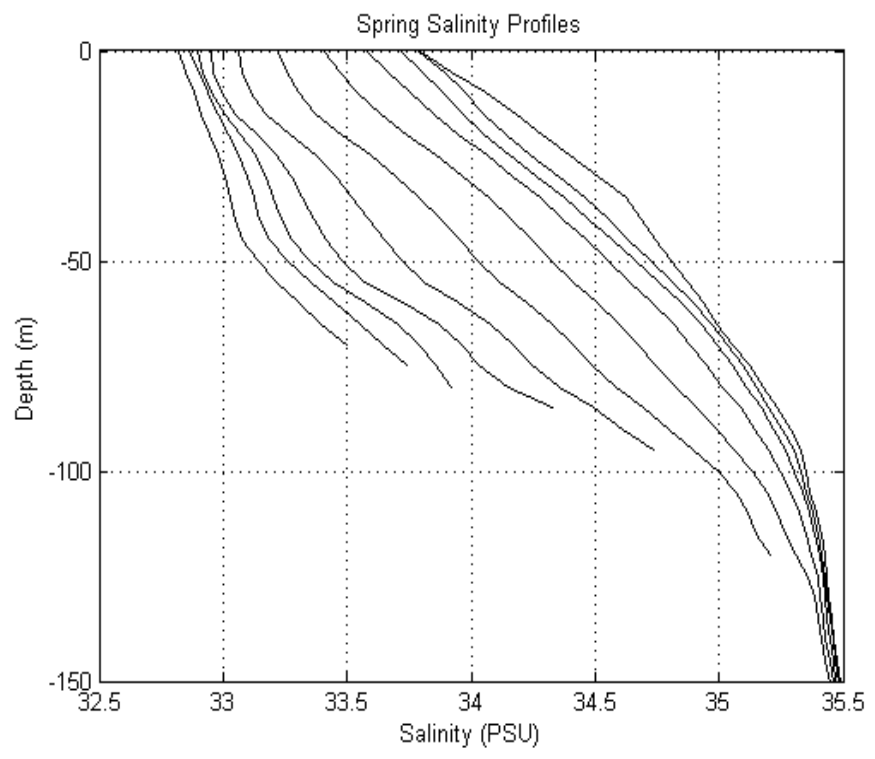

Figure 18. Spring salinity profiles (PSU) crossing the front within the Nantucket Shoals region, extracted from climatology (Linder, et al., 2006).

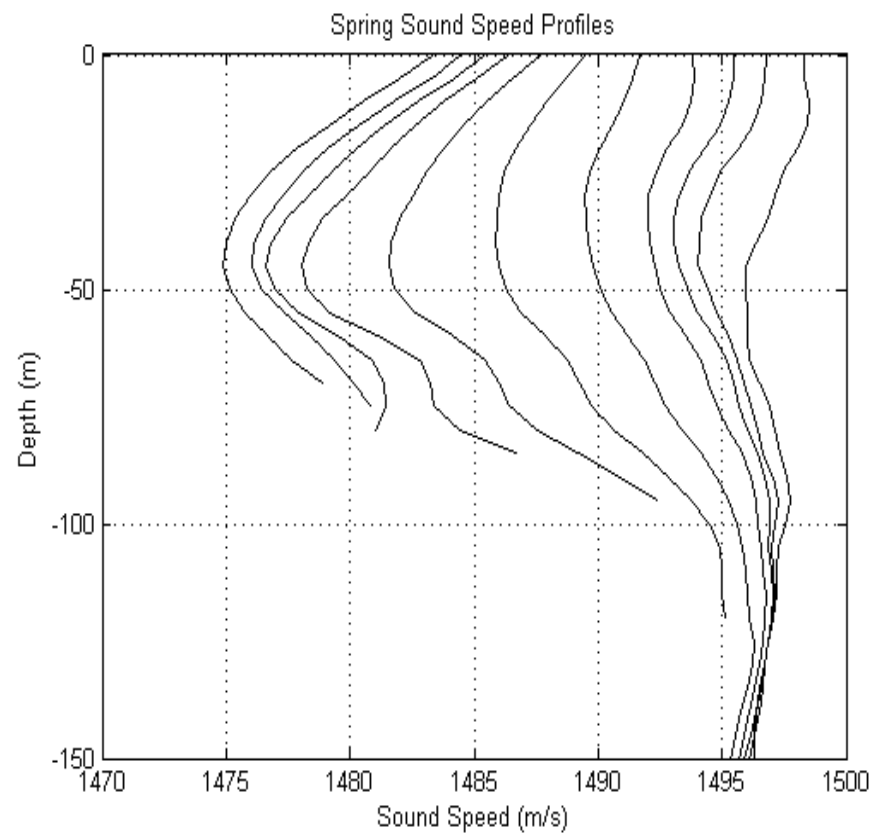

Figure 19. Spring sound speed profiles $(\mathrm{m} / \mathrm{s})$ crossing the front within the Nantucket Shoals region, extracted from climatology (Linder, et al., 2006). 


\subsection{The NEST Experiments}

The NEST experiments took place in the northern MAB region, known as Nantucket Shoals, during May and June, 2007 and 2008 (Figure 20). Objectives of the experiment were to test the Autonomous Wide Aperture Cluster for Surveillance (AWACS) utilizing multiple autonomous platforms for environmental sampling, and acoustic detection and tracking of underwater sound sources. Benign bathymetry and dynamic, yet fairly well understood, oceanography provided an excellent setting for testing AWACS.

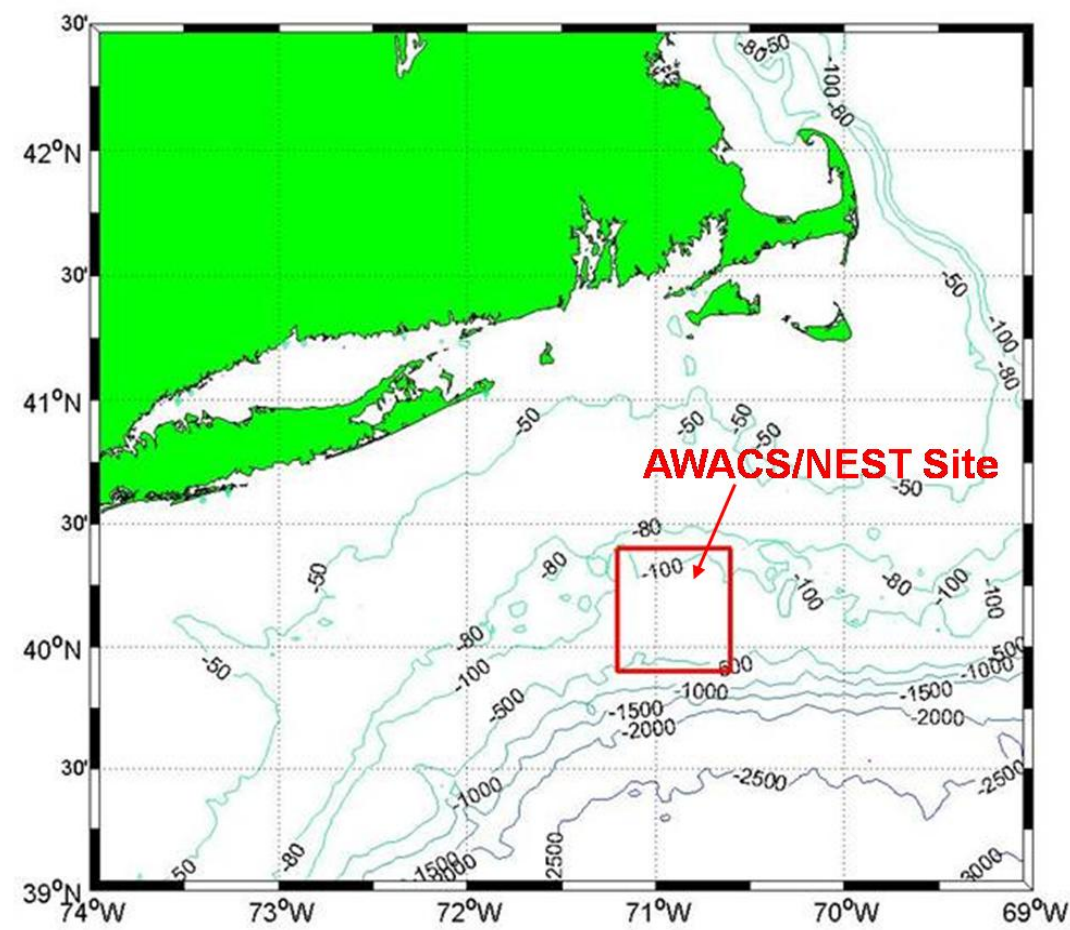

Figure 20. AWACS/NEST Test area for NEST I (2007) and II (2008). Figure courtesy of G. Gawarkiewicz. 
The NEST experiments did not include a bottom survey; however, previous experiments within the area have included extensive seafloor surveys. Bottom sediment characteristics were taken from the results of the series of PRIMER experiments conducted from 1996 to 1997 in the same area as NEST. Throughout the MAB area, the seafloor consists of a top layer of fine sediments over fine to medium grained sands and clays (Potty, et al., 2000). As the seafloor transitions from shelf to slope the surface layer of fine sediments becomes progressively thinner (Potty, Miller, \& Lynch, 2003). Inversion methods from Potty, et al. (2000) resulted in a sound speed of $1660 \mathrm{~m} / \mathrm{s}$ for the upper $15 \mathrm{~m}$ of the seafloor, which corresponds to silty sands or sandy silts, while cores taken slightly east and west of $71^{\circ} \mathrm{W}$ showed a range of $1575-1600 \mathrm{~m} / \mathrm{s}$ within the upper several meters of seafloor.

Acoustic experiments were conducted from May 26-30, 2007 during NEST I, and from May 30 to June 2, 2008 during NEST II. Although the NEST experiment area covered approximately $3000 \mathrm{~km}^{2}$, the environmental analysis is limited to the immediate area of the acoustic experiments. The region of interest is a $60 \mathrm{~km}$ section from $40.05^{\circ} \mathrm{N}$ to $40.6^{\circ} \mathrm{N}$, along $71^{\circ} \mathrm{W}$ with a $1 \mathrm{~km}$ buffer zone on either side. Scanfish physical oceanography surveys (scans) of the NEST area were conducted during each 24-hr period, with the middle transect of each survey sampling the region of interest. Three moorings were deployed with rapid sampling thermistors placed at multiple depths to continuously record water temperature at 10 second intervals in a line along $71^{\circ} \mathrm{W}$ during both experiments. Table 1 provides information about the location, deployment and retrieval, and sensor depths for each mooring. Generally, mooring A was located on the 
shelf (80m isobath), mooring B at the shelfbreak (102m isobath), and mooring $\mathrm{C}$ on the slope (152m isobath). The shipboard conductivity, temperature, and depth (CTD) sensor was used to augment the Scanfish data and provide immediate, single point profiles as necessary. Figure 21 shows the locations of all Scanfish and CTD profiles within the region of interest.

Table 1. Location, deployment, and sensor information for NEST I and II moorings.

\begin{tabular}{|c|c|c|c|c|c|c|c|}
\hline \multicolumn{2}{|c|}{ NEST } & Location & Deployed & Recovered & Depth $(\mathrm{m})$ & \# of T-pods & Depth of T-pods (m) \\
\hline \multirow{4}{*}{-} & A & $40.501 \mathrm{~N} / 71.000 \mathrm{~W}$ & $5 / 24 / 2007$ & $5 / 31 / 2007$ & 80 & 13 & $1,20-65(\Delta \mathrm{z} 5 \mathrm{~m}), 78$ \\
\cline { 2 - 9 } & B & $40.313 \mathrm{~N} / 70.999 \mathrm{~W}$ & $5 / 24 / 2007$ & $5 / 31 / 2007$ & 102 & 17 & $1,20-85(\Delta \mathrm{z} 5 \mathrm{~m}), 100$ \\
\cline { 2 - 9 } & C & $40.135 \mathrm{~N} / 71.000 \mathrm{~W}$ & $5 / 24 / 2007$ & $5 / 31 / 2007$ & 152 & 27 & $1,20-135(\Delta \mathrm{z} 5 \mathrm{~m}), 150$ \\
\hline \multirow{3}{*}{$=$} & A & $40.500 \mathrm{~N} / 71.000 \mathrm{~W}$ & $5 / 29 / 2008$ & $6 / 4 / 2008$ & 80 & 13 & $1,20-65(\Delta \mathrm{z} 5 \mathrm{~m}), 78$ \\
\hline & B & $40.313 \mathrm{~N} / 71.000 \mathrm{~W}$ & $5 / 29 / 2008$ & $6 / 4 / 2008$ & 102 & 17 & $1,20-85(\Delta \mathrm{z} 5 \mathrm{~m}), 100$ \\
\cline { 2 - 9 } & C & $40.126 \mathrm{~N} / 71.000 \mathrm{~W}$ & $5 / 29 / 2008$ & $6 / 4 / 2008$ & 152 & 27 & $1,20-135(\Delta \mathrm{z} 5 \mathrm{~m}), 150$ \\
\hline
\end{tabular}

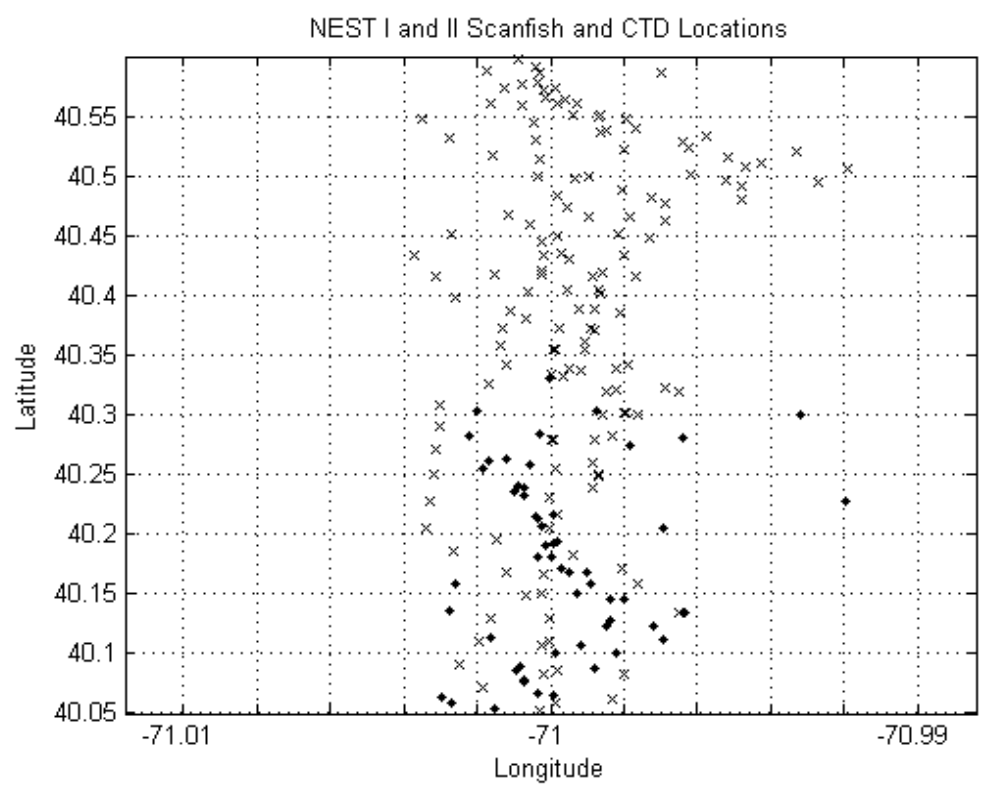

Figure 21. Geographic locations of Scanfish and CTD profiles collected during NEST I and II. Selected profiles are limited to those within the region of interest, as shown by the geographical limits of the figure. NEST I locations are shown by the black dots. NEST II locations are shown by the black x's. 
The bathymetry profile was created from the Ship's Monitoring System (SMS) onboard the Research Vessel Hugh R. Sharp (R/V Sharp) during NEST II. The depth ranged from $230 \mathrm{~m}$ at the southern end of the region of interest to $70 \mathrm{~m}$ on the shelf. The $100 \mathrm{~m}$ isobath is approximately in the middle of the region of interest. The bathymetry profile was compared to data from the National Geophysical Data Center (NGDC) with excellent agreement (Figure 22).

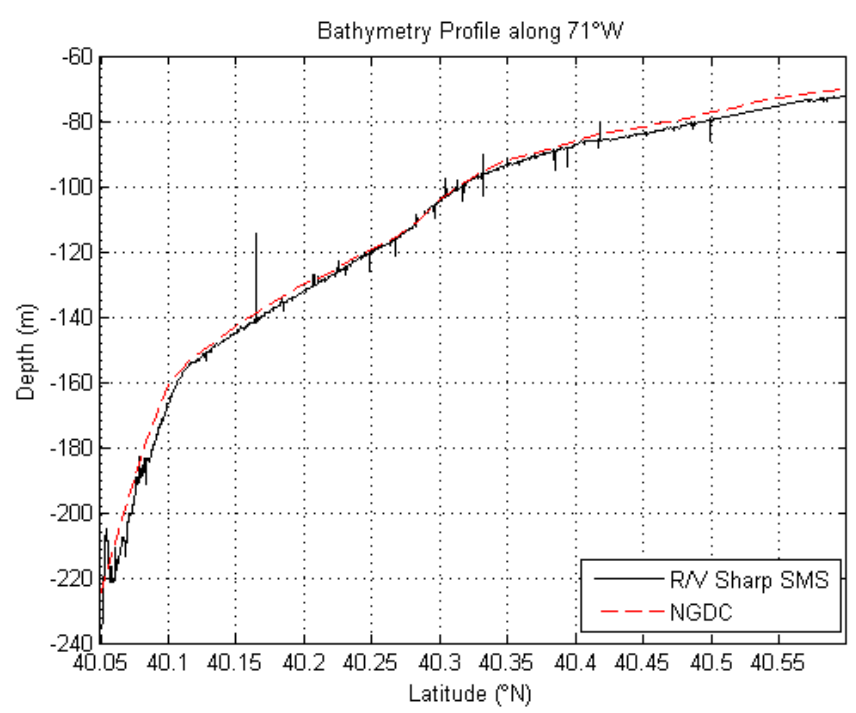

Figure 22. Bathymetry profile along $71^{\circ} \mathrm{W}$. R/V Sharp bathymetry from the Ship's Monitoring System (SMS). Comparison data provided by the National Geophysical Data Center (NGDC) IHO Data Center for Digital Bathymetry (http://www.ngdc.noaa.gov/mgg/bathymetry/iho.html).

CTD profiles were used to augment the Scanfish profiles for each NEST experiment. The Scanfish profiles were limited to a maximum depth of $120 \mathrm{~m}$ due to the operating limits of the equipment. The NEST I profiles were densely populated to the south, beyond the $120 \mathrm{~m}$ isobath. CTD profiles were used to interpolate sound speed from $120 \mathrm{~m}$ to the bottom. Nine CTD profiles were selected which were spatially and temporally best fit (Figure 23). Only two CTD profiles were deep enough to provide data 
for the missing depth region 120-230m. CTD 26 was selected from these two as the best fit, since the only other deep profile, CTD 27, was on the outer edge of the region of interest. Initially, a curve was fit to CTD 26 to provide interpolated sound speed for the missing depth region. However, warm ring water within a slope eddy located just below the shelfbreak near the $120 \mathrm{~m}$ isobath caused an increase in sound speed from $120-200 \mathrm{~m}$. Although the calculated curve was a good fit to the CTD 26 profile, it created a steep artificial sound speed gradient from 100-120m when appended to the Scanfish profiles. To prevent this artificial gradient, a mean profile of the 9 CTDs was used, which smoothed the effect of the ring water and improved the transition from Scanfish profiles to the extended profile (Figure 24).
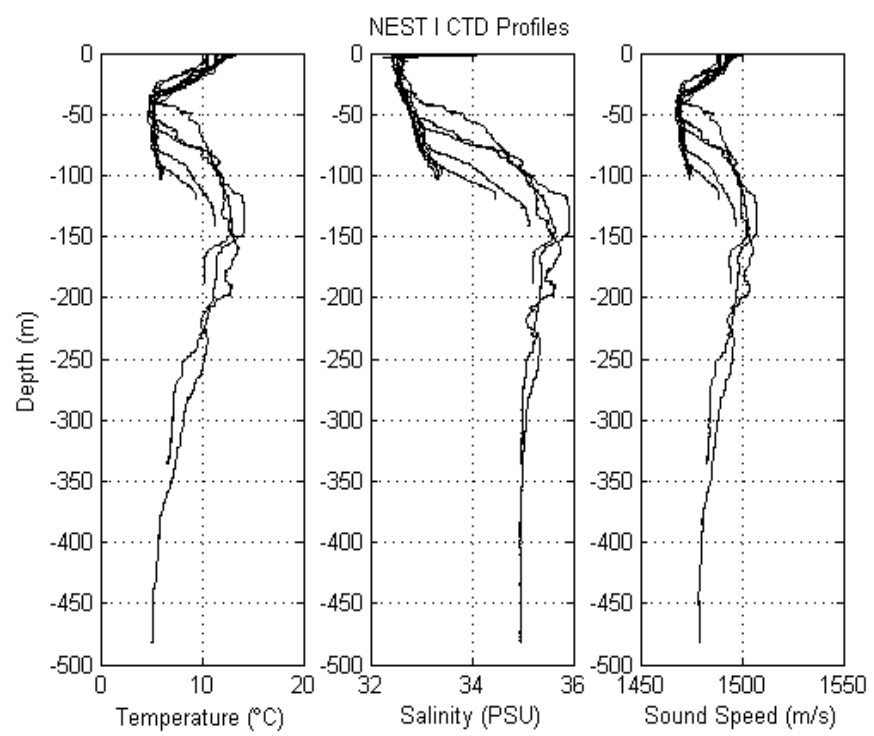

Figure 23. NEST I CTD profiles collected from May 26-30, 2007 within the region of interest from $40.05^{\circ} \mathrm{N}$ to $40.6^{\circ} \mathrm{N}$, along $71^{\circ} \mathrm{W}$ with a $1 \mathrm{~km}$ buffer to either side. 


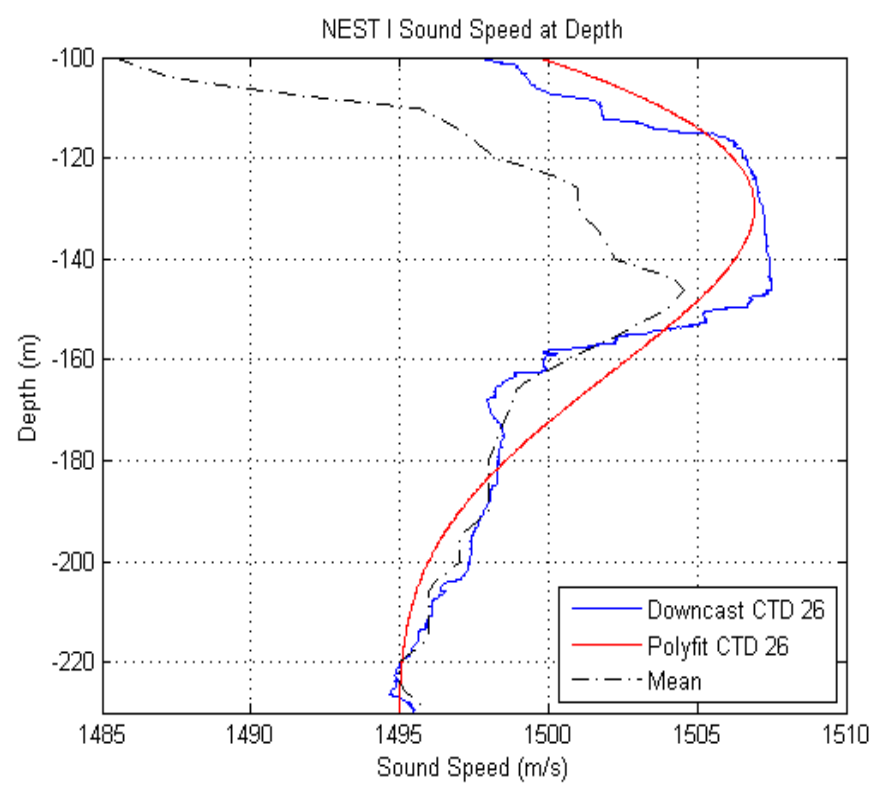

Figure 24. Comparison from 100-230m of CTD 26, fitted curve, and the mean of 9 NEST I CTD profiles.

NEST II Scanfish surveys were more densely populated toward the northern end of the region of interest, which was shallower and within the operating limits of the Scanfish. Therefore, the NEST II profiles did not need to be depth corrected. However, there were limited profiles in the southern portion for Scans 1 and 2, and adverse weather conditions prevented the completion of Scan 4, resulting in the use of the ship's CTD for the remaining transect. CTDs were used to augment the Scanfish profiles for NEST II Scans 1,2 , and 4 .

To understand, on a basic level, the variability within the water column, a simple definition is constructed using commonly measured properties, such as temperature and salinity. If the vertical profile of the water column is anisotropic, then there exists a gradient $\left(\frac{d p}{d z}\right)$ of the water column property $(p)$. The vertical variability $\left(\Delta p_{v}\right)$ is found by moving up or down. 


$$
\Delta p_{v}=\frac{d p}{d z} d z
$$

In a vertically isotropic water column, the variance would be zero because there is no gradient. The strength of the vertical gradient can be affected by the horizontal movement of the water column, for example, the seaward movement of the Cold Pool. Vertical movement across the gradient is mostly caused by internal waves. In an environment with weak gradients and little to no internal wave activity, we would expect little variability of the water column properties. Likewise, large variability indicates the presence of either strong gradients, internal waves, or both.

The ocean is not a horizontally homogeneous environment and property gradients exist in the horizontal as well as the vertical. The definition described above is easily adapted to measure the horizontal variability within the environment by measuring the horizontal derivatives ( $\frac{d p}{d x}$ and $\frac{d p}{d y}$ ).

$$
\Delta p_{h, x}=\frac{d p}{d x} d x \quad, \quad \Delta p_{h, y}=\frac{d p}{d y} d y
$$




\subsection{NEST I}

\subsubsection{Scanfish Surveys}

During NEST I, there was a clearly defined horizontal front and a Cold Pool of water with a minimum temperature of $4^{\circ} \mathrm{C}$. Slope water was present directly beneath the front, with more saline ring water below. The ring water was a remnant of a warm, saline meander from the Gulf Stream, creating an offshore slope eddy (Figure 6). The satellite SST image from May 27, 2007 shows a remnant of warm water near the NEST area. The Cold Pool extended over the offshore slope eddy, which did not extend to the surface. Although a similar slope eddy existed during the Shallow Water 06 (SW06) experiment, the cold shelf water did not flow over the eddy during that experiment (Gawarkiewicz, Bahr, Beardsley, \& Brink, 2001). The mean water temperature was $7.6^{\circ} \mathrm{C}$, with a range of $5.3-12.3^{\circ} \mathrm{C}$ and a standard deviation of $0.96^{\circ} \mathrm{C}$. The depth of maximum variability differed daily from either the main thermocline or the foot of the front. The mean salinity during NEST I was 33.3 PSU, with a range of 32.4 - 35.1 PSU, and a standard deviation of only 0.22 PSU. The maximum variability was located between $100-120 \mathrm{~m}$, indicating that the intersection of the bottom of the Cold Pool and the top of the warm, saline slope water was likely the source of the variability. Unlike temperature, a near surface halocline did not exist, only a deeper one defined by the shelfbreak front. Shoreward of the front, the fresh shelf water extended from the base of the Cold Pool to the surface. This indicates that the surface layer is made up of fresh shelf water which has been warmed by solar radiation creating a surface thermocline. The mean sound speed was $1479.4 \mathrm{~m} / \mathrm{s}$, with a range of $1470.1-1497.0 \mathrm{~m} / \mathrm{s}$ and a standard deviation of $3.87 \mathrm{~m} / \mathrm{s}$. The 
variability in the sound speed resembled that of the temperature, indicating that either the thermocline or the bottom layer, or both, were the source of maximum variability.

NEST I Scan 1 (abbreviated N11) shows a shallow, warm, fresh mixed layer, with a thermocline from $10 \mathrm{~m}$ to $35 \mathrm{~m}$ (Figure 25 ). From a temperature minimum at $35 \mathrm{~m}$ $\left(5.1^{\circ} \mathrm{C}\right)$, the water column is fairly isothermal with a warm bottom layer beneath $100 \mathrm{~m}$. The horizontal temperature slice shows the dominant Cold Pool (Figure 26). The standard deviation of the temperature profiles is $1.0^{\circ} \mathrm{C}$, and the maximum variance is at a depth of 100m. The intersection of the bottom of the Cold Pool and the warm bottom layer appears to be the source of the maximum temperature variability. The less saline surface water (32.5 PSU) extends down to a depth of approximately $100 \mathrm{~m}$, where there is an intrusion of more saline water (35.1 PSU) near the bottom. However, there is a continuous increase in salinity from the surface to the bottom, as represented by the mean salinity profile, with a standard deviation of 0.3 PSU. There is a sound channel bounded by the warm layers at the surface and seafloor, with a sound speed minimum at $30-35 \mathrm{~m}$. From $30 \mathrm{~m}$ to $80 \mathrm{~m}$, the sound speed profiles are roughly isovelocity until the warm saline bottom water causes an increase in sound speed and an upward refracting profile. The maximum standard deviation $(\sigma=8.26 \mathrm{~m} / \mathrm{s})$ is located at a depth of $96 \mathrm{~m}$, however, the depth region from $60-110 \mathrm{~m}$ has increased variability compared with shallower regions. Therefore, we can estimate for N11 that the bottom layer is the dominant source of variability. 


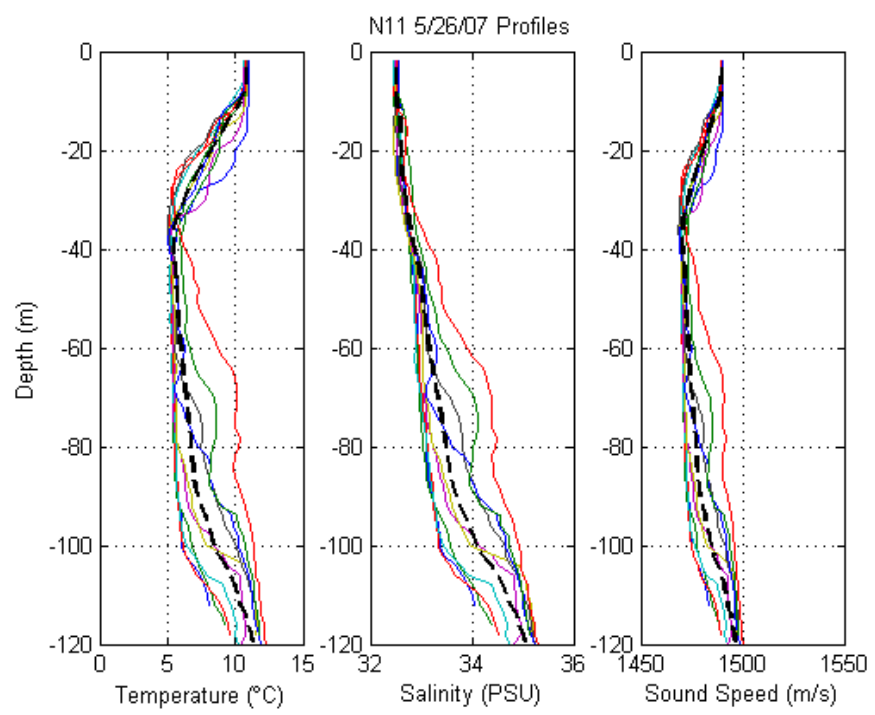

Figure 25. Temperature, salinity, and sound speed profiles from N11, 5/26/07. Dashed line shows mean profile.

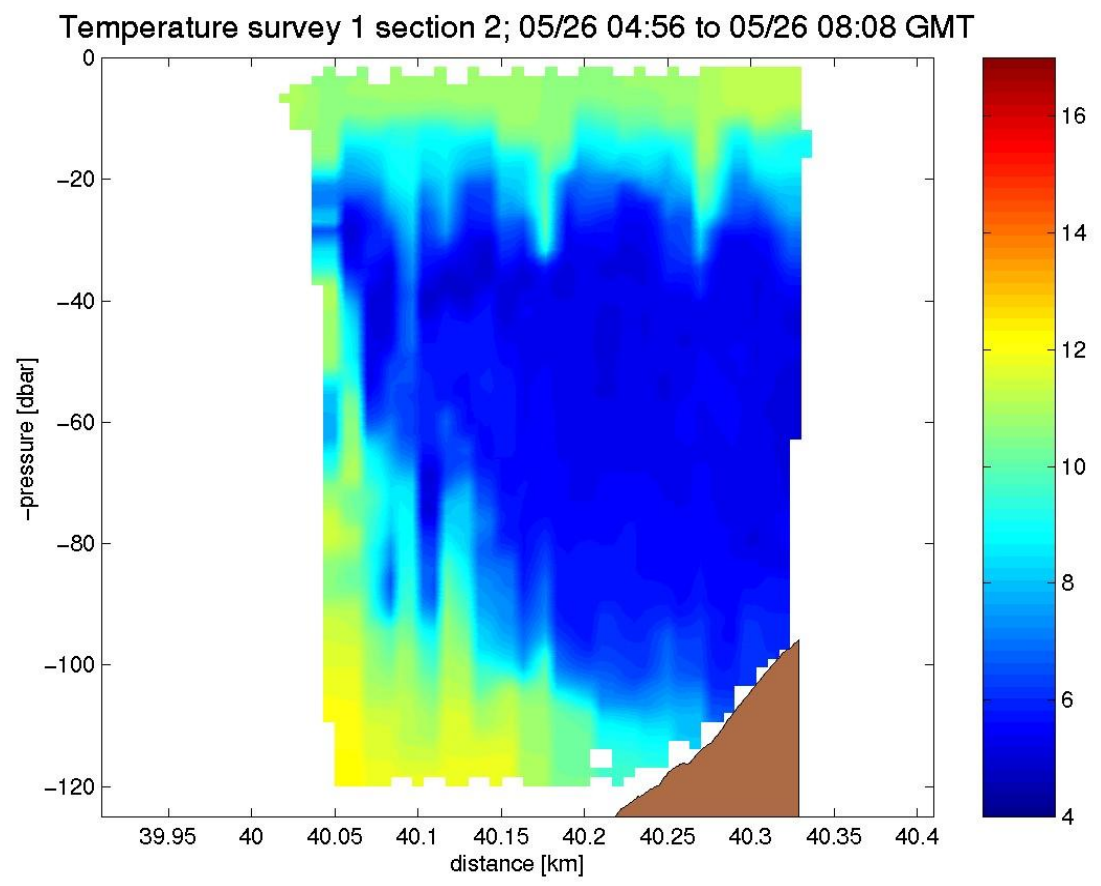

Figure 26. Temperature $\left({ }^{\circ} \mathrm{C}\right)$ cross section of $\mathrm{N} 11$ on 5/26/07. Figure courtesy of F. Bahr. 
N12 shows the greatest variability during NEST I. There is warm surface water with no clearly defined mixed layer but a thermocline present from the surface to a temperature minimum $\left(4.9^{\circ} \mathrm{C}\right)$ at $40 \mathrm{~m}$ (Figure 27$)$. The temperature slowly increases from $40 \mathrm{~m}$ to the bottom. The mean water temperature is warmer $\left(8.4^{\circ} \mathrm{C}\right)$ than each of the other scans, or the NEST I mean, and the standard deviation is at a maximum $(\sigma=$ $2.17^{\circ} \mathrm{C}$ ). N12 profiles show maximum variance at two depths, $30 \mathrm{~m}$ and $72 \mathrm{~m}$, indicating that both the thermocline and the bottom layer contribute, almost equally, to the variability. The horizontal temperature slice shows a slightly smaller Cold Pool, possibly indicating that the Cold Pool has moved slightly shoreward, affecting both the thermocline and bottom layer, and causing an increase in mean water temperature (Figure 28). The salinity profiles show less saline water from the surface to approximately $60 \mathrm{~m}$ where the more saline water is present in the bottom half of the water column. The mixing of fresh and saline water from $60-80 \mathrm{~m}$ results in increased variability between these depths, with a standard deviation of 0.59 PSU. The sound speed profiles show decreasing sound speed from the surface to a minimum at $44 \mathrm{~m}$, then increasing sound speed to the bottom. The standard deviation of the sound speed peaks at $32 \mathrm{~m}$ and $72 \mathrm{~m}$, with a much greater magnitude than any of the other scans $(8.89 \mathrm{~m} / \mathrm{s})$. The increased standard deviation in temperature and sound speed at approximately $30 \mathrm{~m}$ and $75 \mathrm{~m}$ suggests that the thermocline and bottom layer are both important sources of variability. Driving mechanisms for variability along both the main thermocline and bottom thermocline could be internal waves, horizontal movement of the Cold Pool or advection of cross-shelf gradients into the region of interest. 

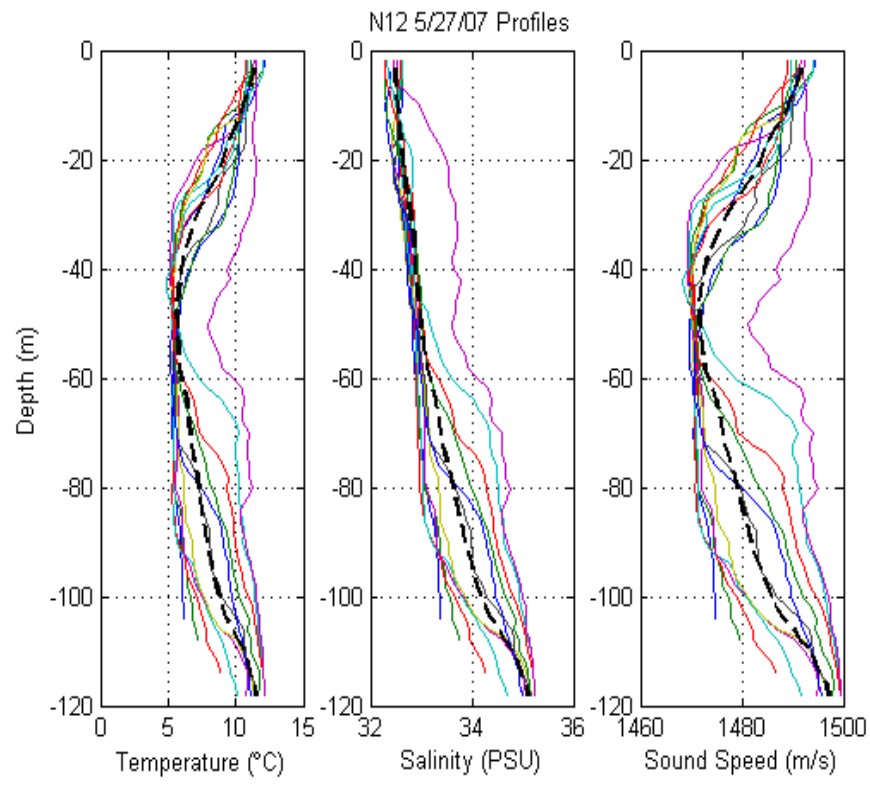

Figure 27. Temperature, salinity, and sound speed profiles from N12,5/27/07. Dashed line shows mean profile.

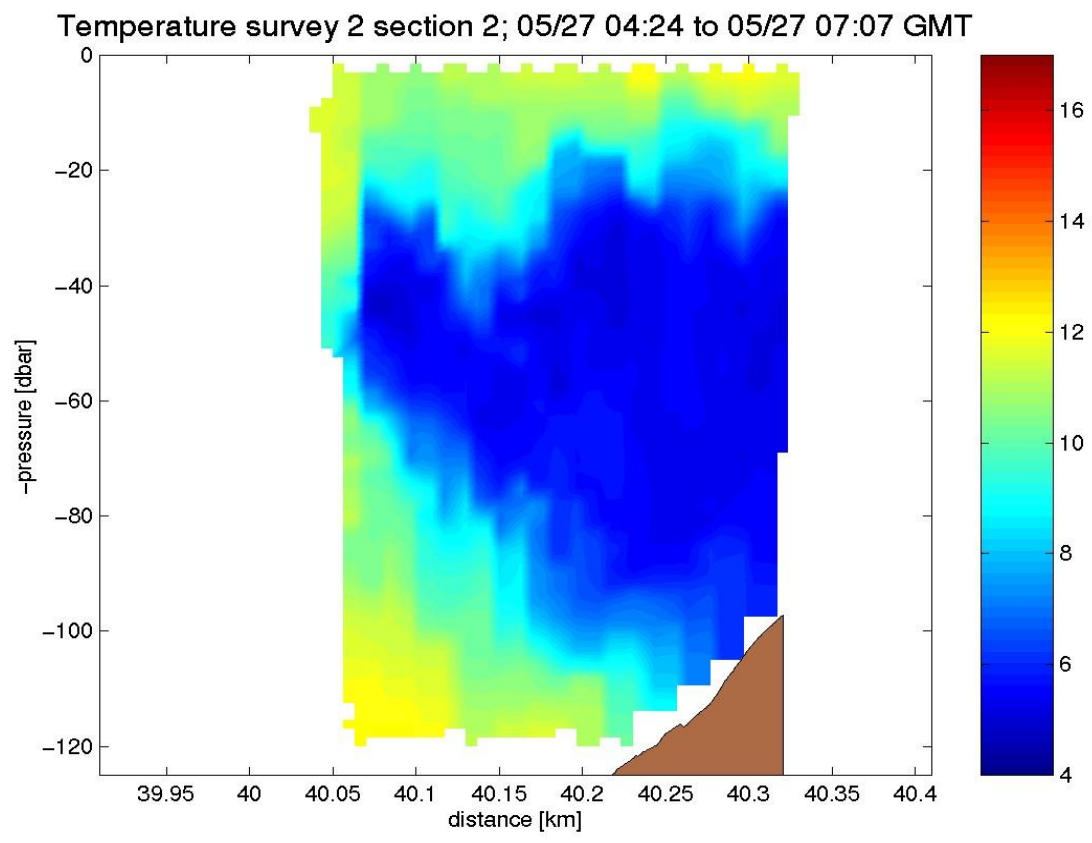

Figure 28. Temperature $\left({ }^{\circ} \mathrm{C}\right)$ cross section of N12 on 5/27/07. Figure courtesy of F. Bahr. 
N13 profiles show a similar water column structure to N11 and N12 (Figure 29). A few individual profiles show that a thin mixed surface layer is being reestablished, although this is not yet represented in the mean profile. The mean temperature has decreased $\left(7.5^{\circ} \mathrm{C}\right)$ while the range of temperatures remains the same. This implies that the Cold Pool may be moving in and out of the region of interest, creating a shift in the mean temperature. The movement of the Cold Pool could be a result of barotropic tidal effects, or frontal waves. Frontal waves, or topographic shear waves, propagate along the front and are a result of baroclinic instability. These waves are affected by both the degree of stratification and bottom slope. Common during the summer in the MAB, frontal waves often have a bottom trapped mode with a period of approximately 2 days (Gawarkiewicz, 1991). The variable position of the foot of the front may be driven by this bottom trapped mode, directly affecting the seaward extent of the Cold Pool. Although movement of the Cold Pool appears within the Scanfish slices, the short duration of collected data is insufficient to resolve the actual driving mechanism. The maximum temperature variance is located at $104 \mathrm{~m}$, where the standard deviation reaches $1.9^{\circ} \mathrm{C}$. The salinity continues to increase from the surface to the bottom, with an average standard deviation of $0.24 \mathrm{PSU}$, and maximum occurring at $106 \mathrm{~m}$. The sound speed profiles have two areas of increased variability corresponding to the thermocline and the bottom layer, with slightly greater standard deviations in the bottom layer. It appears that the N13 variability is dominated by the bottom layer. 

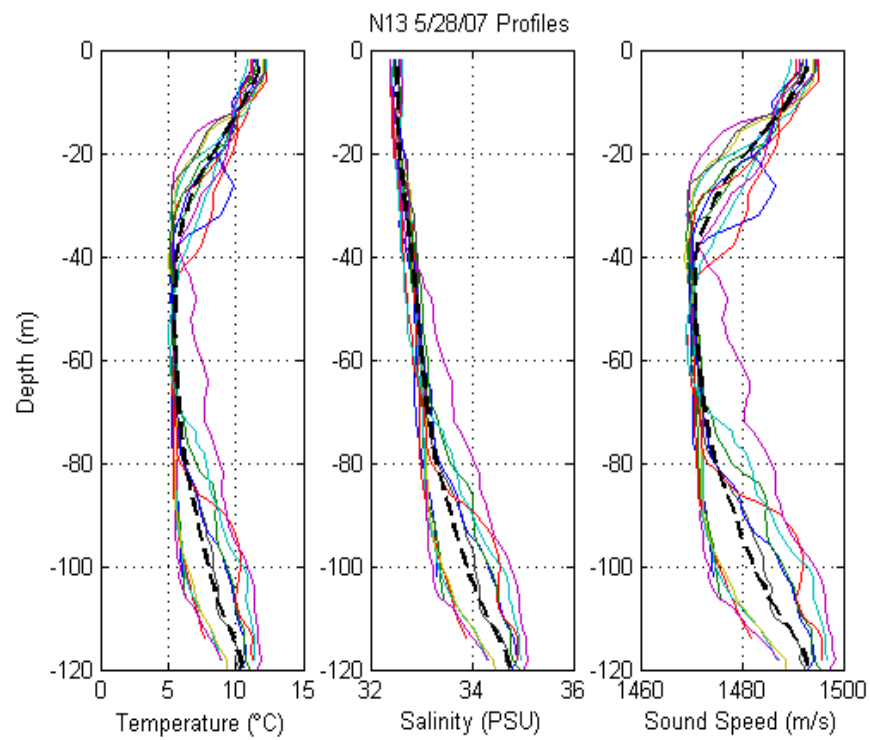

Figure 29. Temperature, salinity, and sound speed profiles from N13,5/28/07. Dashed line shows mean profile.

N14 profiles show less variability than scans $1-3$. The thermocline extends to a minimum temperature at $44 \mathrm{~m}\left(5.1^{\circ} \mathrm{C}\right)$, and remains fairly isothermal until approximately $80 \mathrm{~m}$ where it begins to mix with the warm bottom layer (Figure 30). Of all NEST I scans, $\mathrm{N} 14$ has the lowest mean temperature $\left(7.0^{\circ} \mathrm{C}\right)$ with the smallest standard deviation $\left(0.65^{\circ} \mathrm{C}\right)$. Although the magnitude of the standard deviation is low, there are still two areas of increased variability at the thermocline $(22 \mathrm{~m})$ and bottom layer $(104 \mathrm{~m})$. The Cold Pool extends to the offshore edge of the Scanfish section (Figure 31). There is very little variability in the salinity profiles above $75 \mathrm{~m}$. Below $75 \mathrm{~m}$, variability increases slightly, however even the maximum standard deviation is low (0.37 PSU). Analogous to the temperature profiles, the sound speed profiles show increased variability at $22 \mathrm{~m}$ and $100 \mathrm{~m}$. However, the maximum standard deviation $(5.49 \mathrm{~m} / \mathrm{s})$ is considerably less than that of all other NEST I scans. It appears that during N14, the water column was fairly 
stable with warm surface waters, a thermocline, a deep, Cold Pool, and a warm, saline bottom layer.
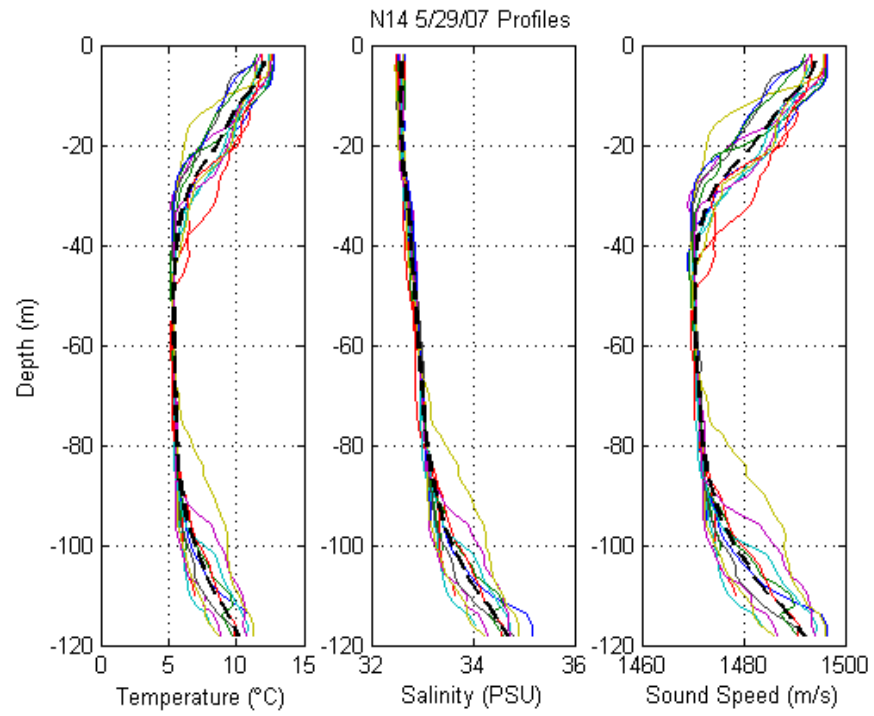

Figure 30. Temperature, salinity, and sound speed profiles from N14, 5/29/07. Dashed line shows mean profile.

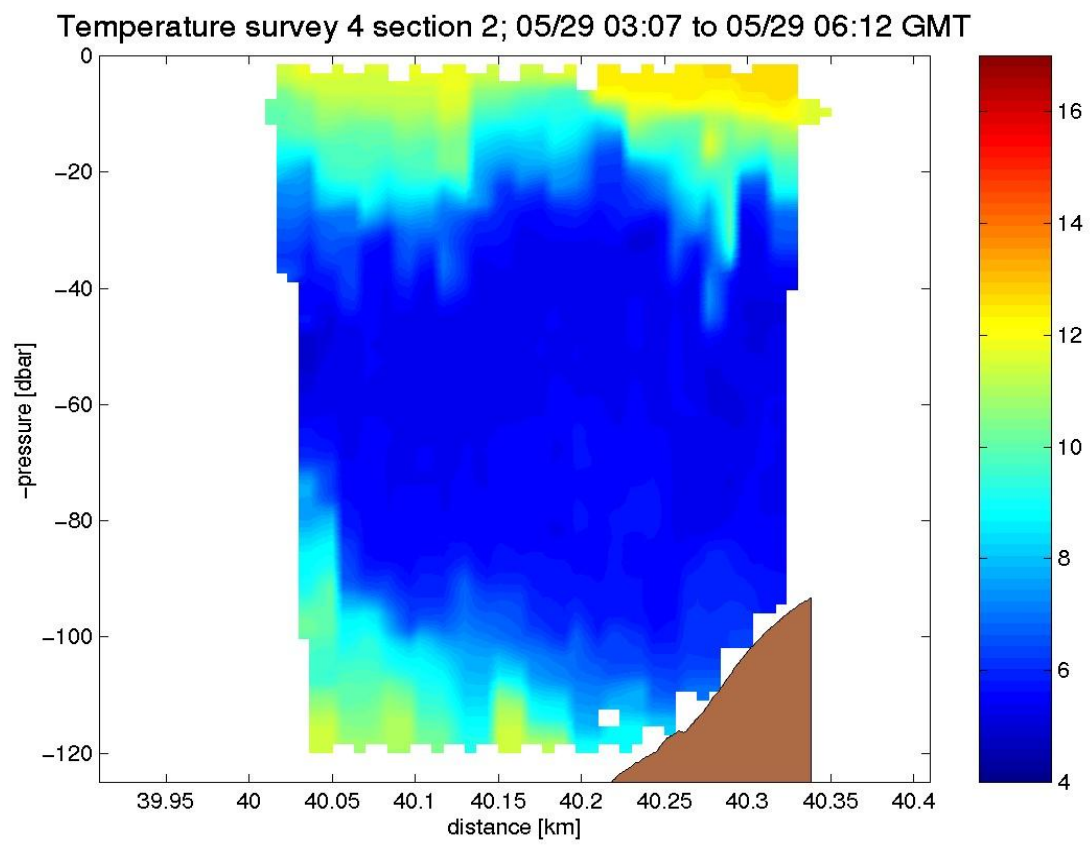

Figure 31. Temperature $\left({ }^{\circ} \mathrm{C}\right)$ cross section of N14 on 5/29/07. Figure courtesy of F. Bahr. 
N15 profiles showed little variability. Similar to N14, these profiles indicate a stable multi-layer water column (Figure 32). There is a shallow surface layer, with a thermocline extending from approximately $5 \mathrm{~m}$ to a minimum temperature at $56 \mathrm{~m}$ $\left(4.6^{\circ} \mathrm{C}\right)$. The lower than average mean temperature $\left(7.1^{\circ} \mathrm{C}\right)$ suggests that the Cold Pool, which pushed further into the area during N14, remains present. With a standard deviation of only $0.7^{\circ} \mathrm{C}$, the mean profile is a good representation of the temperature structure. As seen in the entire set of NEST I profiles, salinity increases from the surface to the bottom, with maximum variance at $116 \mathrm{~m}$, slightly deeper than previous scans. N15 has one of the lowest average standard deviations of the sound speed profiles $(2.66 \mathrm{~m} / \mathrm{s})$. However, unlike the rest of NEST I scans, the maximum variability is within the thermocline $(30 \mathrm{~m})$ and not near the bottom layer. Although slight, this shift in the depth of maximum variance may signify that as the foot of the front moved further offshore, the thermocline became the dominant source of variability as the mixed layer was reestablished.

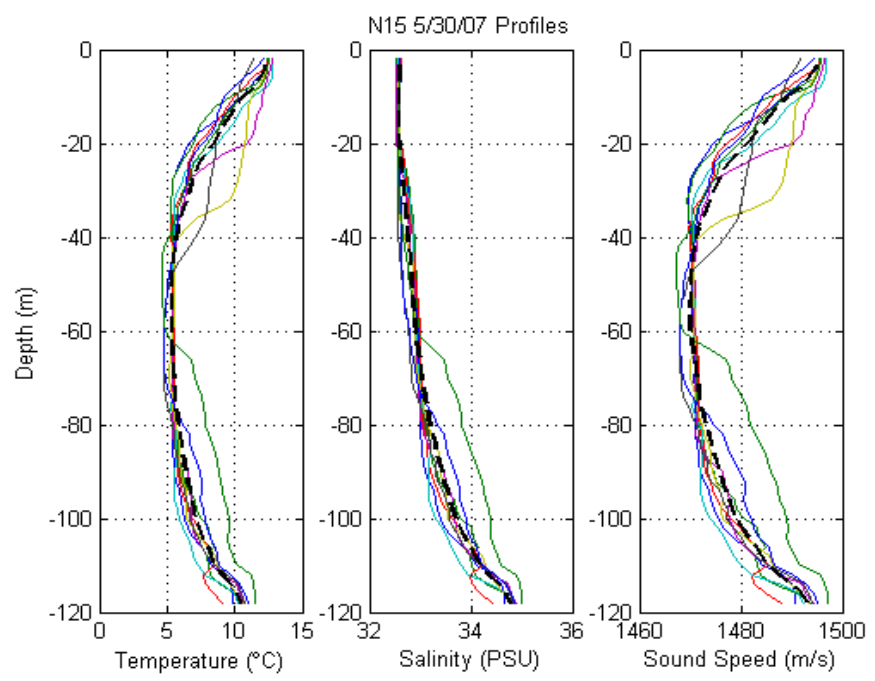

Figure 32. Temperature, salinity, and sound speed profiles from N15, 5/30/07. Dashed line shows mean profile. 


\subsubsection{Mooring Data}

Mooring data collected during NEST I provided a continuous temperature record throughout the experiment and additional insights to the possible sources of variability. Frequency analysis was conducted on each of the mooring time series. The strongest frequency component was, as expected, the semi-diurnal M2 tidal component. Additionally, each temperature series showed the presence of internal waves at all three mooring locations.

The Nantucket Shoals region contains all three of the elements generally known to create propagating internal waves, which are stratification, tidal influences, and significant bathymetry changes. Internal waves have been documented in this region from May through October (Colosi, et al., 2001; Jackson, 2004). Although we expect internal wave presence at the shelfbreak and shelf moorings, the presence of internal waves at the slope mooring $(152 \mathrm{~m})$ suggest that the lee-wave theory of generation, mentioned in Section 1.2, may be accurate for this area. This speculation is also supported by an acoustic survey conducted in this area and described by Jackson (2004).

Evidence of internal wave activity was present in data sets from each of the NEST I moorings. However, mooring B, at the shelfbreak (102m), recorded data for only 2 days before the acoustic release mechanism malfunctioned. Therefore, we will limit our analysis to moorings $\mathrm{C}$ and $\mathrm{A}$, working shoreward from the slope mooring where generation of the internal wave generally occurs. 
Mooring $\mathrm{C}$ time series data clearly shows both the tidal influence and the small scale variability of internal waves (Figure 33). Additionally, the deepening of cold water is consistent with the offshore movement of the foot of the front observed in the Scanfish data. By looking at a single 24-hr time series from May 30, 2007, we can see the finer structure of the internal waves (Figure 34). The 24-hr time series shows two periods of the internal tide. Each internal tidal cycle includes a depression of the thermocline, a large leading soliton, followed by decreasing amplitude oscillations and a thermocline which slowly shoals to its equilibrium depth. Although during this time period, the Scanfish profiles showed smaller variability than other scans, similar internal wave events occurred throughout NEST I, particularly during scans 1-3. The variability in the Scanfish profiles showed that maximum variance was located within the surface and bottom gradient layers, from $10-40 \mathrm{~m}$ and $70-120 \mathrm{~m}$ respectively. A waterfall plot of the thermistor time series clearly shows that the internal wave activity is strongest within these depth regions, and relatively weak in the mid water column (Figure 35). Temperature times series from mooring A also showed internal waves propagating through the area (Figure 36). 


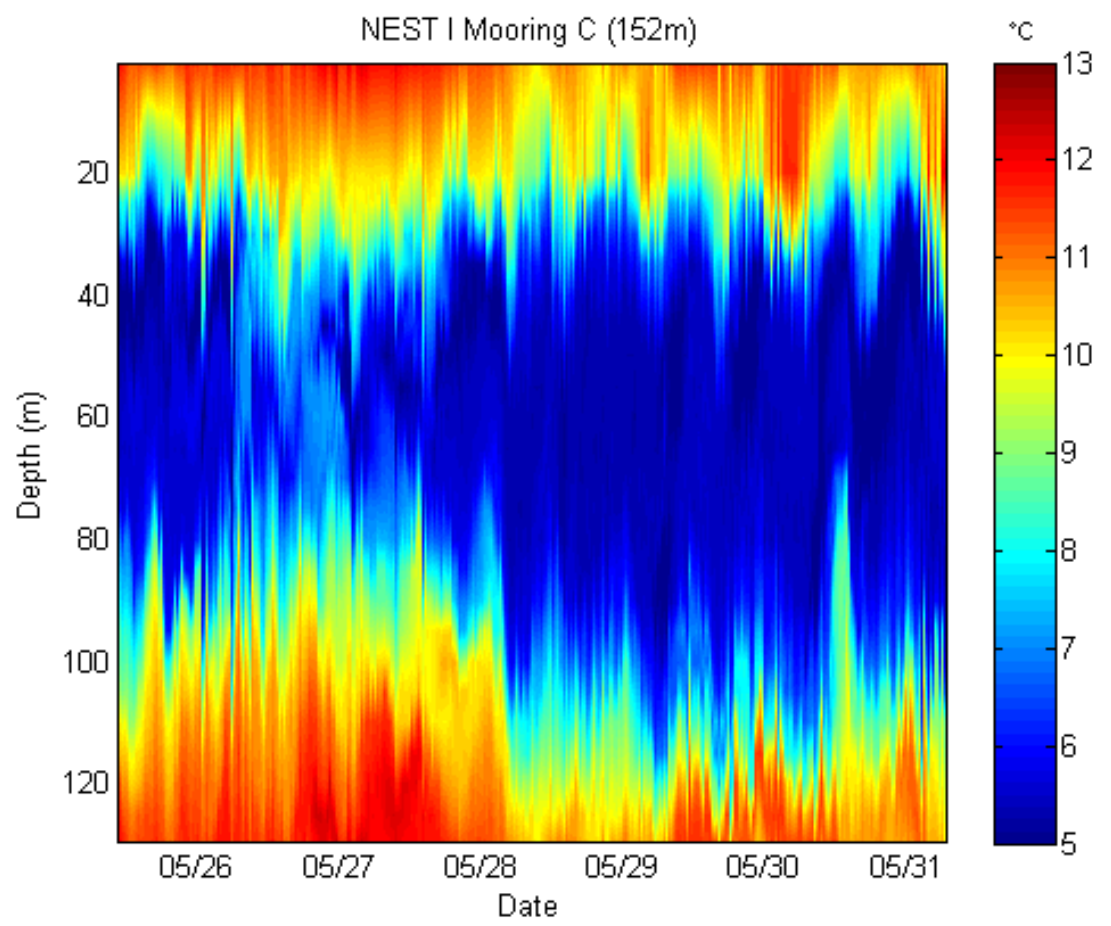

Figure 33. Temperature $\left({ }^{\circ} \mathrm{C}\right)$ time series for NEST I Mooring C, deployed at $40.135^{\circ} \mathrm{N} / 71.000^{\circ} \mathrm{W}$ along the $152 \mathrm{~m}$ isobath.

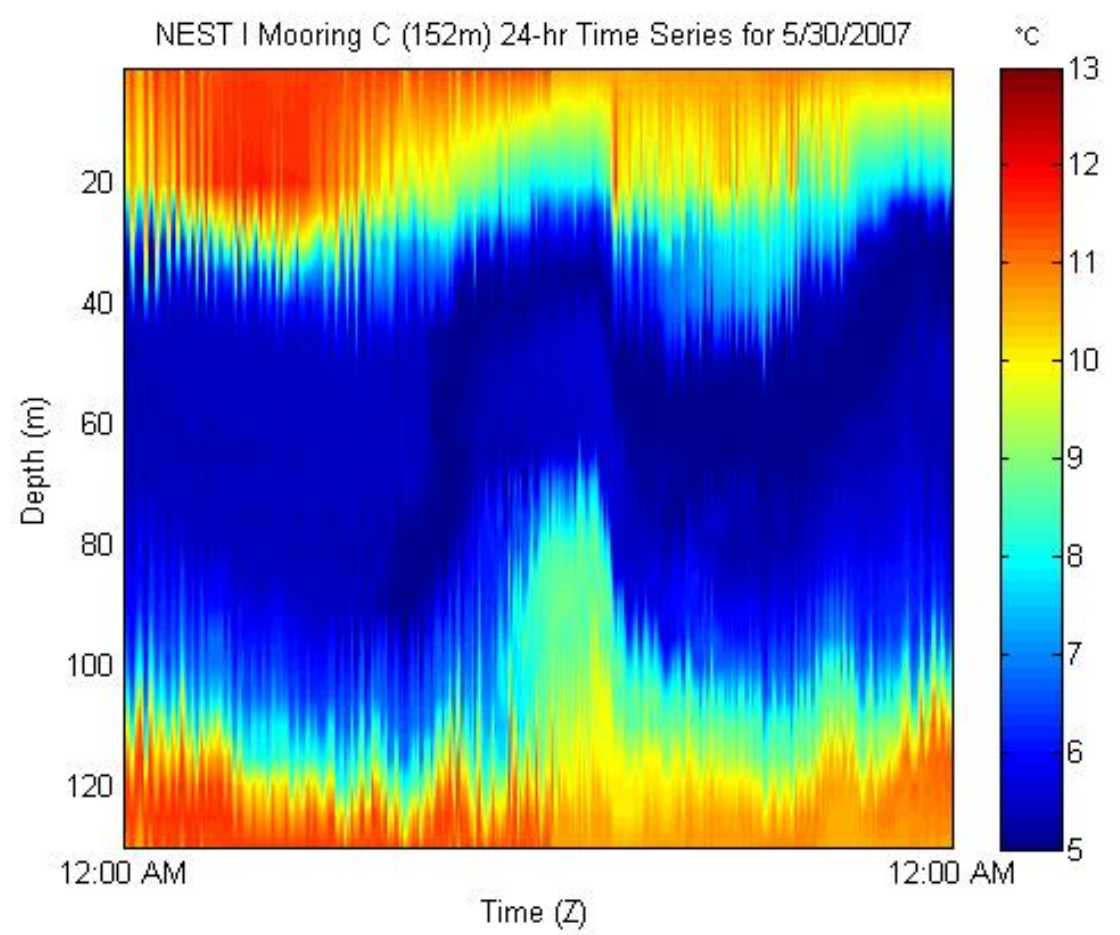

Figure 34. 24-hr temperature $\left({ }^{\circ} \mathrm{C}\right)$ time series for NEST I Mooring C on May 30, 2007. 


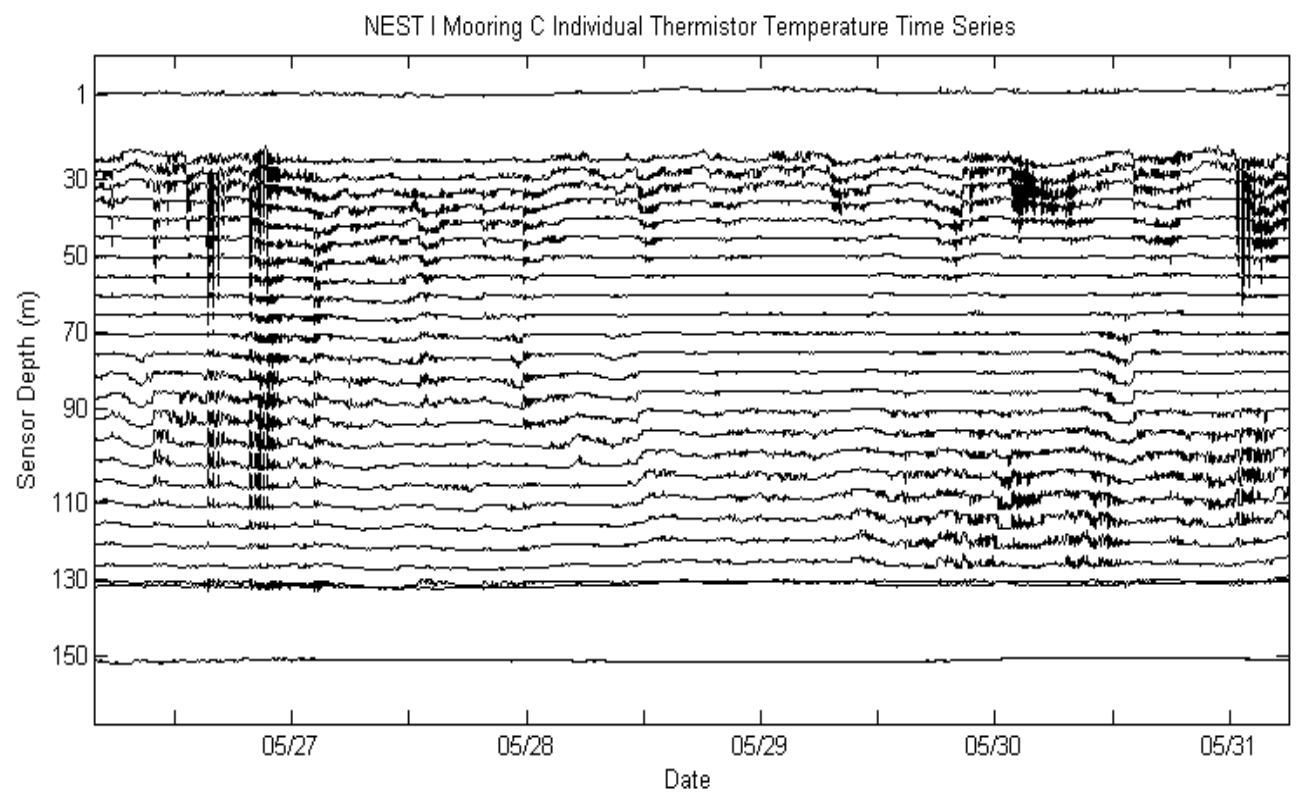

Figure 35. Temperature time series of individual thermistors from NEST I Mooring C.

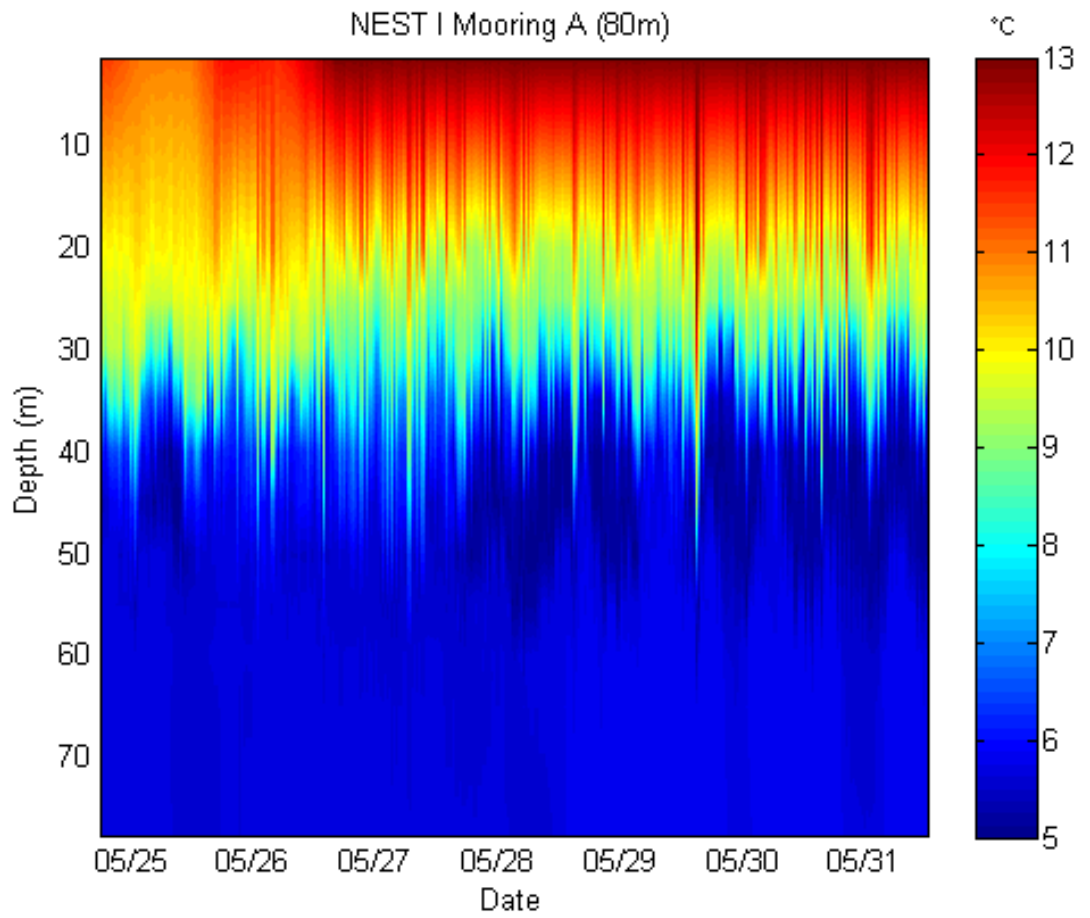

Figure 36. Temperature $\left({ }^{\circ} \mathrm{C}\right)$ time series for NEST I Mooring A, deployed at $40.501{ }^{\circ} \mathrm{N} / 71.000^{\circ} \mathrm{W}$ along the $80 \mathrm{~m}$ isobath. 
Data from moorings A and C provide characteristic spatial and temporal scales for internal waves within the region of interest (Table 2). As discussed in Section 1.2, internal waves spread out spatially and decrease speed as they propagate. Thus we would expect values such as wavelength, period, packet length, and packet separation to increase. It appears that internal waves, generated near mooring $\mathrm{C}$, have increased packet length and separation by the time they propagate past mooring A. Additionally, the minimum individual oscillation wavelength and wave period are also increasing. Measurements from both moorings compare remarkably well with New England shelf internal wave characteristics presented in Jackson (2004) and included for comparison in Table 2. It was also noted that the number of oscillations per packet increased from mooring $\mathrm{C}$ to $\mathrm{A}$, and agreed with reported observations from the PRIMER study stating that packets near the shelfbreak generally consisted of 0-8 oscillations, whereas over the shelf, packets contained up to 30 oscillations (Colosi, et al., 2001).

Table 2. Summary of internal wave characteristics, calculated from NEST I mooring data. A nominal long wave speed of $0.7 \mathrm{~m} / \mathrm{s}$ was used for experimental calculations. These characteristics are compared to those published in Jackson, 2004.

\begin{tabular}{|l|c|c|c|}
\hline \multicolumn{5}{|c|}{ Characteristics of Internal Waves Observed During NEST I } \\
\hline & Mooring A (80m) & Mooring C (152m) & Jackson, 2004 \\
\hline Amplitude (m) & $+/-5-25$ & $+/-5-25$ & $+/-5-25$ \\
\hline Long Wave Speed (m/s) & 0.7 & 0.7 & $0.5-1.0$ \\
\hline Oscillation Wavelength (km) & $0.9-1.4$ & $0.6-1.6$ & $0.6-1.5$ \\
\hline Wave Period (min) & $21-34$ & $13-38$ & $8-25$ \\
\hline Packet Length (km) & $9-12$ & $4-6$ & $1-10$ \\
\hline Packet Separation (km) & 24 & 12 & $15-40$ \\
\hline
\end{tabular}




\subsubsection{NEST I Summary}

During NEST I, the region of interest was dominated by a five layer water column. There was a warm, surface mixed layer over a thermocline extending to $40 \mathrm{~m}$, a Cold Pool of less saline (32 PSU) shelf water, a deep thermocline associated with the shelfbreak front, and a bottom layer of warm saline slope water. The first two days (N11, N12) showed the Cold Pool retreating shoreward, resulting in higher mean temperatures and greater variability along both thermoclines. Because barotropic tidal effects are not particularly strong in this area, it is likely that the movement of the Cold Pool on and off shore was a result of frontal waves propagating along the shelfbreak front. However, due to the short observation period, we cannot adequately resolve the motion of the Cold Pool and will leave that for future work. Most of the variability shown in the Scanfish profiles occurred along the main and bottom thermoclines, with slightly greater variance along the bottom thermocline. Based on the mooring data, internal waves were propagating through the region of interest during the experiment and had the most effect along these gradient layers. Because N11-N13 showed the greatest variability, it is likely that both the internal waves and the Cold Pool movement were contributing factors. During these scans, the variability along the bottom thermocline was slightly greater than the main thermocline. It is possible that the warm slope eddy and its interaction with the existing warm slope water was an additional source of variability. The shift of variability to the main thermocline during N14 and N15 suggests that as the Cold Pool pushed offshore, the variability along the Cold Pool-warm bottom water interface decreased. If the movement of the Cold Pool is indeed the result of frontal waves, particularly dominated 
by the bottom trapped mode affecting the foot of the front, it seems that at some point, however brief, in the wave phase, the foot position stabilizes and water column variability is dominated by changes to the surface layer from solar radiation and winds.

The presence of a slope eddy may have had an influence on the extent of the Cold Pool and thinness of the bottom warm layer. Throughout NEST I, the foot of the front was located along the $120 \mathrm{~m}$ isobath approximately $7-10 \mathrm{~km}$ seaward of the climatological foot of the front. From spring climatology, the foot of the front is located along the $100 \mathrm{~m}$ isobath and the front itself is almost vertical. However, during NEST I, the shelf water flowed much farther offshore, decreasing cross-shelf gradients. Unlike previous years when slope eddies have extended to the surface, the NEST I slope eddy was overlain by cold shelf water. When small eddies shed from Gulf Stream generated warm core rings, shelf water is often entrained in the rotating eddy and pulled seaward (Garfield \& Evans, 1987). The most likely cause of the extreme seaward position and maximum thickness of the cold shelf water is entrainment by the decaying warm core ring and its resulting slope eddy. Although the movement of the Cold Pool and internal wave activity created variability along water mass interfaces, the relative stability of the thick Cold Pool created an acoustic duct with a sound speed minimum from 30-60m which provided excellent conditions for acoustic propagation throughout the duration of the experiment. 


\subsection{NEST II}

\subsubsection{Scanfish Surveys}

The NEST II mean temperature and sound speed profiles indicate that under a warm surface layer and highly variable thermocline, there was a thin Cold Pool with a deep warm bottom layer. The shelfbreak front was nearly horizontal through the area, reaching the surface beyond the southern extent of region of interest, with the foot of the front continuously retreating shoreward. During NEST II, there was a very large, warm Gulf Stream meander south of the experiment area and a large cyclonic eddy to the east (Figure 37). Cold water was pulled from the shelf in a $200 \mathrm{~km}$ wide entrainment between the meander and the eddy, east of the NEST area. A thin layer of cold shelf water flowed offshore just beneath the warm surface layer and was bound by saline slope water creating a deep warm bottom layer which flowed much farther inshore than seen in either climatology or NEST I. The slope water in the lower layer dominated the temperature and salinity characteristics of the outer shelf. Scanfish profiles and 2-D slices show a highly variable water column. In addition to internal wave activity, there were two shelfbreak eddies present over the slope in the region of interest. In contrast to the slope eddy of NEST I which spawned from a warm core ring, shelfbreak eddies contain cool, fresh shelf water. The NEST II mean water temperature was $11.4^{\circ} \mathrm{C}$ with a range of 8.0$13.7^{\circ} \mathrm{C}$, and a standard deviation of $0.8^{\circ} \mathrm{C}$. The mean salinity was $34.2 \mathrm{PSU}$ with a range of 32.5-35.4 PSU and a standard deviation of 0.27 PSU. The mean sound speed was $1494.6 \mathrm{~m} / \mathrm{s}$ with a range of $1480.3-1504.5 \mathrm{~m} / \mathrm{s}$ and a standard deviation of $3.11 \mathrm{~m} / \mathrm{s}$. The maximum variance for temperature, salinity, and sound speed were all collocated within 
the main thermocline at approximately $30-45 \mathrm{~m}$. The variability in the thermocline is likely the influence of both internal wave activity over the shelf and the presence of shelfbreak eddies.

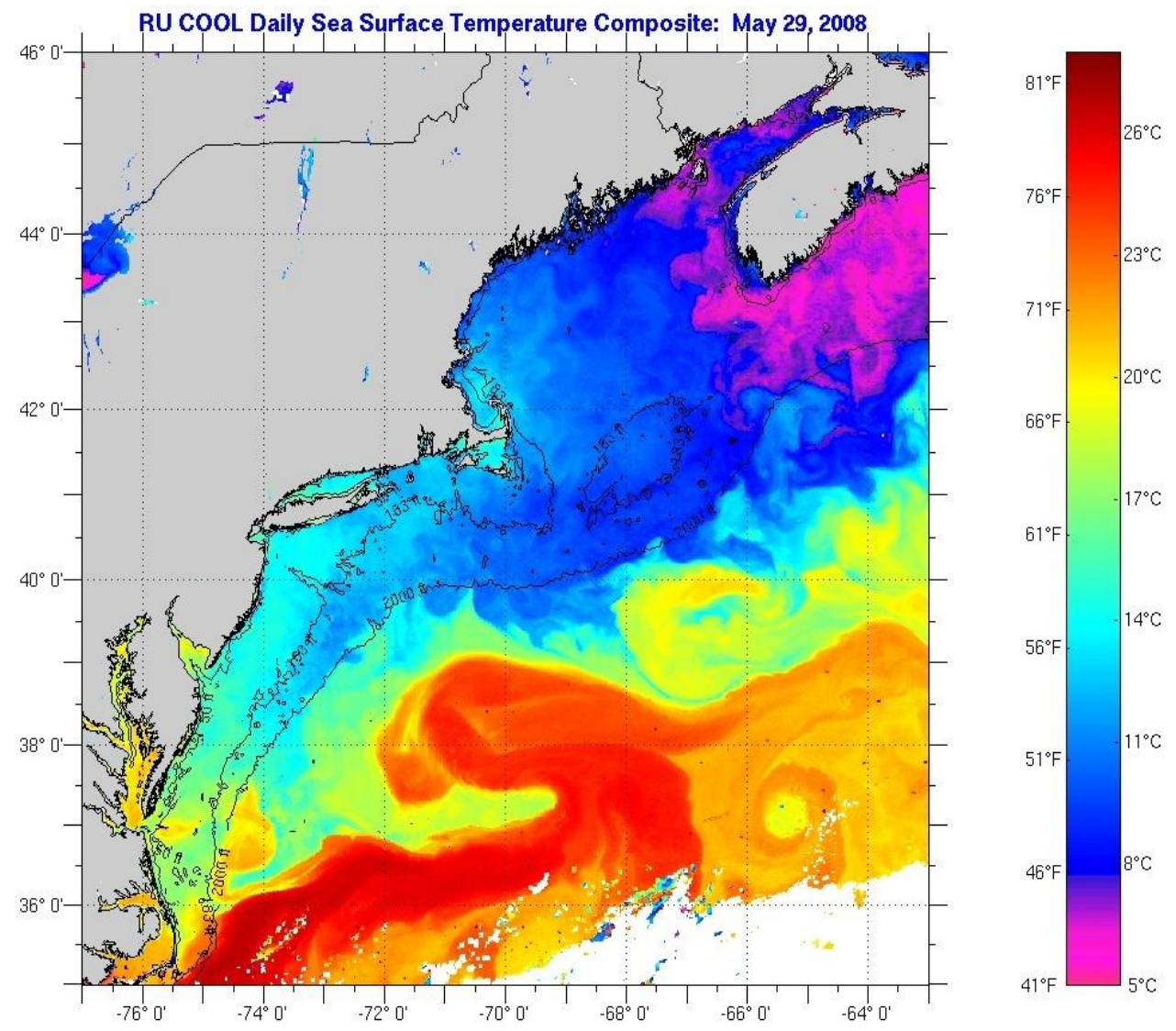

Figure 37. Satellite sea surface temperature composite showing the presence of a warm Gulf Stream meander in the vicinity of the NEST II experiment area. Image from Rutgers University Coastal Ocean Observation Lab (http://marine.rutgers.edu/mrs/sat_data/?nothumbs=0).

The N21 water column had a surface mixed layer, highly variable thermocline, and warm bottom layer (Figure 38). The mean water temperature was $10.9^{\circ} \mathrm{C}$, with a standard deviation of $1.09^{\circ} \mathrm{C}$, and maximum variability located within the thermocline (44m). From Figure 38, it appears that the temperature profile is highly variable along the thermocline, which is confirmed by the highest standard deviation $\left(2.2^{\circ} \mathrm{C}\right)$ of all 
NEST profiles. The temperature increases from the base of the thermocline to the bottom. The depth of the temperature minimum varies from $20-50 \mathrm{~m}$, which suggests increased variability due to internal waves. The salinity profiles show less saline water near the surface (32.5 PSU) with constantly increasing salinity to the bottom (35.3 PSU). The mean salinity is $34.0 \mathrm{PSU}$, with a standard deviation of $0.35 \mathrm{PSU}$. The maximum salinity variability is located within the thermocline at $42 \mathrm{~m}$. The sound speed profiles have maximum standard deviation at $42 \mathrm{~m}(8.79 \mathrm{~m} / \mathrm{s})$ which is the highest of all NEST II profiles. It is reasonable that the thermocline variability is partially driven by internal waves. However, the presence of shelfbreak eddies beneath the surface from approximately $15-45 \mathrm{~m}$ is likely to contribute additional variability within that depth region (Figure 39).

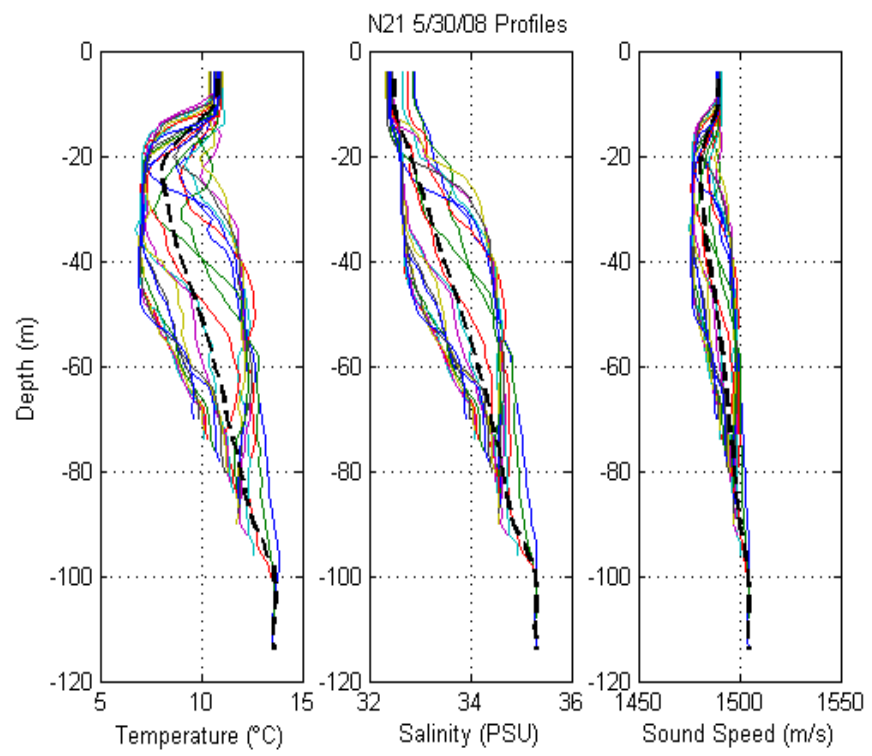

Figure 38. Temperature, salinity, and sound speed profiles from N21, 5/30/08. Dashed line shows mean profile. 


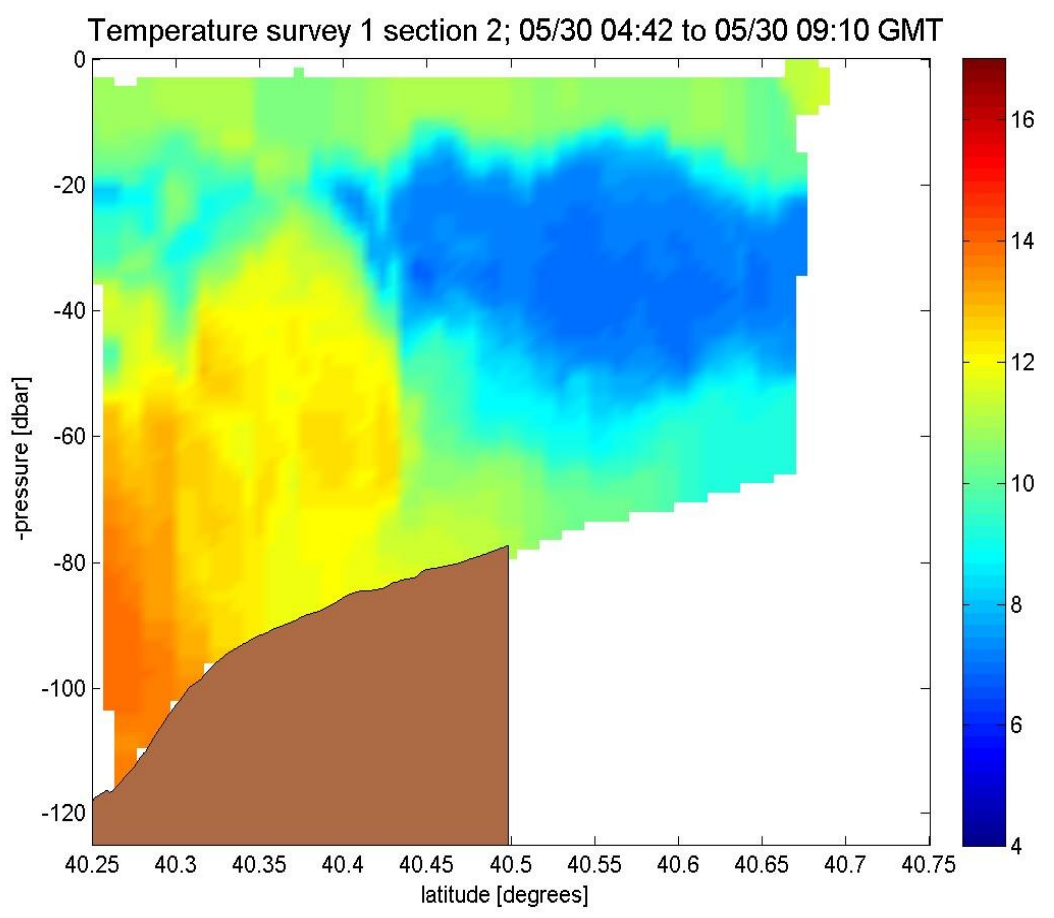

Figure 39. Temperature cross section of N21 on 5/30/08. Figure provided by F. Bahr.

N22 profiles show a very shallow mixed layer and a thermocline extending to approximately $30 \mathrm{~m}$ (Figure 40 ). From the mean temperature minimum $\left(8.9^{\circ} \mathrm{C}\right)$ at $28 \mathrm{~m}$, the water temperature slowly increases to the bottom. The mean temperature is $10.9^{\circ} \mathrm{C}$, with a maximum standard deviation of $1.11^{\circ} \mathrm{C}$ at $38 \mathrm{~m}$. There is high variability within the depth region directly below the thermocline with standard deviations greater than $1{ }^{\circ} \mathrm{C}$ from $32-48 \mathrm{~m}$. The salinity profiles show a layer of constant low salinity at the surface to a depth of $15 \mathrm{~m}$, then gradually increasing salinity to the bottom, with a constant layer of higher saline water below $100 \mathrm{~m}$. The mean salinity is $34.1 \mathrm{PSU}$, with a maximum standard deviation of $0.39 \mathrm{PSU}$ at $36 \mathrm{~m}$. There are two profiles which show more saline water at the surface, where mixing of the slope and shelf water has occurred near the boundary of the front. N22 sound speed profiles have both the lowest mean and 
maximum variance of all scans. Although low in magnitude, there is increased sound speed variability from $24-70 \mathrm{~m}$. N22 shows some variability within the thermocline; however, it is much less than during other scans.
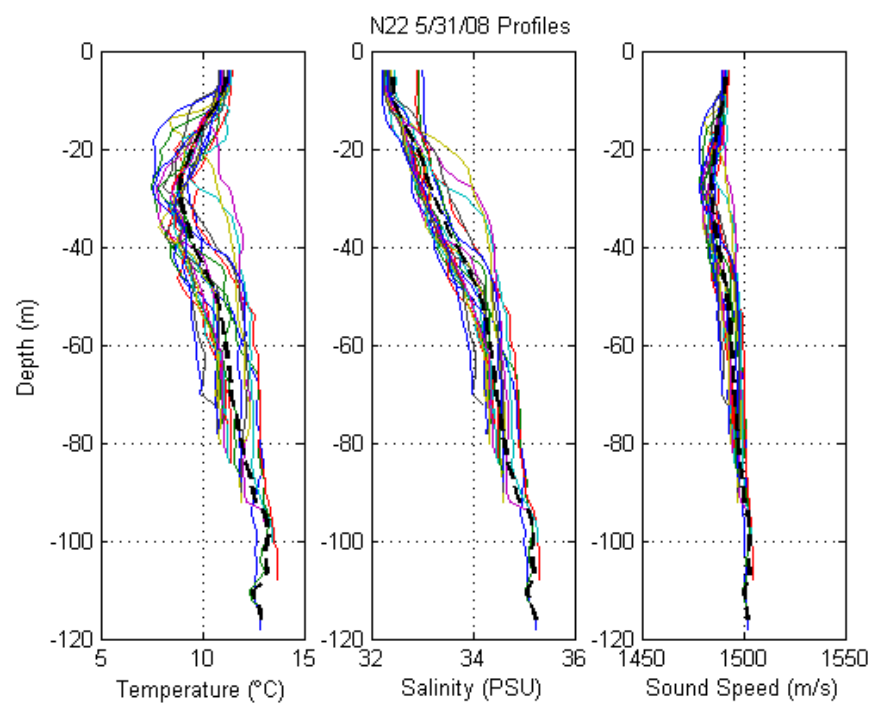

Figure 40. Temperature, salinity, and sound speed profiles from N22, 5/31/08. Dashed line shows mean profile.

During N23, there is a well mixed surface layer of warm, fresh water extending to approximately $18 \mathrm{~m}$ and a highly variable thermocline (Figure 41 ). Although it appears that the final 3 profiles were taken across the shelfbreak front, based on the dramatically different structure, the shelfbreak front was still fairly horizontal and had not yet intersected the surface (Figure 42). These profiles represent the boundary along the shelfbreak front where warm slope water is surrounding the cool shelfbreak eddy. Excluding these three profiles, shown in red in Figure 42, the maximum temperature variance is located at two depths $20 \mathrm{~m}$ and $38 \mathrm{~m}$, with increased variance in the region from $18-46 \mathrm{~m}$. The three seaward profiles show a temperature maximum at approximately $42 \mathrm{~m}$, and a temperature minimum from $80-100 \mathrm{~m}$. The salinity profiles 
show a shallower halocline than the rest of the $\mathrm{N} 23$ profiles, indicating that the shelfbreak eddy only extends to $40 \mathrm{~m}$, bounded by saline slope water beneath. The mean salinity is 34.3 PSU, with maximum standard deviation of only 0.3 PSU when the three seaward profiles are excluded. The mean sound speed is $1495.5 \mathrm{~m} / \mathrm{s}$, with a maximum standard deviation of only $5.5 \mathrm{~m} / \mathrm{s}$. Maximum variability is located within the thermocline; and is likely due to the presence of two shelfbreak eddies located within the depth region from 10-40m (Figure 43). These eddies are isolated pockets of relatively colder water that contribute to the temperature and sound speed variability.

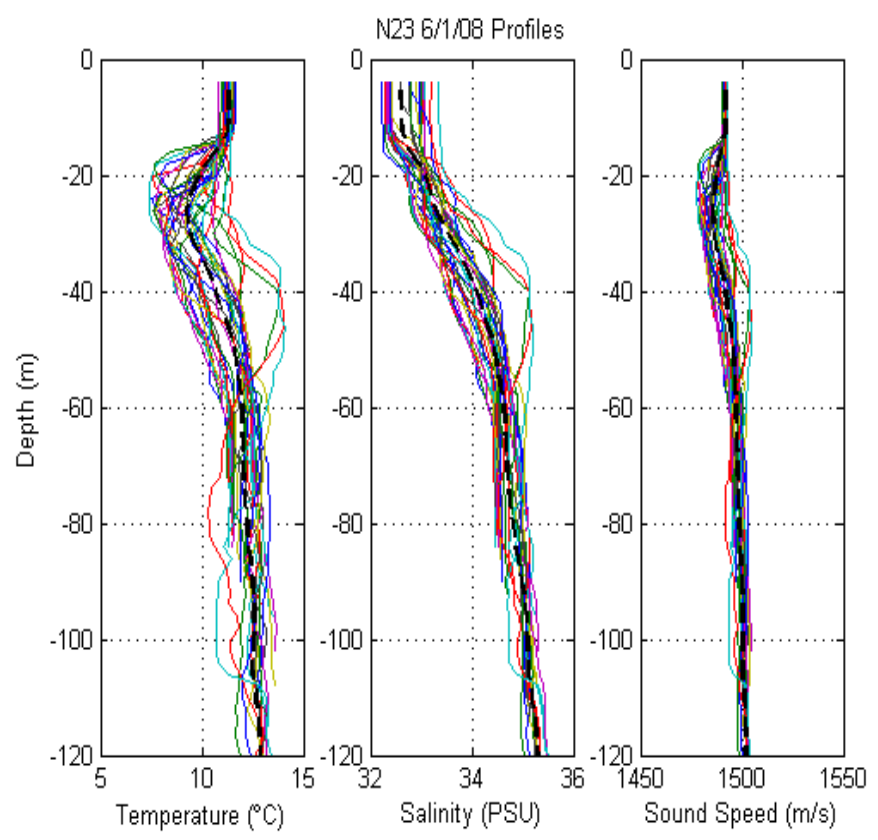

Figure 41. Temperature, salinity, and sound speed profiles from N23, 6/1/08. Dashed line shows mean profile. 

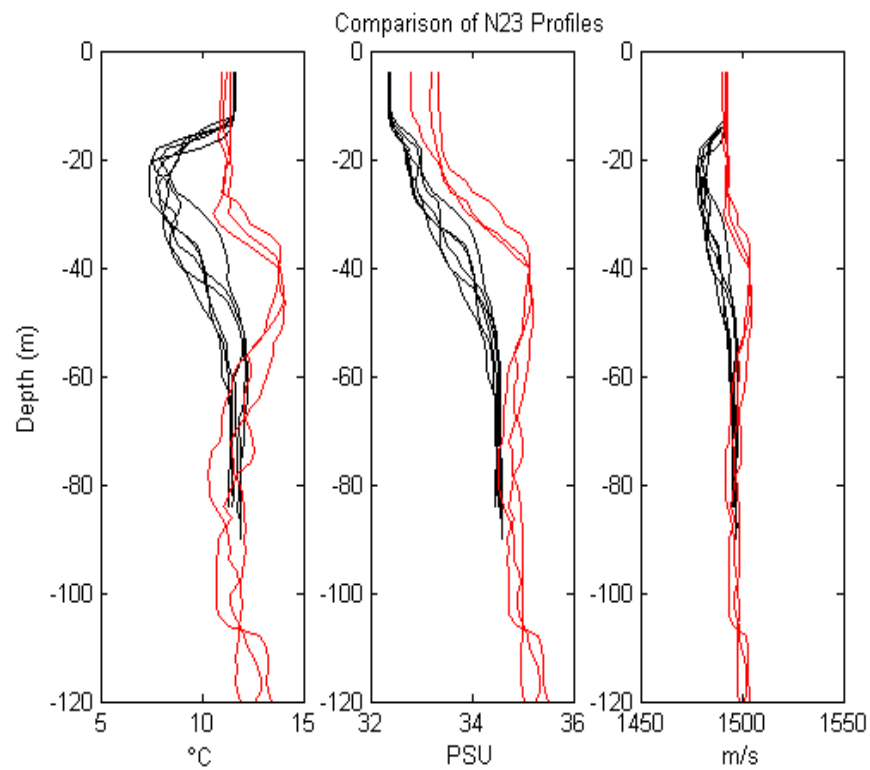

Figure 42. Comparison of vertical profiles from N23. All profiles were collected shoreward of the frontal boundary.

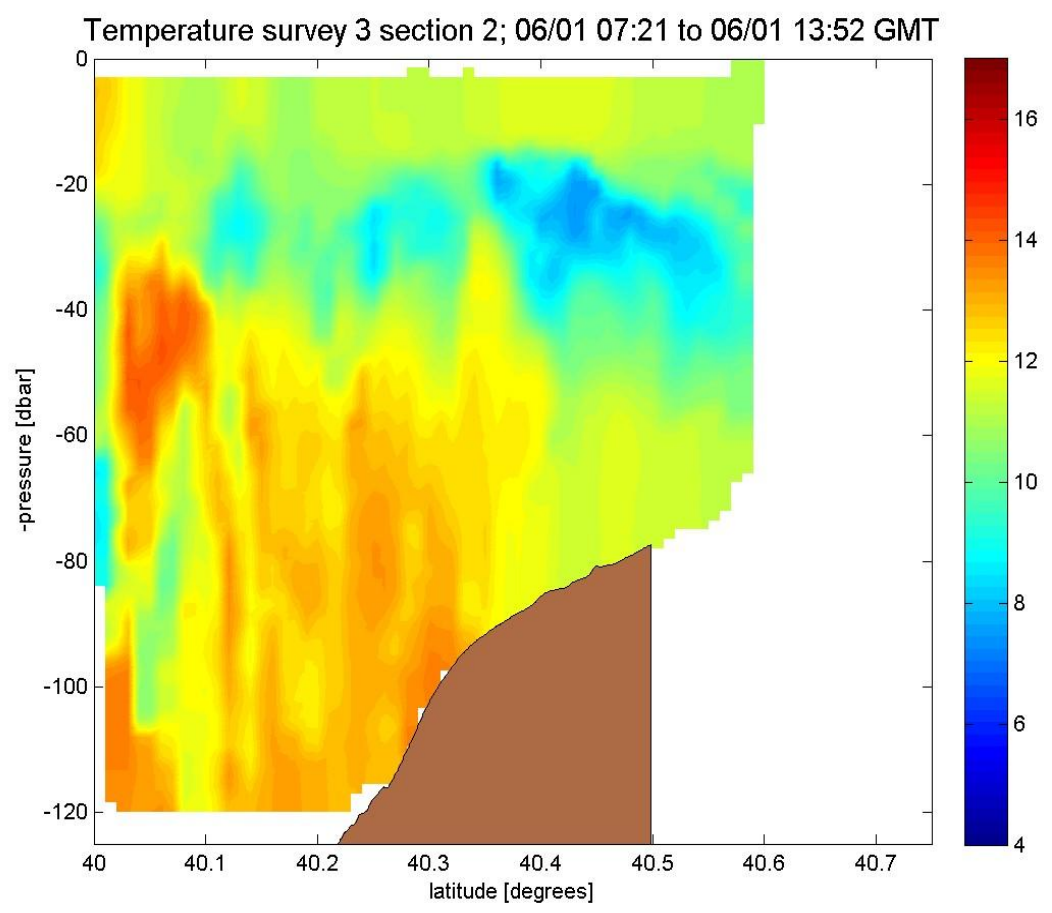

Figure 43. Temperature cross section of N23 on 6/1/08. Figure courtesy of F. Bahr. 
N24 profiles are similar to those of N21, although less variable (Figure 44). There is a warm surface layer overlying the main thermocline and thin Cold Pool with a warm bottom layer. The mean water temperature is slightly warmer $\left(11.6^{\circ} \mathrm{C}\right)$ with a standard deviation of only $0.53^{\circ} \mathrm{C}$, the lowest of all NEST II scans. The maximum temperature variance is again located within the thermocline at $34 \mathrm{~m}$. The salinity profile shows a layer of less saline surface water, with a region of mixing between $20-60 \mathrm{~m}$, and more saline water representative of slope water from $60 \mathrm{~m}$ to the bottom. The horizontal salinity slice shows that the shelf water, defined by less than 34.5 PSU, extends to the offshore edge of the Scanfish section (Figure 45). The mean salinity is 34.2 PSU with a standard deviation of only 0.16 PSU. Although weak in magnitude, the maximum salinity variance $\left(0.04 \mathrm{PSU}^{2}\right)$ is located at $34 \mathrm{~m}$. The mean sound speed standard deviation is low $(2.0 \mathrm{~m} / \mathrm{s})$ compared to other NEST II scans $(2.7-4.3 \mathrm{~m} / \mathrm{s})$, and the weakly defined maximum is located at $34 \mathrm{~m}$, similar to temperature and salinity. Such little variability within the $\mathrm{N} 24$ profiles implies that there was little, if any, internal wave activity during this scan. The decreased variability may indicate that the shelfbreak eddies are being reabsorbed by the Cold Pool which reaches to the offshore edge of the section. 

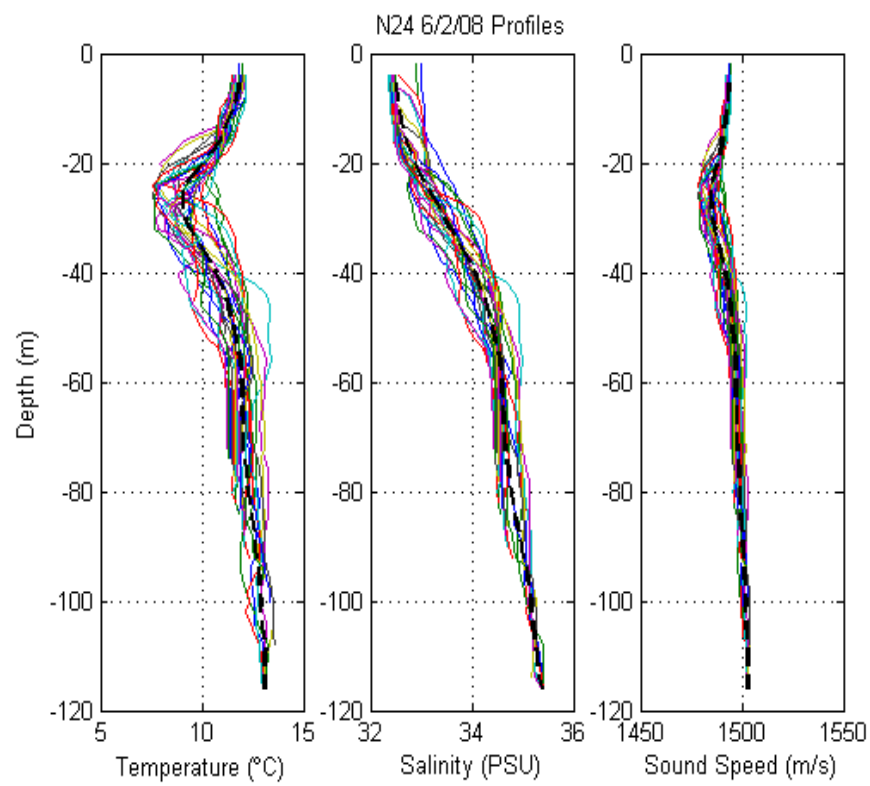

Figure 44. Temperature, salinity, and sound speed profiles from N24, 6/4/08. Dashed line shows mean profile.

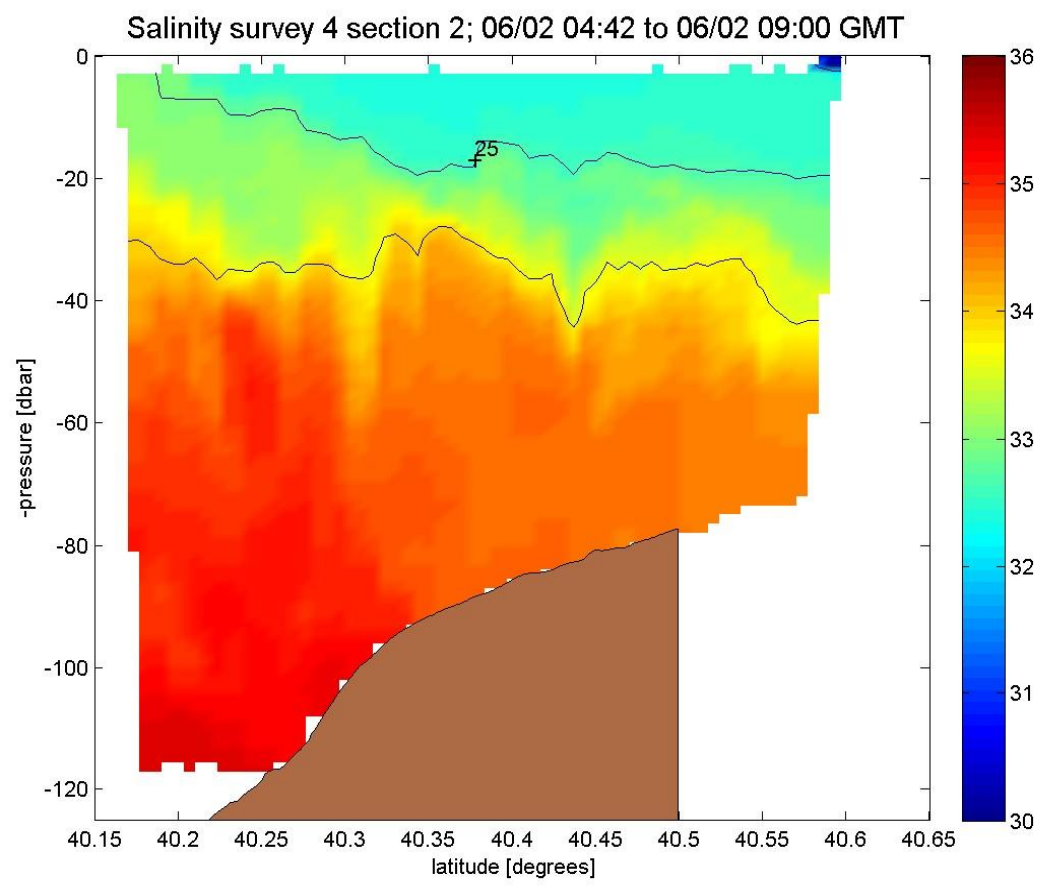

Figure 45. Salinity (PSU) cross section of N24 on 6/02/08. Figure courtesy of F. Bahr. 
N25 profiles show high variability within the thermocline and halocline (Figure 46). The mean water temperature is $11.6^{\circ} \mathrm{C}$, with a maximum standard deviation of $1.85^{\circ} \mathrm{C}$ located at $38 \mathrm{~m}$. Within the region of the thermocline $(22-58 \mathrm{~m})$, the standard deviation was greater than $1^{\circ} \mathrm{C}$. There is increased variance in the salinity profiles from $10-60 \mathrm{~m}$, with decreasing variance toward the bottom. The average salinity is 34.3 PSU, similar to the other NEST II scans; however, there is more variability within the water column. The high variability of both temperature and salinity from $10-60 \mathrm{~m}$ is likely the effect of the shelfbreak eddies and surrounding slope water. Furthermore, there appears to be an influx of even warmer water over the slope between $20-80 \mathrm{~m}$ which may be the result of filaments from the large Gulf Stream meander pushing onshore (Figure 47). The maximum standard deviation in sound speed $(7.41 \mathrm{~m} / \mathrm{s})$ occurs at $36 \mathrm{~m}$, with greater than average standard deviation from $18-62 \mathrm{~m}$. Similar to N23, there is complex structure in the temperature field for N25, making the three southernmost profiles appear to be crossfront profiles, when in fact, they represent profiles within the eddies. Contrary to the presumption that the intensity of the shelfbreak eddies was weakening in N24, N25 still clearly shows increased variability caused by the eddies. Once again, the shelfbreak front does not intersect the surface until further south than the extent of the scan. The thermocline region from $20-60 \mathrm{~m}$ is the source of maximum variability during this scan, resulting from the interactions of multiple features including shelfbreak eddies and warm meander filaments. 

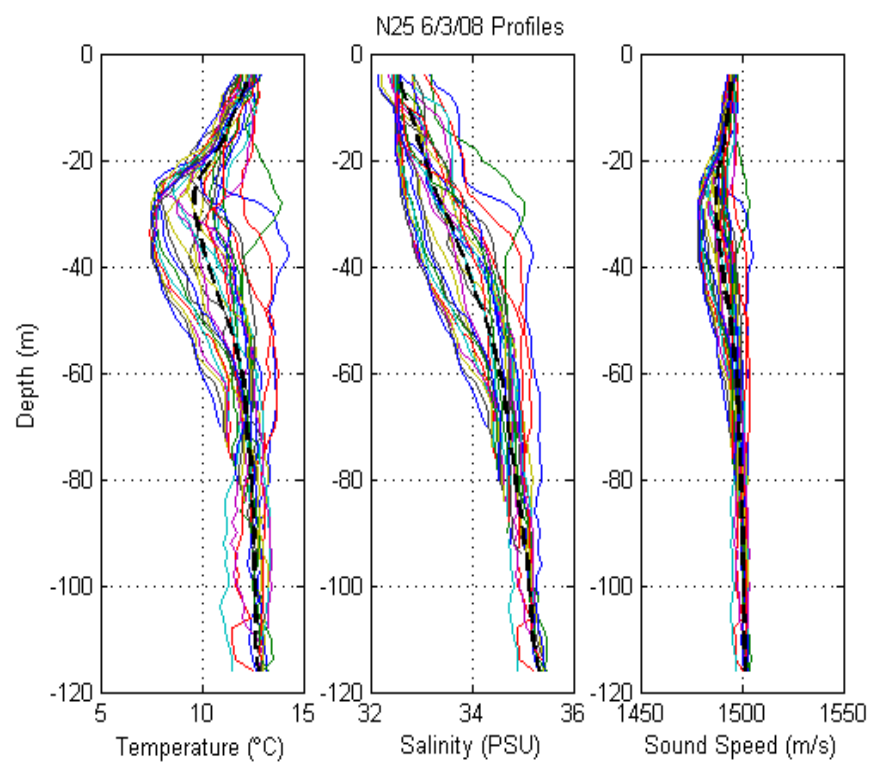

Figure 46. Temperature, salinity, and sound speed profiles from N25, 6/3/08. Dashed line shows mean profile.

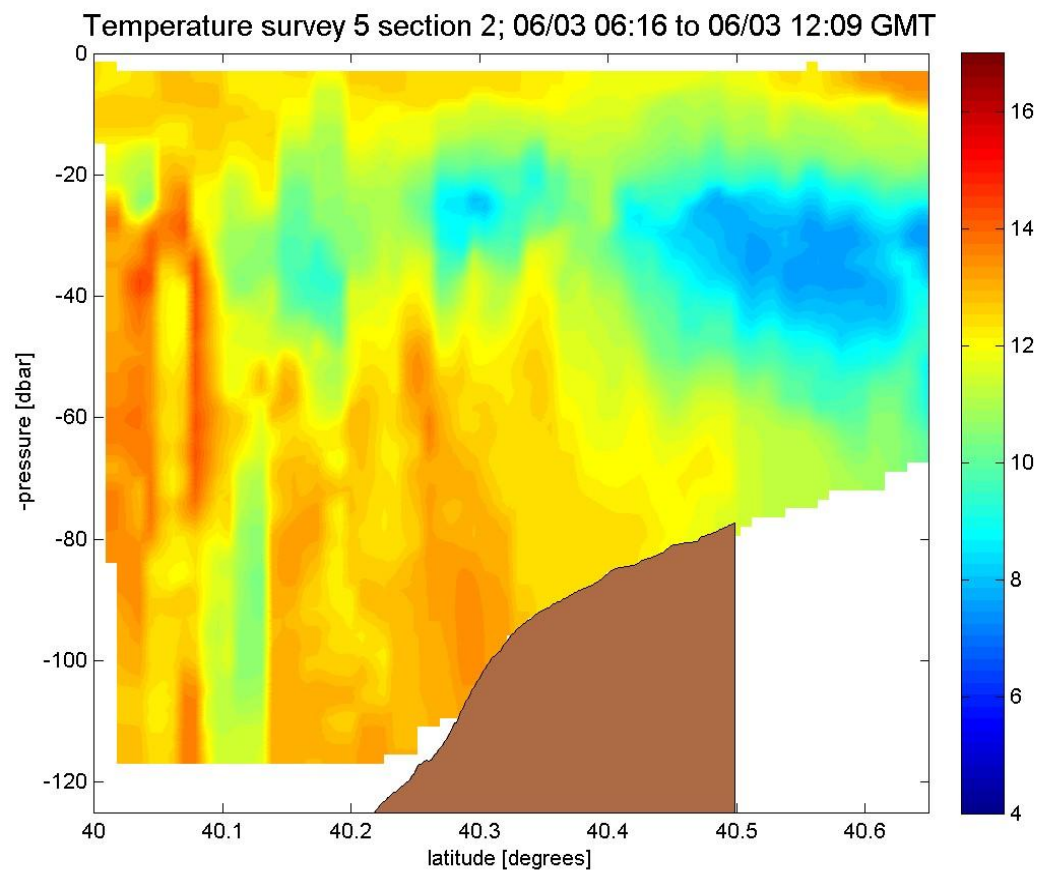

Figure 47. Temperature $\left({ }^{\circ} \mathrm{C}\right)$ cross section of $\mathrm{N} 25$ on 6/03/08. Figure courtesy of F. Bahr. 


\subsubsection{Mooring Data}

During NEST II, moorings were deployed for the duration of the experiment in approximately the same locations as the NEST I moorings. Continuous temperature records from these moorings show internal wave activity at all three locations. As in NEST I, the semidiurnal tide was the largest frequency component. However, it is the finer structure of the internal waves in which we are most interested.

We have suggested that internal wave activity was a contributing factor to the variability within the Scanfish profiles, particularly during N21, N22, and N25, corresponding to 5/30,5/31,6/3. The temperature record from NEST II mooring C, shown in Figure 48, shows a much different structure compared to that of NEST I mooring C (Figure 33). While there is evidence of internal wave activity during these scans, there are also shelfbreak eddies which add to the variability. The cold pockets of water shown in the mooring $\mathrm{C}$ record are indicative of the presence and movement of these eddies. At the shelfbreak, mooring B did not show evidence of the shelfbreak eddies, but did show a deepening of cold water down to 50m (Figure 49). The thin Cold Pool stretching out from the shelf is evident and there is variability characteristic of internal wave activity. From Figure 50, we see that two of our assumptions from the Scanfish profiles are accurate. First, the internal wave activity appears to be concentrated within the thermocline from $20-45 \mathrm{~m}$, and second, there seems to be greater activity during N21, N22, and N25, with a period of weaker internal wave activity during N23 and N24. The mooring A temperature record shows similar variability to mooring B. 


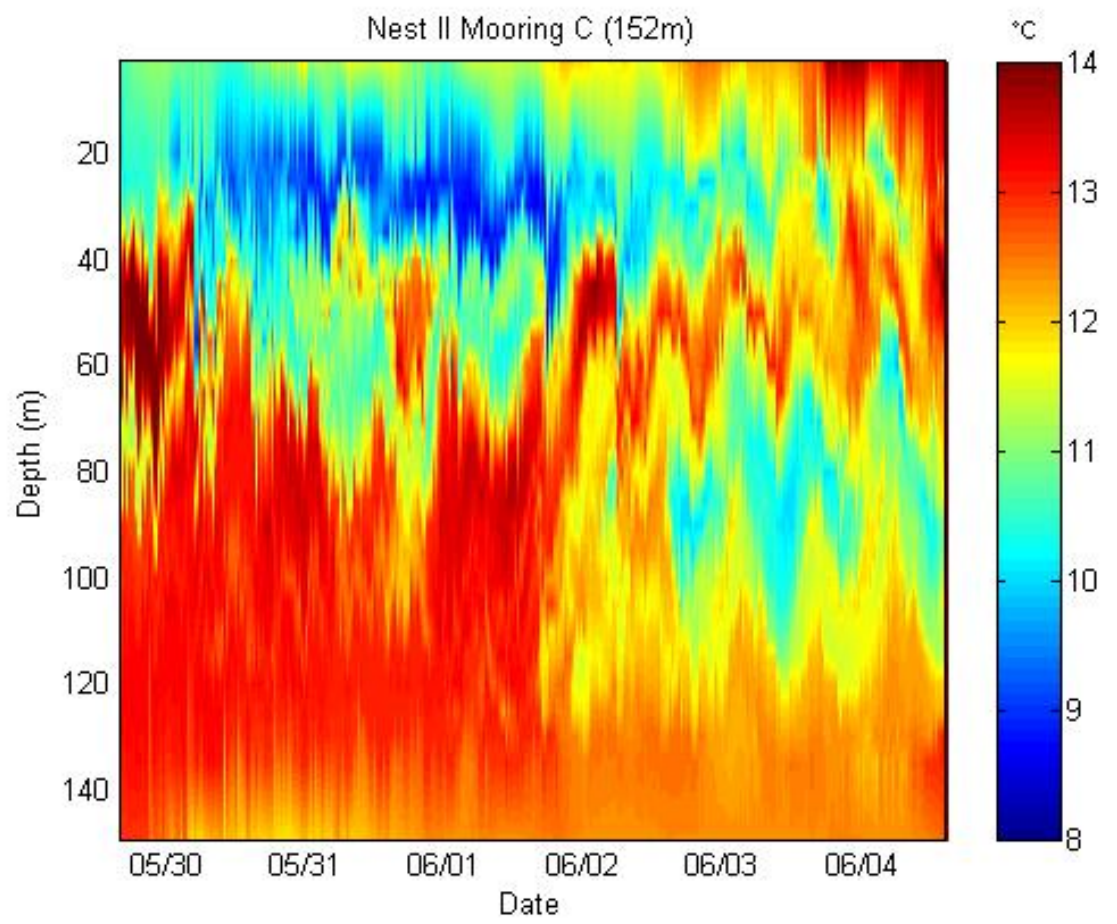

Figure 48. Temperature $\left({ }^{\circ} \mathrm{C}\right)$ time series for NEST II Mooring C, deployed at $40.126^{\circ} \mathrm{N} / 71.000^{\circ} \mathrm{W}$ along the $152 \mathrm{~m}$ isobath.

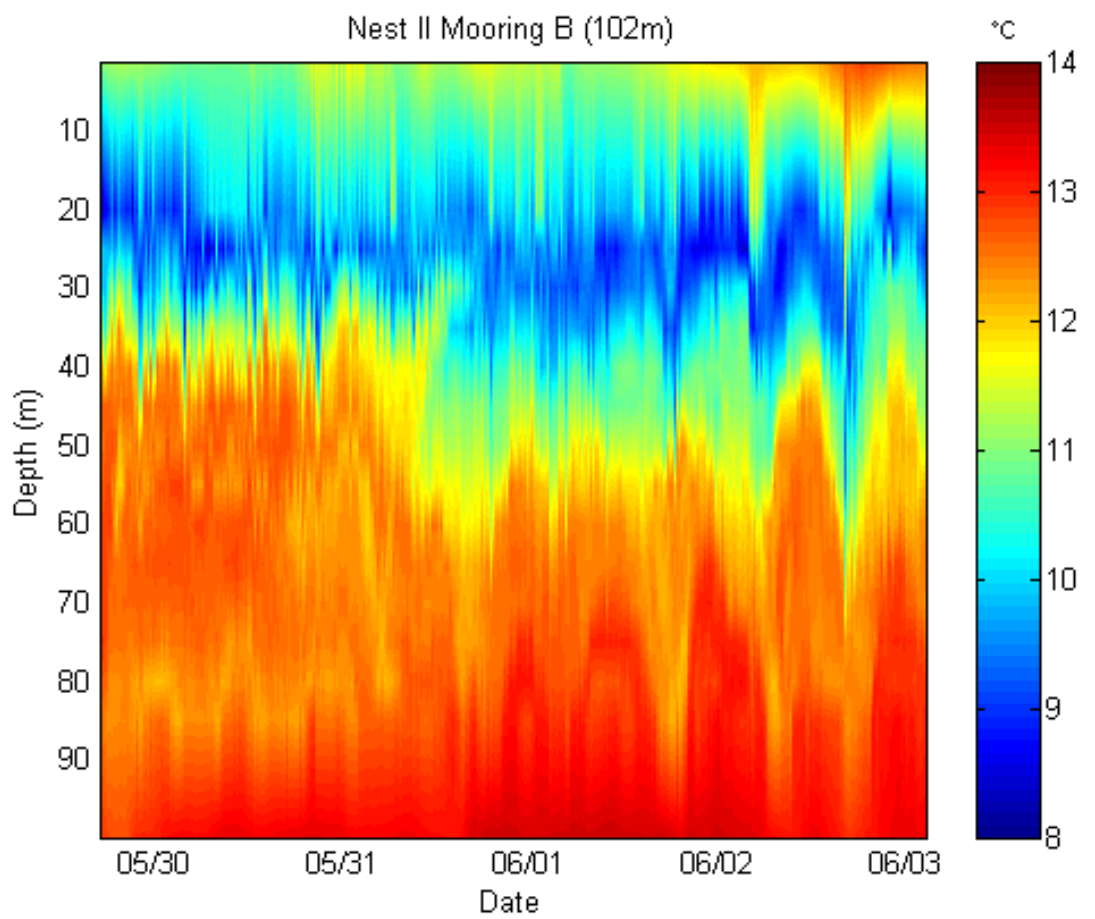

Figure 49. Temperature $\left({ }^{\circ} \mathrm{C}\right)$ time series for NEST II Mooring B, deployed at $40.313^{\circ} \mathrm{N} / 71.000^{\circ} \mathrm{W}$ along the $102 \mathrm{~m}$ isobath. 


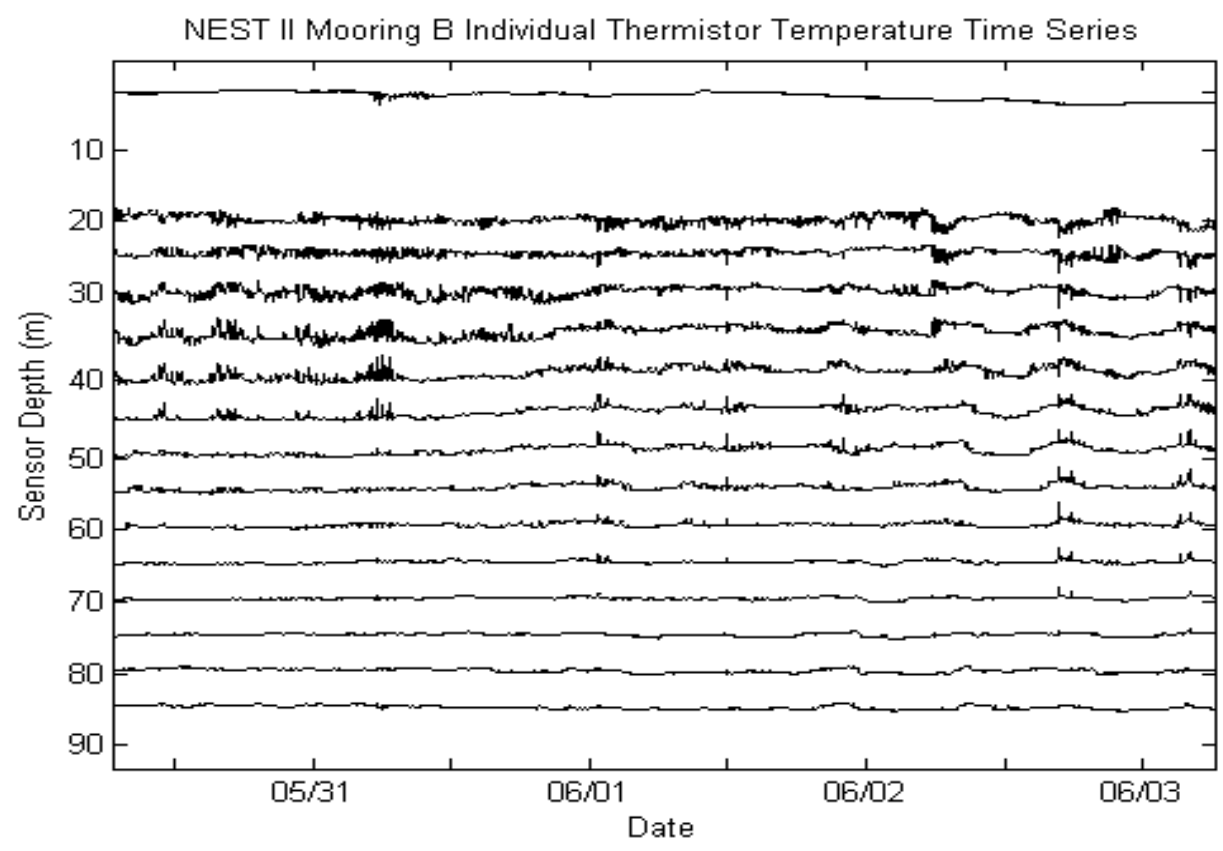

Figure 50. Temperature time series of individual thermistors from NEST II Mooring B.

Beginning at the slope mooring and moving shoreward, we evaluate the internal waves passing each location. Internal wave characteristics from each mooring are presented in Table 3. With the exception of packet separation, which shows a slight decrease at mooring $\mathrm{A}$, the values for packet length, oscillation period, and wavelength provide an excellent example of aging, propagating internal waves. For example, the oscillation wavelength increases from a range of $0.5-0.9 \mathrm{~km}$ at mooring $\mathrm{C}$, to $1.0-1.4 \mathrm{~km}$ at mooring B, to $1.2-1.6 \mathrm{~km}$ at mooring A. NEST II internal wave characteristics agree well with previously published values for the New England shelf area (Jackson, 2004). As expected, the internal waves present during NEST II stretch spatially and temporally as they propagate shoreward. 
Table 3. Summary of internal wave characteristics, calculated from NEST II Mooring data. A nominal long wave speed of $0.7 \mathrm{~m} / \mathrm{s}$ was used for experimental calculations. These characteristics are compared to those published in Jackson, 2004.

\begin{tabular}{|l|c|c|c|c|}
\hline \multicolumn{5}{|c|}{ Characteristics of Internal Waves Observed During NEST II } \\
\hline & Mooring A (80m) & Mooring B (102m) & Mooring C (152m) & Jackson, 2004 \\
\hline Amplitude (m) & $+/-5-25$ & $+/-5-25$ & $+/-5-25$ & $+/-5-25$ \\
\hline Long Wave Speed (m/s) & 0.7 & 0.7 & 0.7 & $0.5-1.0$ \\
\hline Oscillation Wavelength (km) & $1.2-1.6$ & $1.0-1.4$ & $0.5-0.9$ & $0.6-1.5$ \\
\hline Wave Period (min) & $28-38$ & $25-33$ & $11-20$ & $8-25$ \\
\hline Packet Length (km) & $10-22$ & $7-14$ & $3-10$ & $1-10$ \\
\hline Packet Separation (km) & 17 & 18 & 10 & $15-40$ \\
\hline
\end{tabular}

\subsubsection{NEST II Summary}

The NEST II environment is characterized by a five layer water column. There was a warm, fresh surface layer, a highly variable thermocline, a thin Cold Pool, a secondary thermocline, and a thick, warm, saline bottom layer. Influenced by the unusually large, northern Gulf Stream meander, the Cold Pool remains almost entirely over the shelf with exception of a very thin layer which reaches out beyond the region of interest. The foot of the shelfbreak front moves from the $80 \mathrm{~m}$ isobath continually onshore past the $60 \mathrm{~m}$ isobath. The foot is located greater than $25 \mathrm{~km}$ from the climatological foot of the front along the $100 \mathrm{~m}$ isobath. The shoreward extent of the foot of the front is quite anomalous compared to the many experiments conducted in this area and is likely the result of the meander. Warm Gulf Stream meanders, while common, do not usually occur so far north. Thus, this particular meander is pushing warm water much further on shelf than anticipated. Unlike NEST I where cold water was entrained in the slope eddy and pulled offshore, the warm meander pushed shoreward near the NEST 
area allowing only a very thin Cold Pool to flow seaward. The anti-cyclonic motion of the meander and cyclonic rotation of a nearby eddy pulled cold water off the shelf in the largest entrainment plume seen in this area. The extremely low variability of the Scanfish profiles below $80 \mathrm{~m}$ suggests that the sustained, meander-induced shoreward flow of warm water allows the slope water to dominate the lower water column. N21, N23, and N25 showed the greatest variability within the thermocline. Internal wave activity was the likely source of increased variability during N21 and N25. However, there was little internal wave activity during N23. Therefore, the shelfbreak eddies were the likely source of variability during the middle of the experiment. The NEST II environment provides a unique level of complexity for acoustic propagation. While the internal waves, as already discussed, are difficult to predict, the discontinuity of the sound channel between the Cold Pool and the shelfbreak eddies create a particularly challenging environment.

\subsection{Mesoscale Analysis of the New England Shelf}

Our environmental analysis thus far has consisted of the insitu experimental data which provides insight into the fine structure and small scale changes within the local environment. However, it is often the mesoscale features which drive the smaller scale, indirectly affecting the acoustic environment. To evaluate the mesoscale features of the MAB, we will look at satellite sea surface temperature (SST) images available from Rutgers University Coastal Ocean Observation Lab (RU COOL) online archives (Rutgers, 2009). These images provide a snapshot of the complete MAB and allow for 
descriptive analysis of the Gulf Stream current and associated eddies. The eddy field shows two scales: a large scale in the deep water between the Gulf Stream and the slope, and a finer scale of features along the shelfbreak and shelf. As the Gulf Stream spawned mesoscale eddies push toward the slope, they begin to interact with the bathymetry. The larger mesoscale features drive the smaller scale features along the slope and shelf and affect the mean state of the smaller shallow water areas. Therefore, understanding the mesoscale is vital to understanding the smaller features which directly affect the shallow water acoustics in an area such as the region of interest.

During NEST I, the mesoscale field consisted of several Gulf Stream generated eddies of varying size (Figure 51). The largest structure was off slope in the deeper water between the Gulf Stream and the shelfbreak. The Gulf Stream current reached as far north as $38^{\circ} \mathrm{N}$ with one strong, warm filament near $72^{\circ} \mathrm{W}$. A large cold core ring, centered at $38^{\circ} 30^{\prime} \mathrm{N}, 72^{\circ} \mathrm{W}$, had a horizontal scale of approximately $130 \mathrm{~km}$. The outer band of warm water surrounding the cold core was approximately $10 \mathrm{~km}$ wide. Along the shelfbreak and shelf, there was yet another set of finer scale features, eddies ranging from $10-60 \mathrm{~km}$ in diameter shed from larger offshore eddies. Cross shelf temperature changes were seen on the scale of $10-20 \mathrm{~km}$. For example, a small eddy formed at the shelfbreak in the canyon of the Hudson River basin. On May 26, 2007, the smaller warm core eddy is pushing further toward the shelfbreak (Figure 52). By comparison the Scanfish slices at the NEST site show that the surface waters are warming, and the advancing eddy is pushing the Cold Pool waters shoreward (Figure 26). Warm filaments from the main body of the Gulf Stream have separated and are pushing shoreward along the shelf. By 
May 29, 2007, the warmer eddy has moved further shoreward over the Cold Pool mixing with already warmer surface waters, but allowing the Cold Pool to move further offshore underneath the surface layer to the offshore edge of the section (Figure 31). By May 30, 2007, the surface waters were warmer and more homogeneous with less mesoscale structure offshore (Figure 53). The eddies mixed with the surrounding waters, at least on the surface, and the warm meander pushed even further north (Figure 54). Cold core rings often sink beneath the surface, so while SST images suggest that they have mixed with the surrounding waters, they may, in fact, still have been present at depth, as suggested by experimental data.

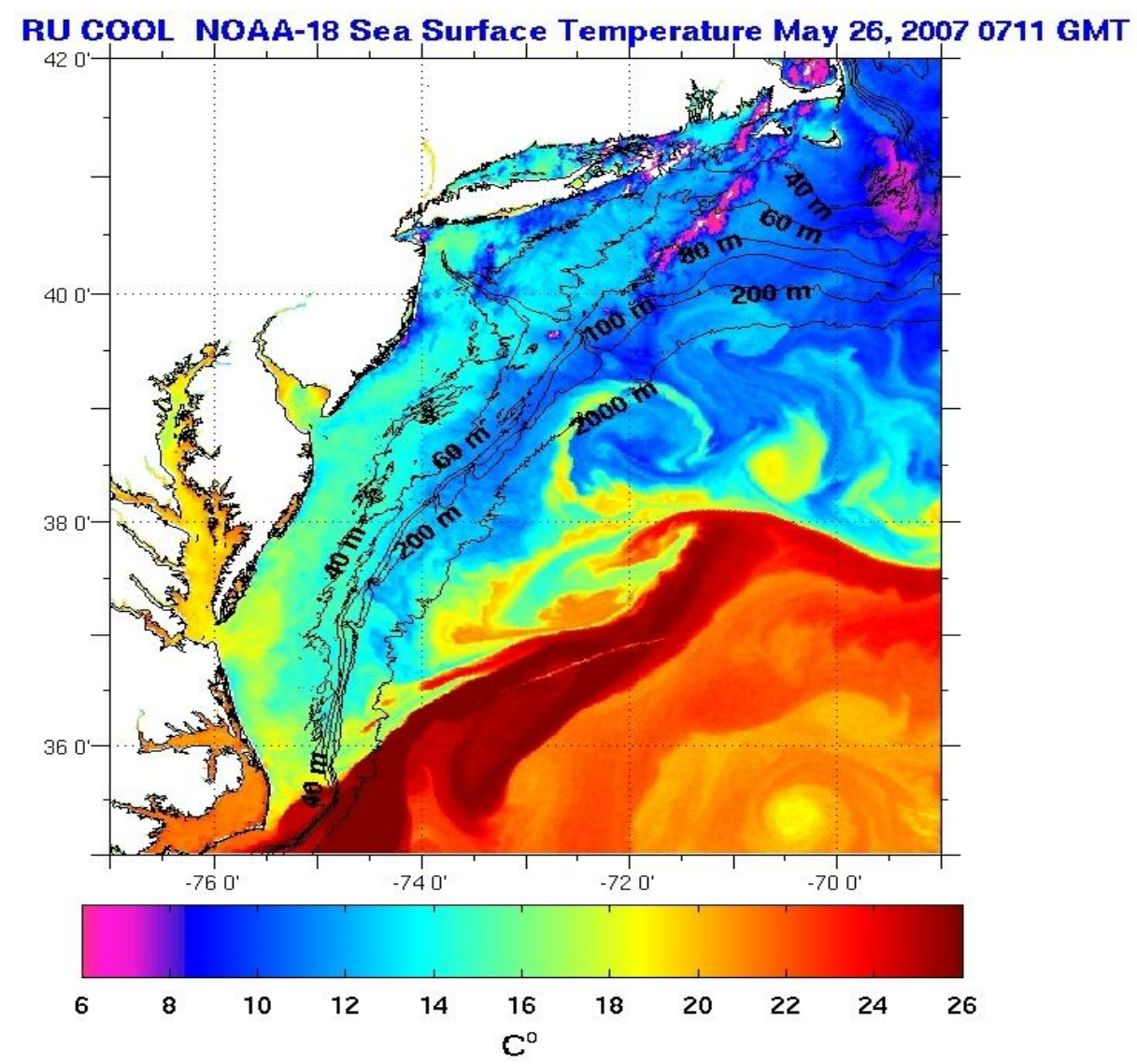

Figure 51. Satellite sea surface temperature composite for the Middle Atlantic Bight. Image from Rutgers University Coastal Ocean Observation Lab (http://marine.rutgers.edu/mrs/sat_data/?nothumbs=0). 


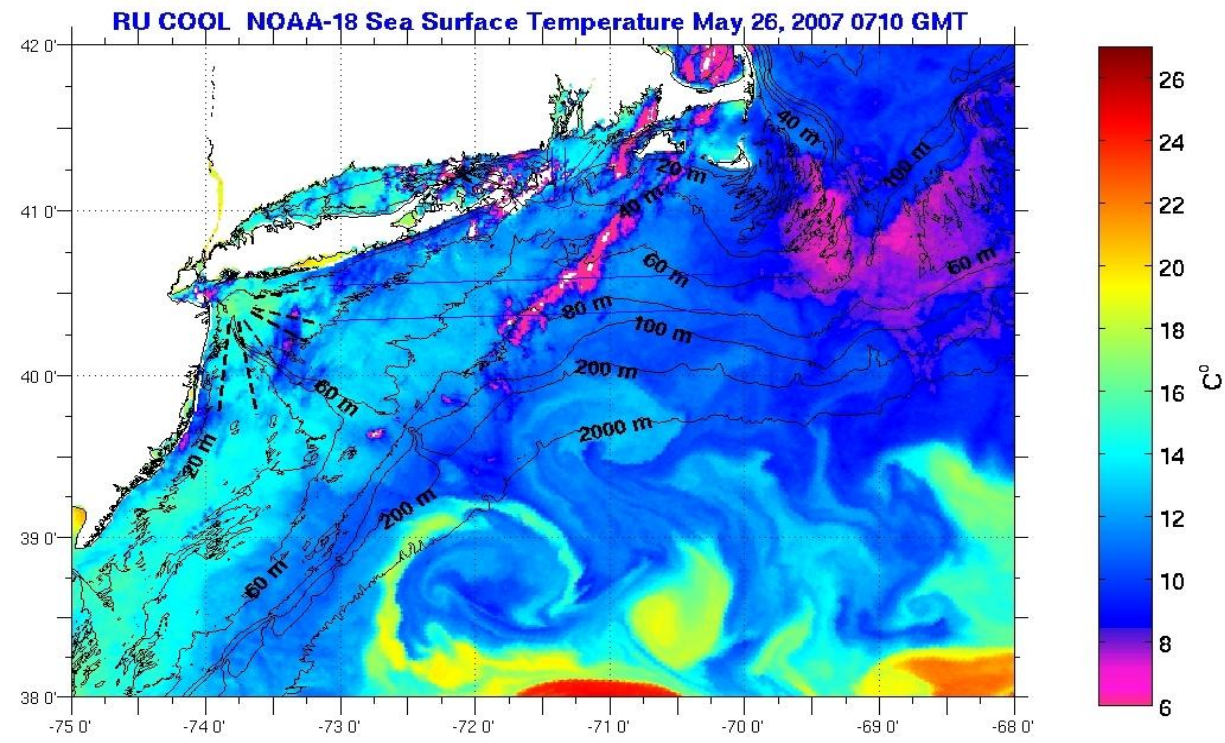

Figure 52. Satellite sea surface temperature composite for the Northern Middle Atlantic Bight. Image from Rutgers University Coastal Ocean Observation Lab (http://marine.rutgers.edu/mrs/sat_data/?nothumbs=0).

RU COOL NOAA-12 Sea Surface Temperature May 30, 20072141 GMT

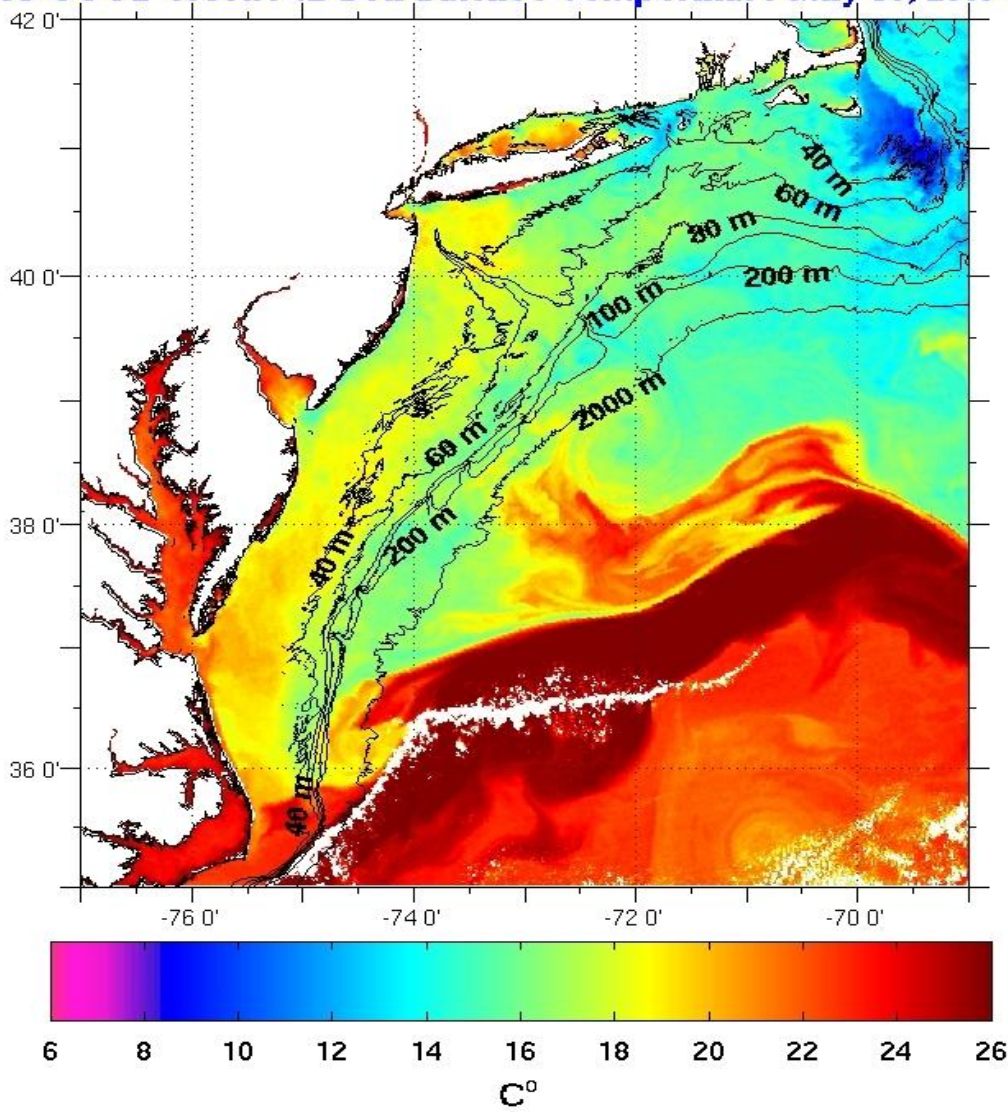

Figure 53. Satellite sea surface temperature composite for the Middle Atlantic Bight. Image from Rutgers University Coastal Ocean Observation Lab (http://marine.rutgers.edu/mrs/sat_data/?nothumbs=0). 


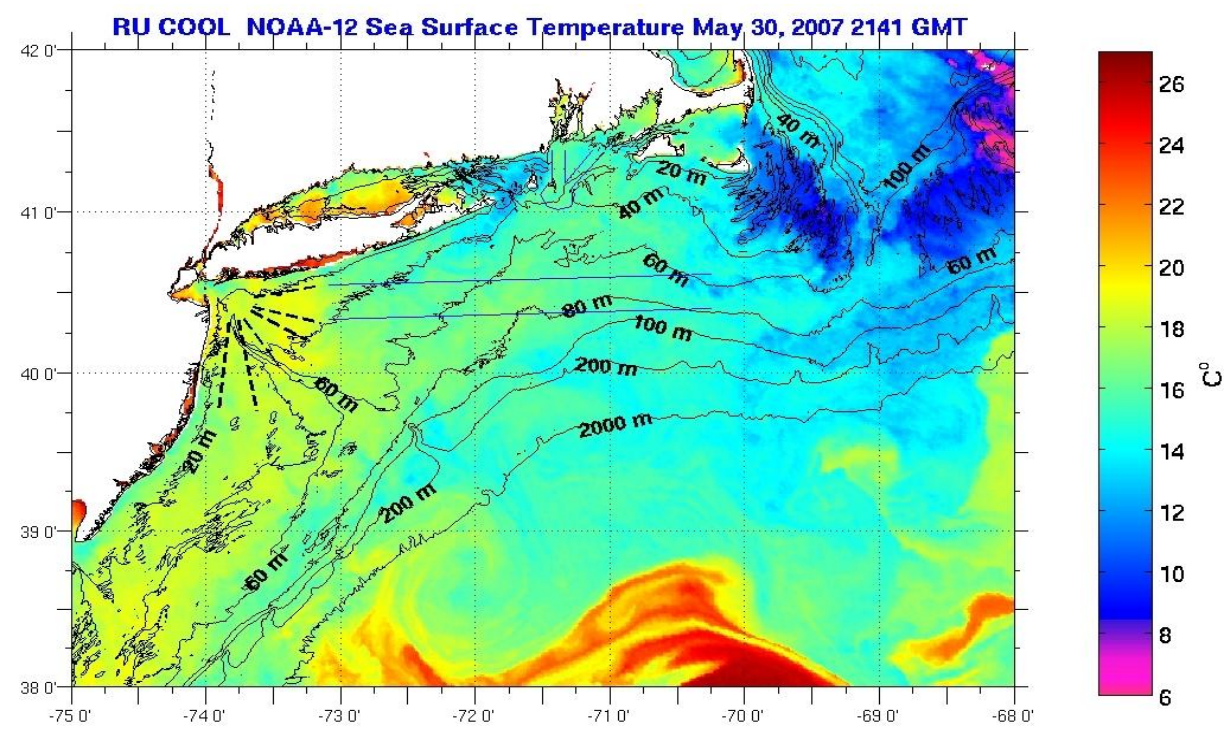

Figure 54. Satellite sea surface temperature composite for the Northern Middle Atlantic Bight. Image from Rutgers University Coastal Ocean Observation Lab (http://marine.rutgers.edu/mrs/sat_data/?nothumbs=0).

The NEST II SST images show less overall mesoscale structure than during NEST I. However, there are three very large features which drive the environment of the region of interest. The offshore area to the south of the region of interest was dominated by a large warm meander from the main body of the Gulf Stream which reached as far north as $39^{\circ} \mathrm{N}$, while the main body of the current remained further south (Figure 55). The diameter of the meander was approximately $100 \mathrm{~km}$. East of the meander there was a cyclonic eddy (Figure 37). The counter-rotation between these two features led to entrainment of cold shelf water offshore in a plume approximately $200 \mathrm{~km}$ wide. Although there were not a lot of mesoscale eddies offshore, there was finer structure along the shelfbreak with scales of 50-60km (Figure 56). Warm filaments splitting off from the meander and reaching shoreward had a width scale of approximately $10 \mathrm{~km}$. The cross shelf temperature field is almost homogeneous along the shelfbreak. 


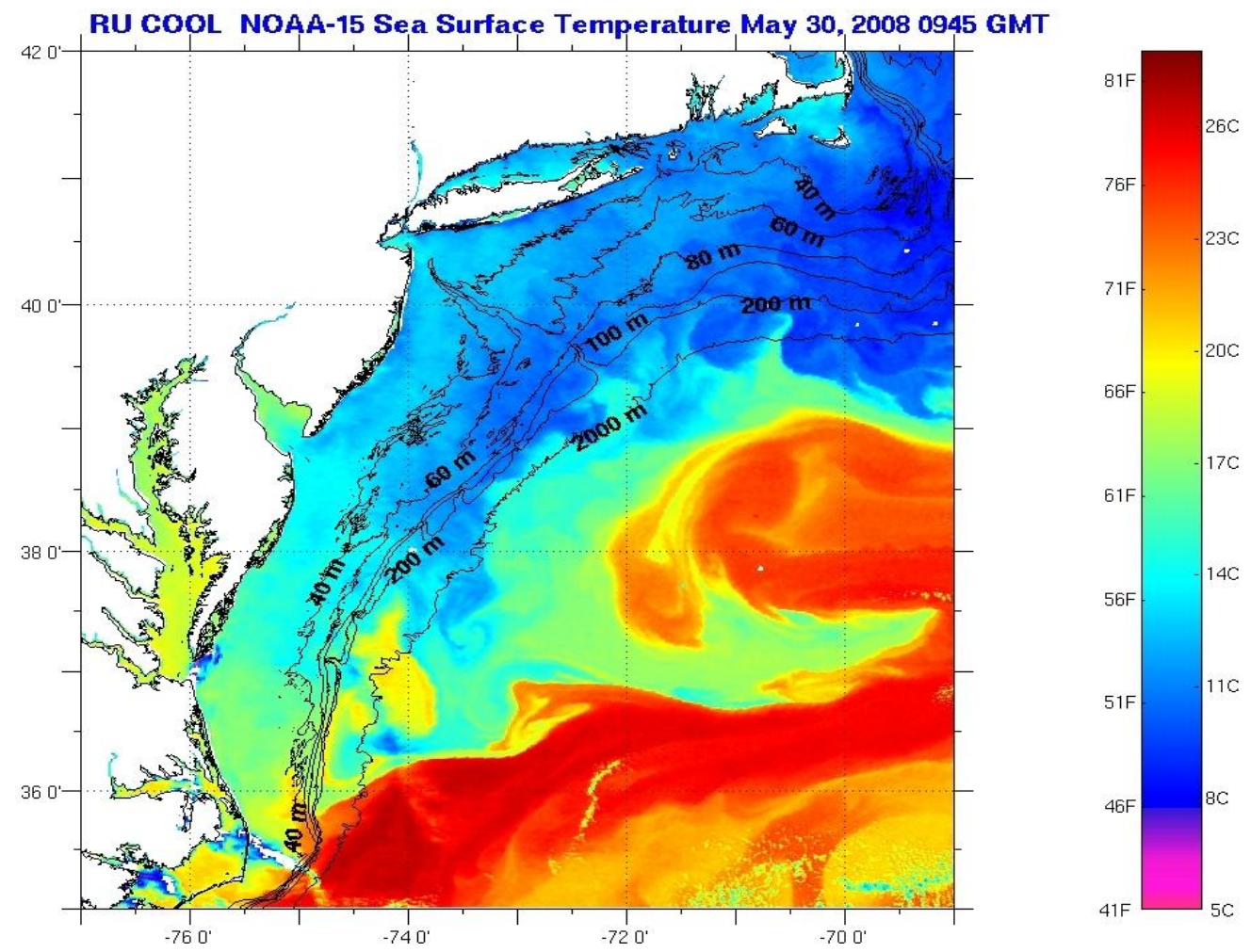

Figure 55. Satellite sea surface temperature composite for the Middle Atlantic Bight. Image from Rutgers University Coastal Ocean Observation Lab (http://marine.rutgers.edu/mrs/sat_data/?nothumbs=0).

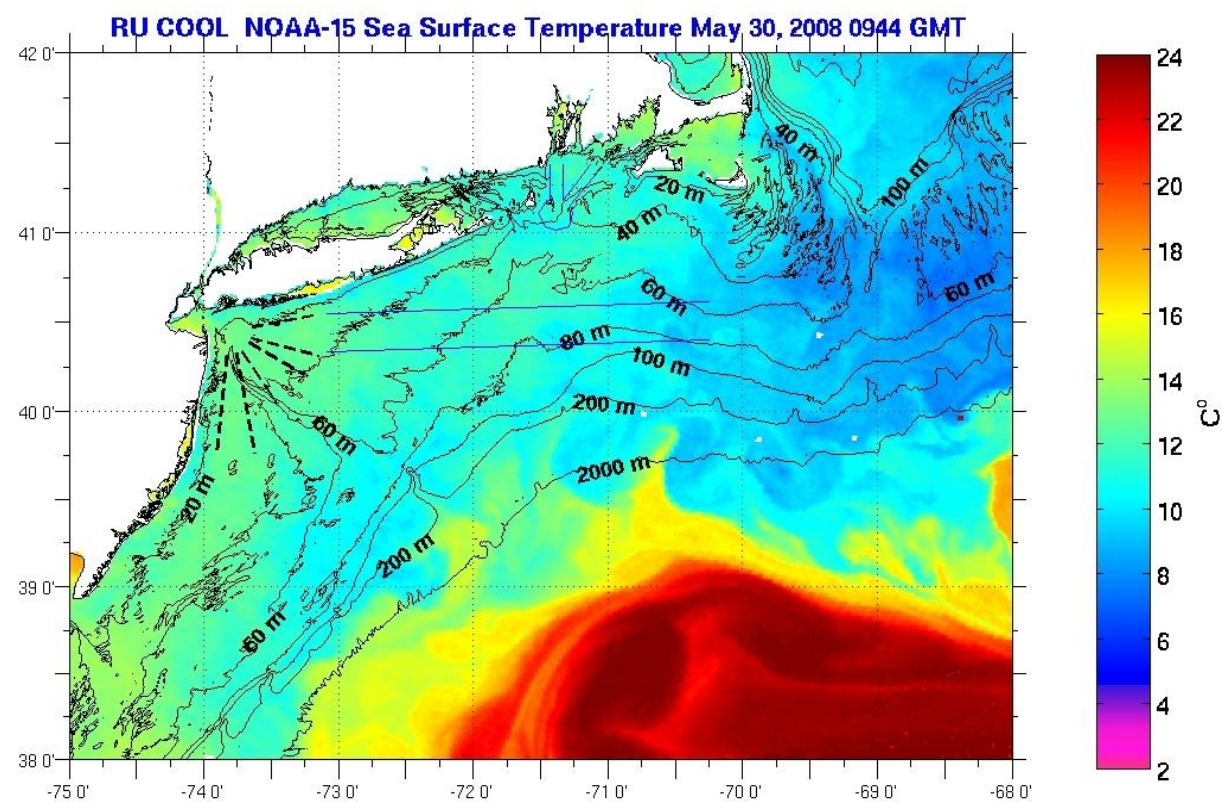

Figure 56. Satellite sea surface temperature composite for the Northern Middle Atlantic Bight. Image from Rutgers University Coastal Ocean Observation Lab (http://marine.rutgers.edu/mrs/sat_data/?nothumbs=0). 
Our conjecture that the large scale features drive the environment of the smaller shallow water areas appears to be valid. During NEST I, the slope eddy just off the shelfbreak entrained cold water, pulling the Cold Pool off the shelf. Interaction between the Cold Pool and the eddy created warm layer boundaries on either side of the cold middle layer. During NEST II, the mean state of the region of interest was warmer than either NEST I or climatology. The large warm Gulf Stream meander was introducing much warmer water into the area just to the south of the region of interest and entraining cold water from the shelf farther east. Instead of a clearly defined, layered water column with a thick Cold Pool, the entire region of interest appeared to be within the transition zone of the shelfbreak front. This was a result of the shelfbreak eddies which separated from the main body of shelf water. In each experiment, mesoscale features of the Gulf Stream current directly and indirectly impacted the finer scale of the NEST area.

Although we have highlighted the necessity of insitu observations, it is important to note that satellite images, particularly SST, of an area just prior to an experiment can provide invaluable clues to anticipate and possibly predict the finer scale oceanography.

\subsection{Summary of the NEST Environment}

NEST I and II environments each consisted of five layer water columns, with remarkably different structures. Although the experiment dates differed by only a few days, the environments were completely dissimilar. In NEST I, we see the direct interaction of a small slope eddy with the shelfbreak front. In NEST II, the mesoscale meander has a remote but powerful impact on the region of interest. 
The most notable difference is the vertical extent of the Cold Pool. During both experiments, the Cold Pool extended to the offshore edge of the region of interest. However, it was the vertical extent which was remarkably different. During NEST I, entrainment of shelf water resulted in a deep Cold Pool from approximately 40-100m. The extensive Cold Pool contributed to the lower mean temperature and salinity during NEST I ( $7.6^{\circ} \mathrm{C}$ and 33.3 PSU compared to $11.4^{\circ} \mathrm{C}$ and $\left.34.2 \mathrm{PSU}\right)$, and provided a deep, continuous sound channel creating excellent propagation conditions, particularly at low frequencies. Whereas during NEST II, the shoreward flow of warm slope water resulted in only thin Cold Pool. Additionally, shelfbreak eddies created a discontinuous sound channel which was difficult to exploit.

During NEST I, variability was greatest along the main and bottom thermoclines where the Cold Pool met with warm surface and bottom waters. Since the foot of the front remained stationary along the $120 \mathrm{~m}$ isobath during NEST I, the bimodal variability is most likely caused by a combination of Cold Pool movement due to frontal waves and internal waves. Alternatively, during NEST II, the sub-thermocline Cold Pool never advanced off shelf and warm slope water extended shoreward over the shelfbreak, moving the foot of the front to an extreme onshore position. The maximum variability was limited to the surface thermocline because the Gulf Stream meander helped to create a sustained warm bottom layer. The mean temperature was warmer, with less daily variation, suggesting that both the Gulf Stream meander dominated, decreasing variability in the movement of the Cold Pool, and that there were no frontal waves propagating during the experiment. 
Although the presence of frontal waves cannot be resolved for either experiment, it is interesting to note that the apparent movement of the Cold Pool in the temperature field is limited to times when the foot of the front was near the shelfbreak. During NEST I, the foot is near the shelfbreak and the Cold Pool appears to move in and out over several days. However, when the foot of the front is much farther inshore during NEST II, there does not appear to be movement of the Cold Pool. Perhaps this is because topographic shear waves are highly unstable over gently sloping bathymetry and become more stable as they approach the abrupt bathymetry of the shelfbreak (Gawarkiewicz, 1991).

One similar characteristic during both experiments was the general salinity structure which decreased consistently from the surface to the bottom. The halocline during NEST II was much shallower (30-40m) than during NEST I (80-100m) which is consistent with the thinner, shallower Cold Pool.

A sound channel created by the Cold Pool was present during both experiments. However, during NEST II, it was thinner, shallower and discontinuous. Both the narrow, irregular sound channel, and overall higher minimum temperature, salinity, and sound speed, led to slightly degraded propagation conditions compared with NEST I.

The climatological shelfbreak front is a vertical boundary, intersecting the seafloor at the $100 \mathrm{~m}$ isobath and the surface in less than $10 \mathrm{~km}$ horizontal distance. In neither of the NEST experiments did the front follow the climatological pattern. During both experiments, the front was nearly horizontal. During NEST I, the foot of the front 
was located at approximately the $120 \mathrm{~m}$ isobath and remained there throughout the duration. The surface intersection was much farther south than the limit of the region of interest. During NEST II, the foot of the front was shallower than climatology and varied from $80 \mathrm{~m}$ to less than $60 \mathrm{~m}$, past the northern limit of the region of interest, and the surface intersection was past the southern limit throughout the entire experiment.

The NEST I mean temperature and salinity values were much lower than those of the climatology presented in Section 2.1 due to the influence of the large Cold Pool. While the mean temperature, salinity, and sound speed during NEST II were more similar to the climatology. However, the NEST II water column in no way resembled the fairly simple structure of the climatology.

The environment of the NEST experiment area was remarkably different during NEST I and II. The general structure of the water column at the shelfbreak appears to be driven by the location and thickness of the Cold Pool, which is in turn driven by the mesoscale field between the shelfbreak and the Gulf Stream. When the Cold Pool is able to flow out to the shelfbreak, bounded on the top and bottom by thin warm layers, the area is dominated by a thick, stable sound channel. However, when other features, such as Gulf Stream meanders, keep the sub-thermocline Cold Pool over the shelf, the water column is increasingly complex, and the acoustic conditions are more variable. In both cases, internal waves along the shelfbreak and shelf region, add to the variability of the water column and complicate the acoustic problem even further. 
Both the daily and annual differences within the NEST area demonstrated the true value of obtaining numerous, high-quality observations. Although detailed climatology, when available, aides significantly in the pre-planning stages of acoustic experiments, it does not replace the need for insitu data in order to fully exploit the ocean environment. Without the detailed oceanographic data, the acoustic predictions presented in Chapter 3 would be highly inaccurate. 


\section{Chapter 3: Acoustics}

\subsection{Basic Acoustics of the Middle Atlantic Bight}

Based on climatology, the Nantucket Shoals continental shelf region provides a moderate sound channel for acoustic propagation, with a sound speed minimum at approximately $40 \mathrm{~m}$ and average vertical gradients of $\pm 0.2 \mathrm{~m} / \mathrm{s}$ per meter (Figure 57 ). The upward refracting profiles continue from the shelf toward the shelfbreak, so that the effective sound channel continues slightly offshore, through the front. Seaward of the front, the fairly homogeneous, warm slope water diminishes the duct, causing sound to spread throughout the deeper water column and increasing transmission loss (Figure 58).

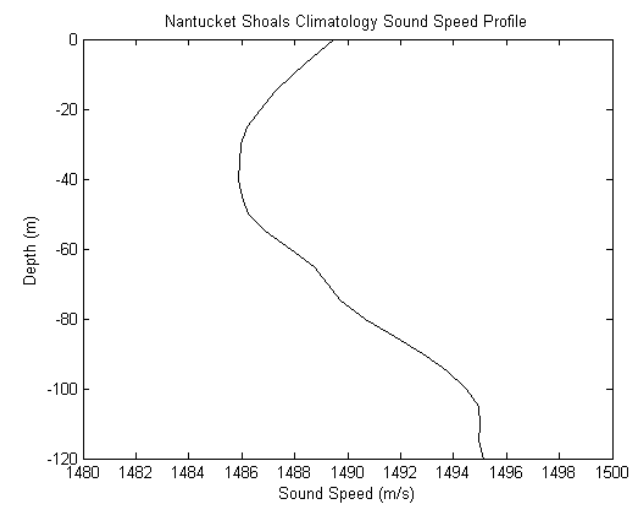

Figure 57. Nantucket Shoals Spring sound speed profile from climatology (Linder, et al., 2006). 


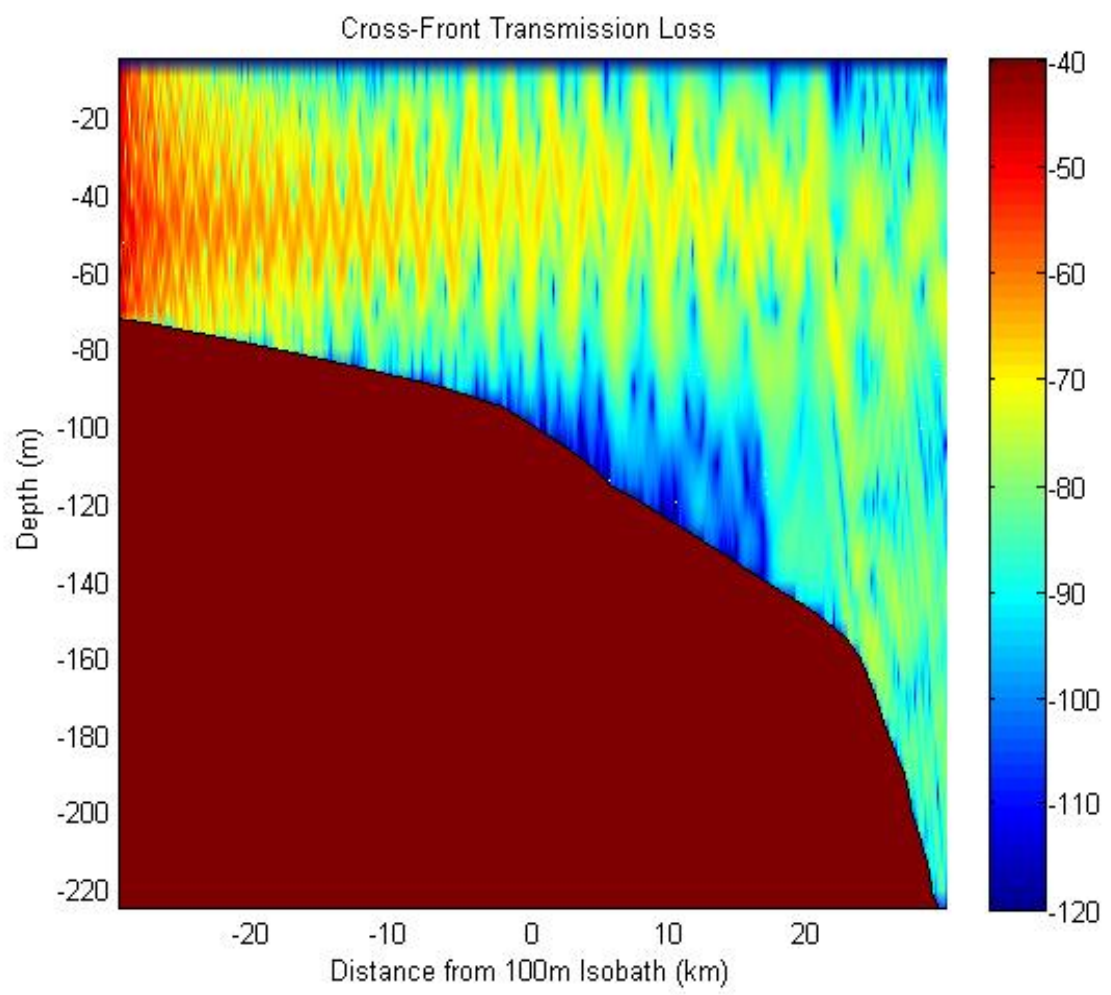

(dB)

Figure 58. Transmission loss $(\mathrm{dB})$ field showing the weakening of sound channel trapping effects and increased transmission loss seaward of the shelfbreak front.

Experimental observations from NEST I and II provided detailed realizations of the acoustic environment of the region of interest. During NEST I, the Cold Pool created a stable and exploitable sound channel with a sound speed minimum at approximately 40m. Internal waves led to variability along the top and bottom boundaries of the Cold Pool, even though the background structure of the water column was fairly stable. The relatively homogeneous water masses in the surface, middle, and bottom layers did not provide the temperature/sound speed contrast necessary to allow the internal waves to be acoustically evident within the layers. However, due to the temperature/sound speed differences along the boundaries, the top and bottom interfaces of this middle layer created the acoustically important temperature/sound speed signature of internal waves. 
As previously discussed, somewhat poorer acoustic propagation conditions persisted throughout NEST II. Although fresh shelf water extended to the offshore edge of the region of interest, the Cold Pool created only a very thin (approximately $20 \mathrm{~m}$ ) sound channel with increased horizontal variability due to the presence of shelfbreak eddies. The influx of warm slope water creating a deep bottom layer resulted in a higher mean sound speed. As expected, the individual and mean profiles from each of the NEST experiments detailed a much more complex water column structure than suggested by the mean spring climatology profiles. However, the variability of the experimental data fell within the variance of the climatology.

\subsection{Simple Sound Speed Profile Models}

From our environmental discussion of the region of interest, we expect the characteristics of the five layer water column to have a significant effect on the propagation conditions, specifically the transmission loss. In order to quantify this effect, we must create basic models of sound speed profiles to isolate and analyze the critical parameters. Two methods were employed to determine the sound speed profile characteristics. First, a qualitative method using general profile patterns was used. This was then compared to our second method, an empirical orthogonal function (EOF) analysis of each water mass.

The NEST Scanfish sound speed profiles were first qualitatively evaluated for key patterns. Each profile segment was simplified into a constant gradient creating a "stick profile", as shown in Figure 59, and then all of the stick profiles were analyzed to determine the general structure of the water masses and identify which features were 
most common. Although crude, the stick profile analysis led to a robust set of five features, surface layer depth, surface gradient, middle layer depth, bottom gradient, and bottom layer depth, which correspond to the dynamic features discussed in Chapter 2.

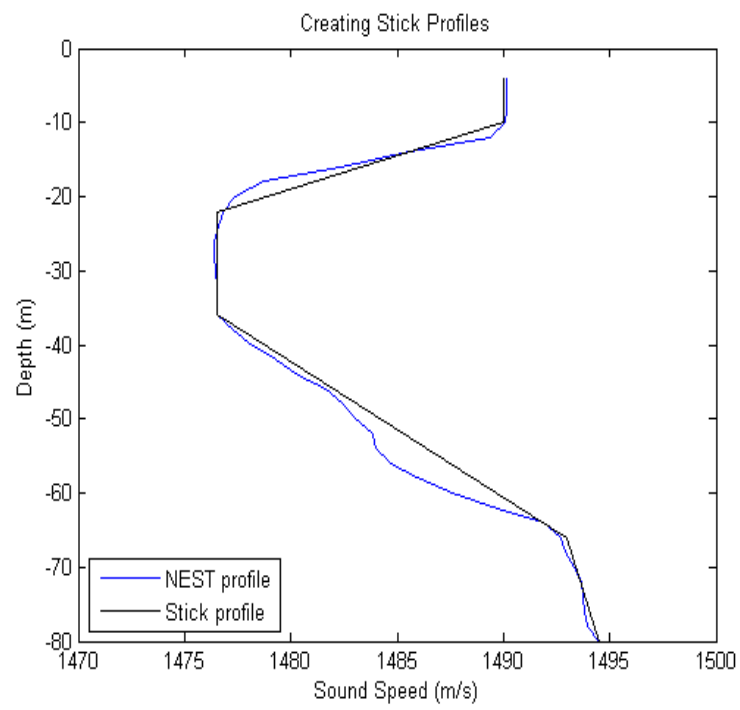

Figure 59. Simplified stick profiles were created for each of the NEST profiles to determine general structure and dominant features.

Next, to validate and compare our stick profile method, EOF modes were analyzed for key features. The first three EOF modes, which represent about $90 \%$ of the energy, show that the five layers identified from the stick profiles indeed represent the regions of maximum variability within the profiles. The value of the EOF mode gives the percent of sound speed deviation from the mean sound speed profile. Figure 60 shows the first three EOF modes from the shelf water profiles which dominated the region of interest during NEST I. Mode one clearly identifies the surface gradient as the major source of variability. Modes two and three show that there is increased variability along the surface and bottom gradients, the boundaries of the surface mixed layer and bottom layer, with little variability in the middle of the water column. During NEST II, the cold 
pool was much thinner and did not create a well defined middle layer. As a result, the maximum variability was within the thermocline, as confirmed by the first three vertical EOF modes (Figure 61). The prominent features from the vertical EOF modes verify that the features identified by the stick profile method are indeed important in our development of simple vertical sound speed profile models.

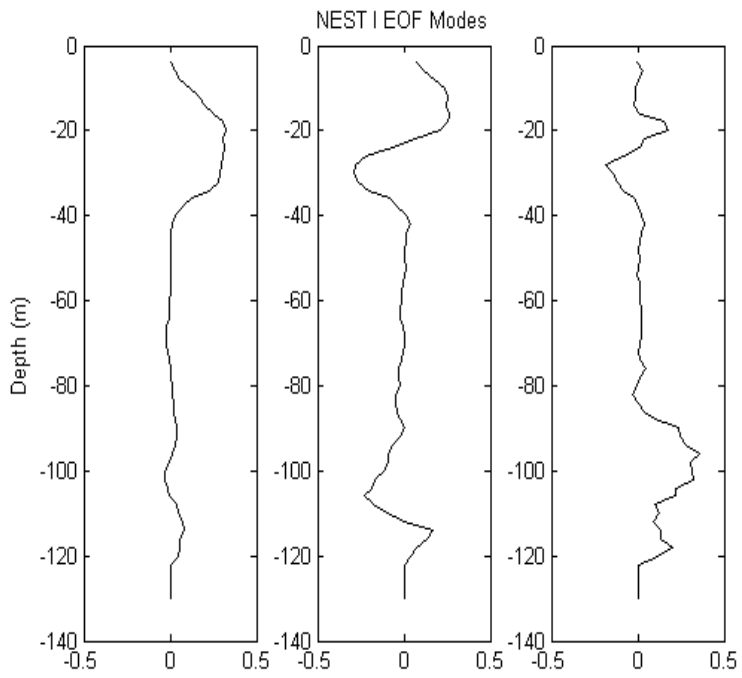

Figure 60. EOF modes 1-3 for shelf water profiles which dominated during NEST I.

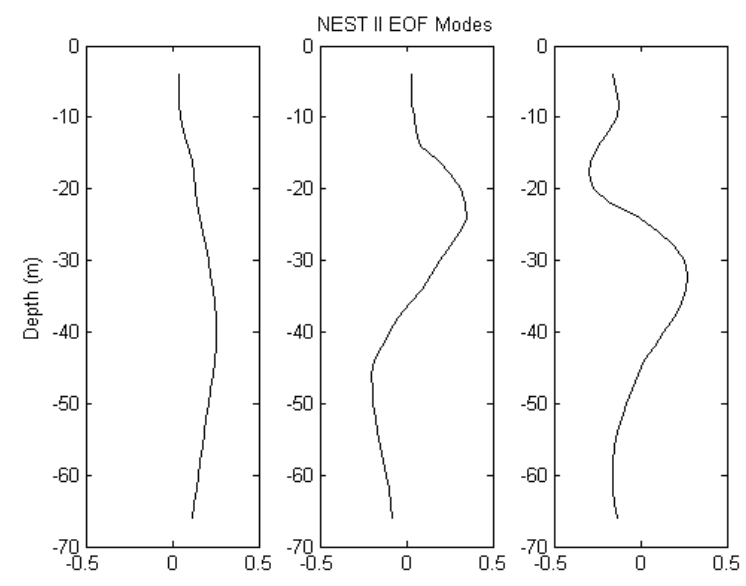

Figure 61. EOF modes 1-3 for NEST II. 
Based on the above, a set of simple sound speed models was developed which encompasses, individually, each of the variable features (Figure 62). Each model focuses on one isolated feature and can be utilized with sound speed or temperature inputs. As expected, the principal features include the surface layer depth, surface gradient, middle layer thickness, bottom gradient, and bottom layer thickness.

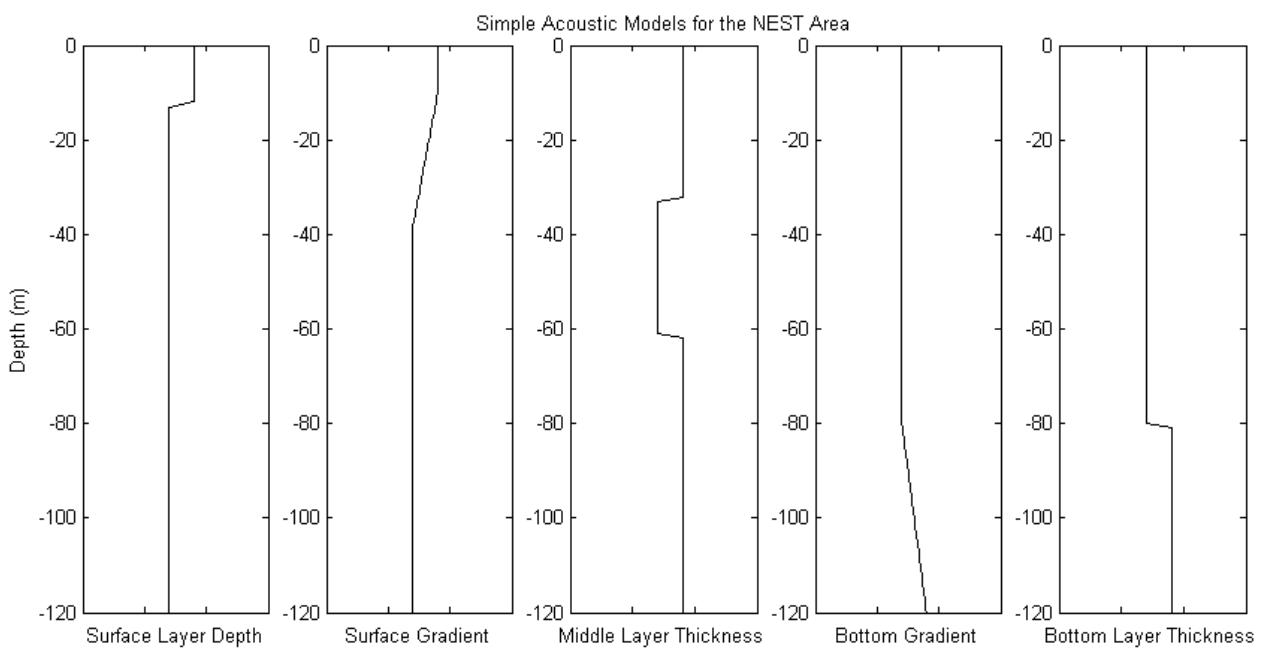

Figure 62. Simple models created from NEST vertical water column profiles, depicting isolated environmental features: a) surface layer depth, b) surface gradient, c) middle layer thickness, d) bottom gradient, e) bottom layer thickness.

The first model depicts the depth of the surface layer (Figure 62a). Insolation combined with winds can generate a warm well mixed layer at the surface of the ocean. The depth of this layer can affect the amount of surface reflection. The strength of this layer, given by the maximum change in sound speed, affects the refraction along the lower boundary of the layer. Critical parameters for the surface layer model are thus the layer depth and the maximum change in sound speed. 
The second model focuses on the near surface gradient (Figure 62b). Although a misnomer when referring to sound speed profiles, the surface gradient is commonly referred to as the thermocline or main thermocline, because temperature is often the governing property in the upper water column. Rarely, if ever, is the bottom of the surface layer a step-like jump in sound speed or temperature. Therefore, the strength of the surface gradient defines the steepness of this boundary. Weak gradients can lead to "leaky" ducts where sound can propagate out of the channel. The gradient and maximum change in sound speed are thus the critical parameters for the surface gradient model.

Middle layer thickness is represented by the third model (Figure 62c). Although not present in all regions, a middle layer of cool, less saline water is present throughout the MAB. The cool middle layer creates a sound channel, which if sustained horizontally, produces excellent conditions for extended propagation. The thickness of this layer determines which frequencies will duct within the layer. The critical parameters for this model are the thickness of the middle layer, the maximum change in sound speed, and the sound speed beneath the middle layer. The latter two parameters define the strength of the middle layer boundaries.

A distinct bottom layer is often present in the water column which can have a variety of effects on sound propagation. A warm bottom layer creates an upward refracting sound speed profile generally improving sound transmission by reducing bottom interaction. A cool bottom layer results in a downward refracting profile and can greatly increase transmission loss when sound is absorbed into the seabed. The final two 
models illustrate important characteristics of this layer, the bottom gradient and the bottom layer thickness.

The fourth model creates a bottom gradient (Figure 62d). The sign of the bottom gradient determines whether the sound speed profile is upward or downward refracting. The strength of the bottom gradient determines the degree of refraction along the boundary between the middle and bottom layers. When the strength of the gradient is weak, the effect of the bottom layer on transmission loss may be minimal.

The fifth model adjusts the thickness of the bottom layer (Figure 62e). As previously discussed, the strength of the bottom layer is dependent upon the maximum change in sound speed. When the change in sound speed is large, the bottom layer will create a boundary between the middle layer and seafloor. When the change in sound speed is small, the effect of the bottom layer may be negligible. Similarly, if the thickness of the bottom layer is much less than one wavelength, the layer is acoustically insignificant. Therefore, the effect of the bottom layer is dependent upon strength, thickness, and acoustic frequency, with the former two being critical parameters of the model.

Each of these vertical models isolates a particular characteristic of the five layer water column of the NEST area. We recognize that these characteristics never vary independently in the real ocean; these models merely provide a tool to identify individual effects on transmission loss before examining more complex variability. 


\subsection{Quantifying the Effects Sound Speed Perturbations}

Deviations from a constant vertical sound speed profile, as created by these simple models, can simulate variability within the water column and be used in perturbation analysis. We will look at that type of analysis in this section. In shallow water acoustics, the major source of transmission loss between a source and a receiver is the absorption of sound energy into the seafloor. Generally, absorption by the seafloor is more than an order of magnitude greater than absorption by the water column. A ray picture of absorption in shallow water is determined by the number of bottom interactions between source and receiver, which is dependent upon the angle of incidence with the seafloor, and the loss to the bottom with each bounce. If we compare the loss per bounce ( $\mathrm{dB} /$ bounce) between a mean background state and different perturbation states, we can thus determine which perturbations in our layered model have the greatest effect on transmission loss.

Perhaps the simplest way to understand how water column variability affects bottom interactions is to utilize Snell's law, which relates the refraction of sound rays to the speed of sound. Rays propagating from a medium with sound speed, $\mathrm{c}_{1}$, to a medium with a different sound speed, $c_{2}$, will bend at the interface according to Equation 3.1. The difference in sound speed between the two media affects the degree of refraction into the second medium, i.e.

$$
\frac{\cos \theta_{1}}{c_{1}}=\frac{\cos \theta_{2}}{c_{2}}
$$


As a propagating sound ray travels through a variable (layered) water column, the ray is refracted at each layer interface. The study of ray theory has resulted in detailed ray tracing programs which help visualize the paths of rays through a layered waveguide. The angle of incidence (complementary to the grazing angle) on the seafloor determines the extent to which the sound is reflected back into the water column and transmitted and absorbed into the seafloor. The critical angle, $\Theta_{c}$, defines an important threshold (Eq. 3.2). At grazing angles below the critical angle there is (almost) complete reflection into the water column. As the grazing angle increases above the critical angle, there is partial transmission and partial reflection of the incident ray into the seabed. This results in a drastically increased loss of sound energy to the bottom. When the change in sound speed $(\Delta \mathrm{c})$ between the water column and the seafloor is small, there is little refraction of the sound rays and the critical angle is small. As $\Delta \mathrm{c}$ increases, the critical angle also increases.

$$
\theta_{c}=\cos ^{-1}\left(\frac{c_{1}}{c_{2}}\right)
$$

The reflection and transmission of sound energy at the water/seafloor interface is not simply dependent on the angle of incidence. The porosity and composition of the sediments affect the amount of absorption, or attenuation. The seafloor of the NEST experiment area is a lossy bottom consisting of a top layer of fine sediments overlaying a variety of silty clay, silty sand, clayey sand, and sandy clay (Potty, et al., 2000).

To find a measure of loss/bounce (LB), let us look at a sound ray propagating through an isovelocity water column over a lossy halfspace at an arbitrary incident angle. 
In order to account for attenuation in the sediment it is necessary to define the sound speed as complex (Eq. 3.3).

$$
c_{2}=c_{2}^{\prime}+i c_{2}^{\prime \prime}
$$

Instead of using the pressure field of a travelling plane wave to determine $c_{2}^{\prime}$ and $c_{2}^{\prime \prime}$ as suggested in Clay \& Medwin (1977), this model uses sediment porosity to find the expected attenuation for the region of interest. Attenuation, $\alpha(\mathrm{dB} / \mathrm{m})$, is dependent on frequency, $f(\mathrm{kHz})$, and the empirical constants, $b$ and $n$ (Eq. 3.4). The constant $b$ is dependent on the porosity of the sediment and $n$ is most often unity for cases of sand, silt and clay (Urick, 1983).

$$
\alpha=b f^{n}
$$

Based on several studies compiled by Hamilton (1972), the porosity of fine sand ranges from 41.0 to $46.7 \%$. Using the regression equation (Eq. 3.5), we find a corresponding value for $b$ ranging from 0.49 to 0.52 , where $p$ is the porosity.

$$
b=0.2747+0.00527 p
$$

Our definition of the complex sound speed requires attenuation in nepers/unit distance $\left(\alpha_{e}\right)$, which relates to $\alpha$ according to Equation 3.6. Using the compressional sound speed of the sediment and $\alpha_{e}$, we use the following series of equations to find the components of the complex sound speed, $c_{2}^{\prime}$ and $c_{2}^{\prime \prime}$. These will be important when calculating the reflection coefficient and reflection loss along the seafloor boundary. 


$$
\begin{gathered}
\alpha=8.686 \alpha_{e} \\
k_{2}^{\prime}=k_{2}+i \alpha_{e} \\
c_{2}^{\prime}=\frac{\omega}{k_{2}^{\prime}} \\
c_{2}^{\prime \prime}=\frac{c_{2}^{\prime 2} \alpha_{e}}{\omega}
\end{gathered}
$$

As a sound ray propagates through a waveguide undergoing a series of bottom and surface interactions, sound energy is lost with each interaction. If we assume that the sea surface is smooth and thus perfectly reflecting $(|R|=-1)$, then our greatest medium loss occurs due to bottom interaction. We can define the reflection coefficient, $\mathrm{R}$, to include a small loss to the bottom even below the critical grazing angle. For each bounce, sound energy, $\epsilon$, is lost to the bottom, giving us the form

$$
|R|=1-\epsilon
$$

A waveguide with no attenuation in the seabed would have a reflection coefficient similar to the solid line in Figure 63. Accounting for bottom attenuation, we see an imperfect reflection coefficient at grazing angles below critical (dashed line in Figure 63). 


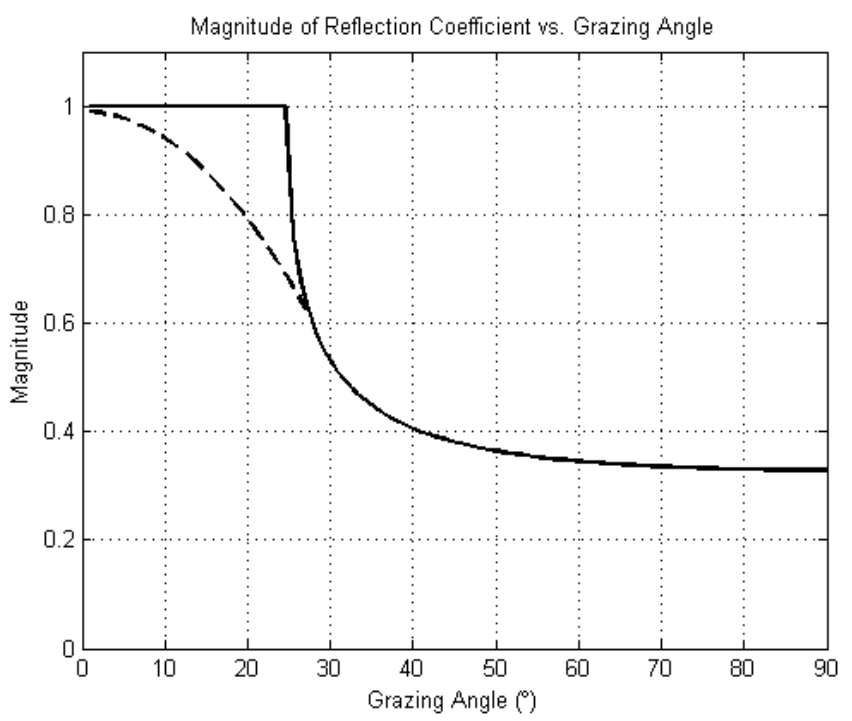

Figure 63. Magnitude of the reflection coefficient for a sample environment with (dashed) and without (solid) bottom attenuation.

In order to estimate the energy lost to the bottom, we calculate the reflection coefficient using a standard derivation, e.g. that from Clay \& Medwin (1977), which incorporates attenuation by using the complex sound speed (Eq. 3.11).

$$
R=\frac{\rho_{2} c_{2}^{\prime} \cos \theta_{0}+i \rho_{2} c_{2}^{\prime \prime} \cos \theta_{0}-\rho_{0} c_{0} \cos \theta_{2}}{\rho_{2} c_{2}^{\prime} \cos \theta_{0}+i \rho_{2} c_{2}^{\prime \prime} \cos \theta_{0}+\rho_{0} c_{0} \cos \theta_{2}}
$$

Now, we can calculate the reflection loss, $\epsilon$ (Eq. 3.10). The change in pressure amplitude with range due to reflection loss is given by Equation 3.12 , where $p_{0}$ is the initial pressure amplitude, $\delta_{m}$ is the attenuation coefficient, and $d$ is the distance between bounces (Clay \& Medwin, 1977).

$$
\begin{gathered}
|p|_{m}=\left|p_{0}\right|_{m} \exp \left(-\delta_{m} r\right) \\
\delta_{m}=\frac{\epsilon}{d}
\end{gathered}
$$




$$
d=2 H \tan \theta_{m}
$$

The distance between bounces is dependent on the height of the water column, $\mathrm{H}$, and the modal angle of incidence, $\theta_{m}$. For any given distance $\mathrm{r}$, the number of bounces, $\mathrm{N}$, is found using $d$ (Eq. 3.15). The loss/bounce (LB) is estimated using Equation 3.16 and transmission loss can be predicted (Eq. 3.17).

$$
\begin{gathered}
N=\frac{r}{d} \\
\frac{20 \log \left(\left[|p|_{m}\right)\right.}{N}=\frac{\text { loss }}{\text { bounce }} \\
T L_{\text {pred }}=-N * L B
\end{gathered}
$$

\subsubsection{Horizontal Wavenumber Perturbation Method}

Sound speed perturbations within the water column affect the angle of incidence with the bottom, which in turn affects the reflection loss and number of bottom bounces within a given range. Therefore, if we can accurately incorporate the sound speed perturbations into the above system of equations, we can compare the LB of each mode or ray. Lynch, Lin, Duda, Newhall \& Gawarkiewicz (2009) derive a method for modal perturbations that is usable in this context. An overview of their method is provided. The background state of the water column to be used in our calculations can be described by the acoustic vertical mode eigenvalues, horizontal mode wavenumbers, and vertical mode functions (Eq. 3.18). To make calculations simple and analytical, we initially 
consider a "rigid bottom" waveguide. The acoustic mode eigenvalues and eigenfunctions for this waveguide are shown in Equation 3.18.

$$
\gamma_{0 m} H=\left(m-\frac{1}{2}\right) \pi, \quad k_{0 m}=\sqrt{k^{2}-\gamma_{0 m}^{2}} \quad, \quad Z_{0 m}(z)=\left[\frac{2}{H}\right]^{\frac{1}{2}} \sin \left(\gamma_{0 m} z\right)
$$

In order to incorporate perturbations from internal waves and other environmental features, we can calculate the perturbation forms of the horizontal wavenumber (Eq. 3.19). The horizontal wavenumber perturbation is given in Equation 3.20, where $\Delta \mathrm{q}$ includes the sound speed perturbation profile, $\Delta \mathrm{c}(\mathrm{z})$ (Eq. 3.21).

$$
\begin{gathered}
k_{1 m}=k_{0 m}+\Delta k_{1 m} \\
\Delta k_{1 m}=\frac{1}{k_{0 m}} \int_{0}^{H} \frac{\Delta q Z_{0 m}^{2}(z) d z}{\rho(z)} \\
\Delta q=-\Delta c(z) \frac{\omega}{c_{0}^{3}(z)}
\end{gathered}
$$

Following the derivation in Lynch et al. (2009), we can use the following equation which allows us to express the horizontal mode wavenumber change $\left(\Delta k_{1 m}\right)$ in terms of mode number, frequency, layer thickness, and sound speed perturbations.

$$
\Delta k_{1 m}=-\frac{1}{k_{0 m}} \frac{\omega^{2}}{c_{0}^{2}} \frac{\Delta c}{c_{0}} \frac{D}{H}\left[1-\operatorname{sinc}\left(\frac{2 \gamma_{0 m} D}{\pi}\right)\right]
$$

With our newly perturbed horizontal wavenumber, $k_{1 m}$, we calculate a new modal angle of incidence. 


$$
\theta_{1 m}=\sin ^{-1} \frac{k_{1 m}}{k}
$$

Then, we recalculate the reflection coefficient, where $\theta_{1 g}$ is the complementary grazing angle to $\theta_{1 m}$ and $\theta_{2 g}$ is the new grazing angle in the bottom water layer.

$$
R=\frac{\rho_{2} c_{2}^{\prime} \cos \theta_{1 g}+i \rho_{2} c_{2}^{\prime \prime} \cos \theta_{1 g}-\rho_{1}\left(c_{0}+\Delta c\right) \cos \theta_{2 g}}{\rho_{2} c_{2}^{\prime} \cos \theta_{1 g}+i \rho_{2} c_{2}^{\prime \prime} \cos \theta_{1 g}+\rho_{1}\left(c_{0}+\Delta c\right) \cos \theta_{2 g}}
$$

Following equations 3.12 through 3.17 above, we can calculate an updated LB and predicted TL from the perturbed state. This LB model can also incorporate the wavenumber perturbation method to evaluate the effects of many different sound speed perturbations.

\subsubsection{Ray Theory Method}

The horizontal wavenumber perturbation method provides a way to incorporate sound speed perturbations within the water column at a particular depth using the modal decomposition. To provide a comparison, an alternate method (a simple ray theory method) was created which does not require knowledge of the water column modal structure. The change in sound speed in each layer creates a variation in the grazing angle in accordance with Snell's law, and correspondingly alters the angle of incidence on the bottom. Snell's law is then used to calculate the transmission angles through the layered media to the bottom in a basic ray tracing technique and then the perturbed grazing angle is used as the input to the LB model. 


\subsubsection{Method Comparison}

To compare and evaluate the wavenumber perturbation and ray theory methods, we first looked at a variety of sound speed perturbations based on climatology and the statistical variance of the NEST environmental data. These examples are not meant to recreate observed perturbations but simply to test the methods using more realistic conditions. Then, we used ocean sound speed EOF modes to create perturbation profiles for each NEST scan and predict changes in transmission loss.

For the following calculations, $800 \mathrm{~Hz}$ is chosen as the acoustic frequency for its relevance to NEST I and II, and also because of its common use in many shallow water experiments. The acoustic wavelength $(\lambda)$ is $1.9 \mathrm{~m}(\mathrm{c}=1500 \mathrm{~m} / \mathrm{s})$ so water layers less than $\lambda$ in thickness will be considered acoustically insignificant. This acoustic frequency falls near the limits of both normal mode and ray theory methods. Normal modes are often used for low frequencies because there is generally one mode for every $1 / 2 \lambda$ of water depth. For example, if the water column is $100 \mathrm{~m}$ deep, which is roughly $50 \lambda$ at $800 \mathrm{~Hz}$, there are approximately 100 modes. As the number of normal modes increases with frequency, the computational efficiency of this method is limiting. Ray theory is often used for higher frequencies where other methods can become cumbersome. A general rule is that ray theory is a good choice when the acoustic wavelength is much smaller than any scale within the waveguide (Jensen, Kuperman, Porter, \& Schmidt, 1994). The acoustic wavelength at $800 \mathrm{~Hz}$ meets this criterion for the NEST area. Since our method 
is a combination of normal modes (wavenumber perturbation method) and ray theory (ray theory method and LB model), $800 \mathrm{~Hz}$ is a good choice for the acoustic frequency.

In the NEST environment, a reasonable place to begin comparison is along the shelfbreak front. From climatology, we can generally describe the water masses on either side of the front by isovelocity profiles with a cross-front variation of $+5^{\circ} \mathrm{C}$ and $+2 \mathrm{PSU}$ from shelf to slope, resulting in a sound speed variation of $+20.2 \mathrm{~m} / \mathrm{s}$. The mean shelf water is $8^{\circ} \mathrm{C}$ and $33 \mathrm{PSU}$, with a sound speed of $1480.8 \mathrm{~m} / \mathrm{s}$ while the mean slope water is $13^{\circ} \mathrm{C}$ and $35 \mathrm{PSU}$, with a sound speed of $1501.0 \mathrm{~m} / \mathrm{s}$. Since the climatological shelfbreak front is nearly vertical along the $100 \mathrm{~m}$ isobath, it is reasonable to go directly from one isovelocity profile to the next (Figure 64). RAM TL curves calculated using two isovelocity profiles of $1480.8 \mathrm{~m} / \mathrm{s}$ (shelf) and $1501.0 \mathrm{~m} / \mathrm{s}$ (slope) show slight differences in $\mathrm{TL},+1.35 \mathrm{~dB}$ difference at $10 \mathrm{~km}$. To first order, these differences can be described by a spatial shift in the interference pattern (Figure 65). Using each method, we can estimate the change in LB across the front. Figure 66 shows the estimated LB across all grazing angles for the shelf profile (isovelocity) and both the wavenumber perturbation and ray theory methods for a cross-front perturbation. Most often we are concerned with small angle (low order mode) propagation. Figure 66 illustrates the angular dependence of the LB model. At small angles, the wavenumber perturbation method shows small deviations of approximately $0.03 \mathrm{~dB} /$ bounce from the shelf profile while the ray theory method shows no deviation. At grazing angles past critical, the ray theory method converges with the wavenumber perturbation method, showing maximum deviation $0.94 \mathrm{~dB} /$ bounce from the shelf conditions. The wavenumber perturbation method shows 
the expected result. At very small angles, there are few bottom bounces and therefore very small loss is expected and thus small changes in loss/bounce. As the grazing angle increases, more bounces result in greater loss/bounce, until it reaches an angle where there is almost total transmission into the bottom.

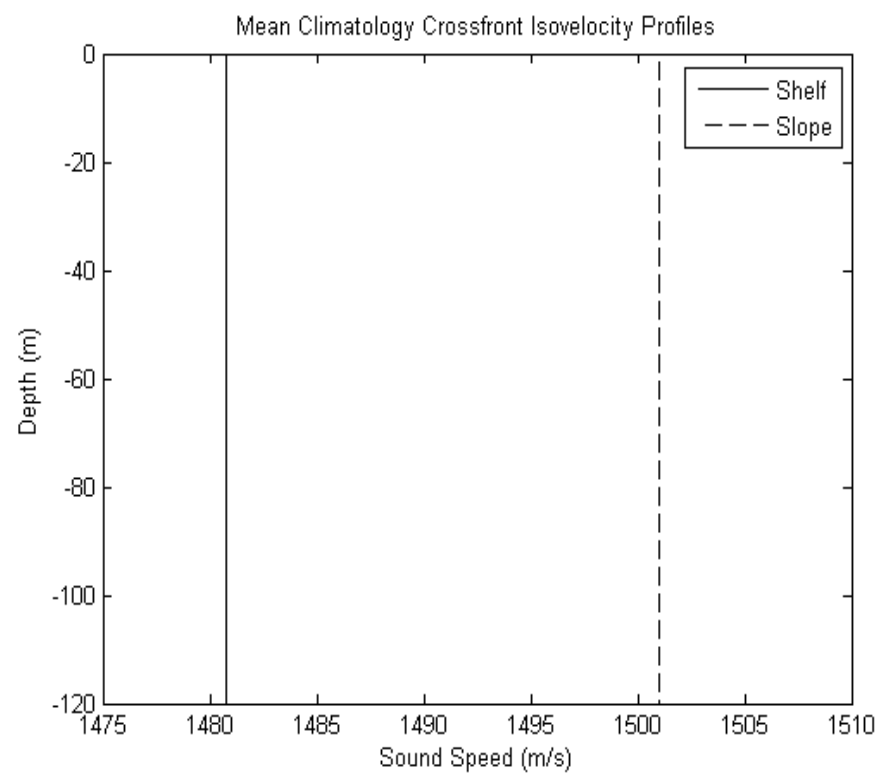

Figure 64. Isovelocity profiles for the continental shelf and slope, representing the mean water masses on either side of the climatological shelfbreak front. 


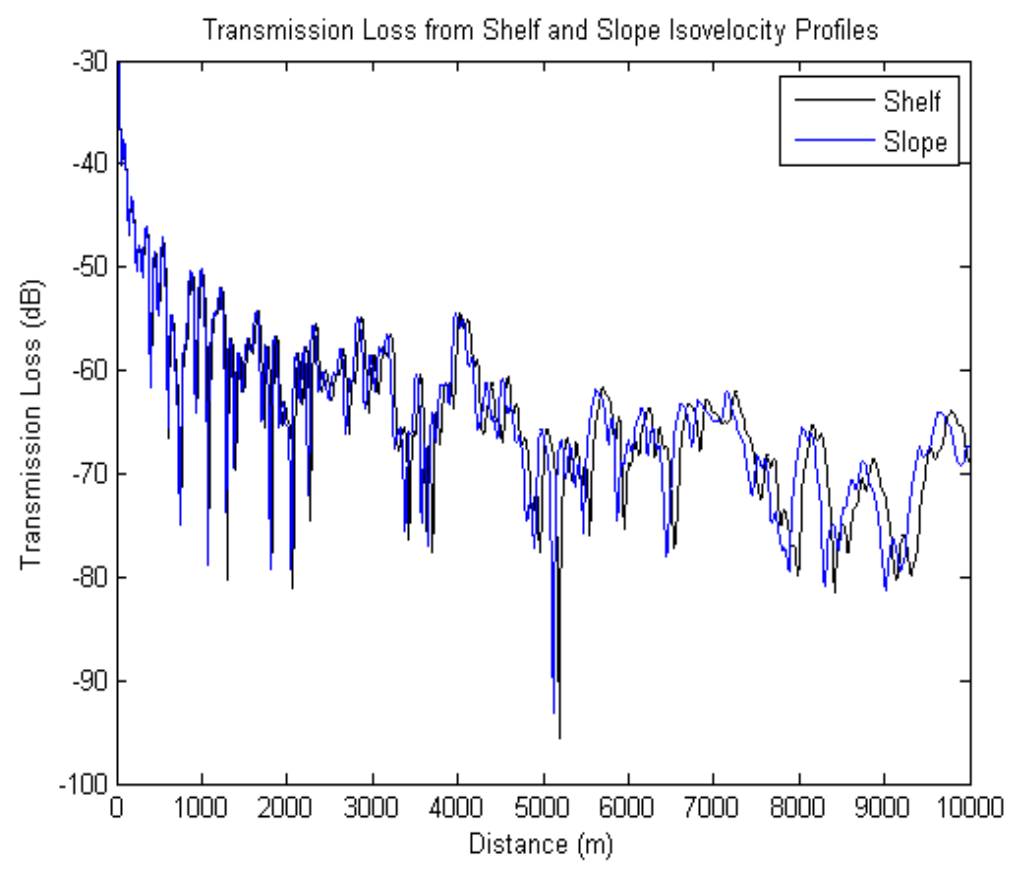

Figure 65. Transmission loss (dB) curves from RAM for two isovelocity profiles representing climatological shelf $(1480.8 \mathrm{~m} / \mathrm{s})$ and slope $(1501.0 \mathrm{~m} / \mathrm{s})$ water conditions on either side of the shelfbreak front.

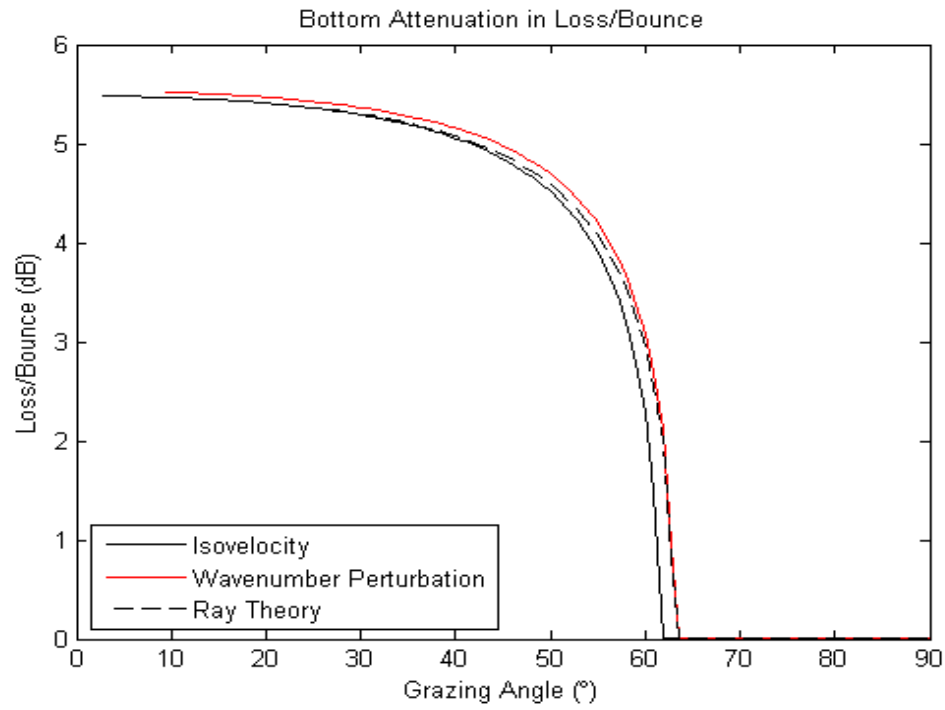

Figure 66. Comparison between isovelocity loss/bounce $(\mathrm{dB})$ and cross-front perturbations using the wavenumber perturbation and ray theory methods. The critical angle is $28^{\circ}$. 
The difference between methods at small angles is a result of how the perturbed grazing angle is calculated. The ray theory method treats the sound speed perturbation as a two-layer water column, where $k_{2}$ is the medium wavenumber in the lower layer. The horizontal wavenumber $\left(k_{l h}\right)$ is conserved at the boundary and the perturbed grazing angle is found by

$$
\theta_{1 g}=\cos ^{-1}\left(\frac{k_{1 h}}{k_{2}}\right)
$$

At small angles $k_{l h}$ is approximately equal to $k_{2}$ so that the perturbed grazing angle is equal to $0^{\circ}$. The ray theory method begins to diverge from the isovelocity condition at grazing angles greater than the critical angle where there is attenuation, partial transmission, and partial reflection. The wavenumber perturbation method incorporates the sound speed perturbation directly into the horizontal wavenumber ( $k_{l m}$, Eq. 3.19) so that the perturbed grazing angle is found by

$$
\theta_{2 g}=\cos ^{-1}\left(\frac{k_{0 m}+\Delta k_{1 m}}{k_{0}}\right)
$$

Even at small angles when $k_{0 m}$ is approximately $k_{0}$, the wavenumber perturbation $\left(\Delta k_{1 m}\right)$ creates a small change in grazing angle. Thus, we see no change between the ray theory method and the isovelocity case, while the wavenumber perturbation method captures the resulting change in LB at small angles.

If we look at the change in transmission loss between a source/receiver pair at $20 \mathrm{~m}$, the angle of the excited mode can be found by 


$$
\theta_{m}=\sin \gamma_{m} z_{s}
$$

For the cross-front example, this gives a modal grazing angle of $14^{\circ}$. The LB estimates at this angle are $5.448,5.449$, and $5.503 \mathrm{~dB} /$ bounce for isovelocity, ray theory, and wavenumber perturbation, respectively. At 10km, this results in a change in LB of 8.6dB, based on the wavenumber perturbation method, and a near zero change in LB based on the ray theory method. Our transmission loss estimate is for a single ray or mode, while the RAM calculated TL gives the total contribution of all rays/modes in the waveguide. Later examples using EOF modal perturbations will provide a better comparison between our predicted TL and RAM TL.

To evaluate positive and negative perturbations of the surface layer, maximum and minimum observed sound speed values from NEST I were used. Each statistical perturbation represents a mode one perturbation. The background environment was an isovelocity profile of the NEST I mean sound speed $(1479.4 \mathrm{~m} / \mathrm{s})$. Perturbations of the maximum and minimum observed sound speeds were applied to the mean creating fast and slow sound speed layers at the surface (Figure 67). A negative perturbation generated an upward refracting profile by creating a layer of slower sound speed above the faster background water. Therefore, negative perturbations should result in less bottom interaction, lower LB, fewer bounces and improved TL. Accordingly, we expect positive perturbations to create stronger downward refracting profiles which result in greater bottom interaction and LB, more bounces, and greater transmission loss. As expected, Figure 68 shows that the negative perturbation causes a decrease in LB and the 
positive perturbation causes an increase in LB. Since the perturbation effects are small, Figure 69 and Figure 70 show finer detail. In Figure 69, we see again that the ray theory method shows no deviation from the isovelocity condition at small grazing angles.

Figure 70 shows that as the grazing angle increases, the ray theory method begins to show some deviation and the methods converge. The methods converge as the grazing angle approaches an angle where there is almost total transmission. The loss/bounce goes to $0 \mathrm{~dB} /$ bounce because sound energy is transmitted into rather than attenuated by the seafloor.

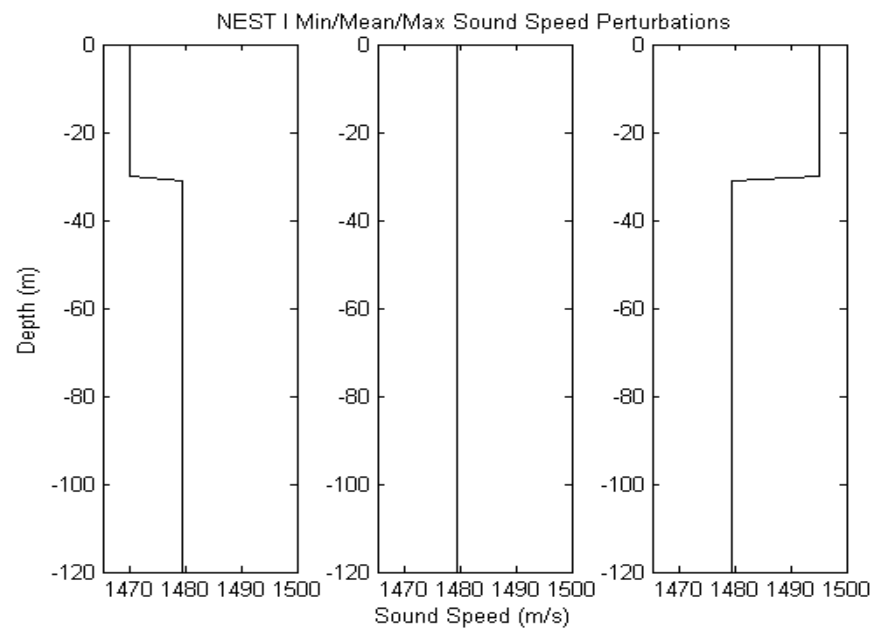

Figure 67. Sound Speed profiles of NEST I a) perturbation of minimum observed sound speed, b) isovelocity mean sound speed, and c) perturbation of maximum observed sound speed. 




Figure 68. Method comparison of loss/bounce (dB/bounce) using NEST I Mean Sound Speed as the isovelocity background and the sound speed extremes as perturbations.

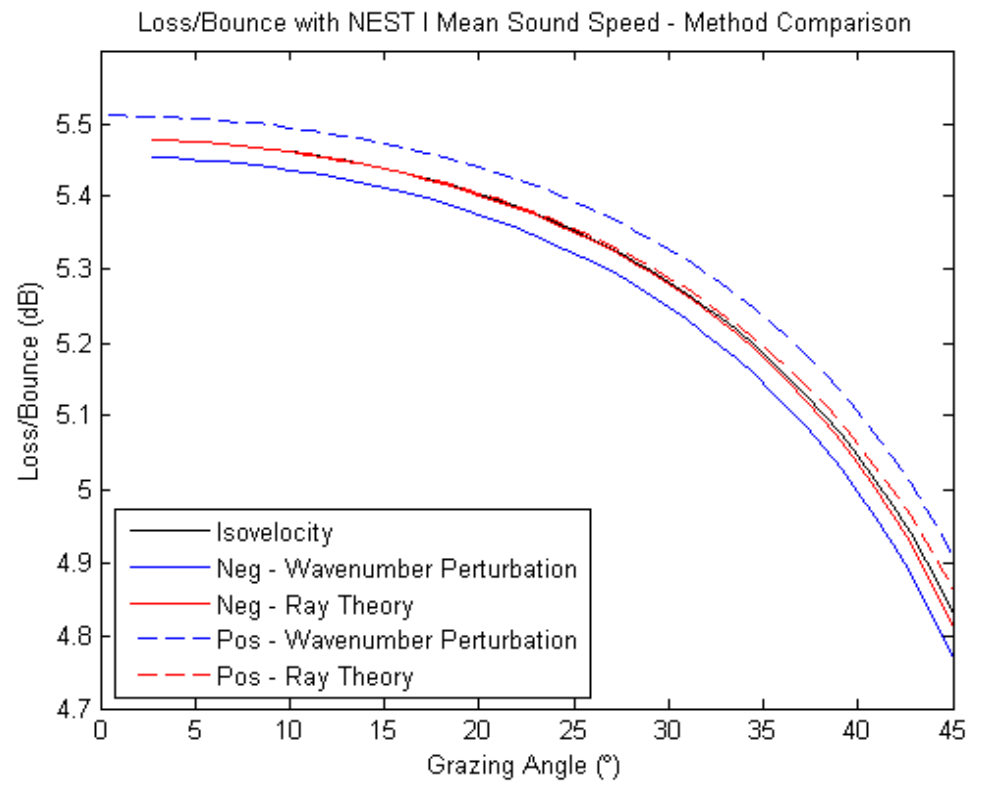

Figure 69. Method comparison of loss/bounce (dB/bounce) using NEST I Mean Sound Speed as the isovelocity background and the sound speed extremes as perturbations. Close-up from $0-45^{\circ}$ propagation angle. 


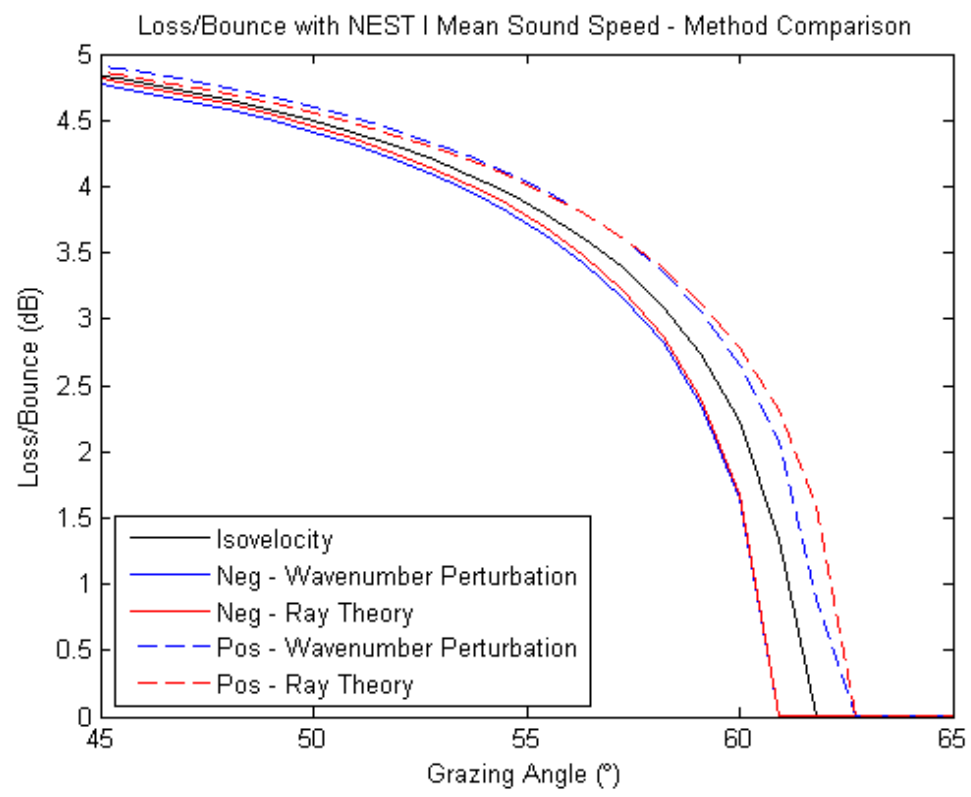

Figure 70. Method comparison of loss/bounce (db/bounce) using NEST I Mean Sound Speed as the isovelocity background and the sound speed extrema as perturbations. Close-up from $45-65^{\circ}$ propagation angle.

In addition to comparing the perturbation methods using the extreme sound speed values for NEST I in the surface layer, a series of small sound speed perturbations at different depths were applied to determine the behavior of each method. The NEST I water column was dominated by variability along the main and bottom thermoclines at approximately $30 \mathrm{~m}$ and $100 \mathrm{~m}$, respectively. Perturbations of $5 \mathrm{~m} / \mathrm{s}$ across the entire range of observed sound speeds $(1470-1495 \mathrm{~m} / \mathrm{s})$ at each of these depths correspond to the profiles described in Table 4 and shown in Figure 71. 
Table 4. Summary of perturbation profile characteristics used for comparison of wavenumber perturbation and ray theory methods.

\begin{tabular}{|c|c|c|c|c|}
\hline Profile & $\begin{array}{c}\text { Bottom Layer } \\
\text { Sound Speed } \\
(\mathrm{m} / \mathrm{s})\end{array}$ & $\begin{array}{c}\text { Surface Layer } \\
\text { Perturbation } \\
(\mathrm{m} / \mathrm{s})\end{array}$ & $\begin{array}{c}\text { Surface Layer } \\
\text { Sound Speed } \\
(\mathrm{m} / \mathrm{s})\end{array}$ & $\begin{array}{c}\text { Depth of } \\
\text { Perturbation } \\
(\mathbf{m})\end{array}$ \\
\hline a & 1479.4 & -9.4 & 1470 & 30 \\
\hline b & 1479.4 & -9.4 & 1470 & 100 \\
\hline c & 1479.4 & -4.4 & 1475 & 30 \\
\hline d & 1479.4 & -4.4 & 1475 & 100 \\
\hline Isovelocity & 1479.4 & N/A & N/A & N/A \\
\hline e & 1479.4 & 5.6 & 1485 & 30 \\
\hline f & 1479.4 & 5.6 & 1485 & 100 \\
\hline g & 1479.4 & 10.6 & 1490 & 30 \\
\hline h & 1479.4 & 10.6 & 1490 & 100 \\
\hline i & 1479.4 & 15.6 & 1495 & 30 \\
\hline j & 1479.4 & 15.6 & 1495 & 100 \\
\hline
\end{tabular}

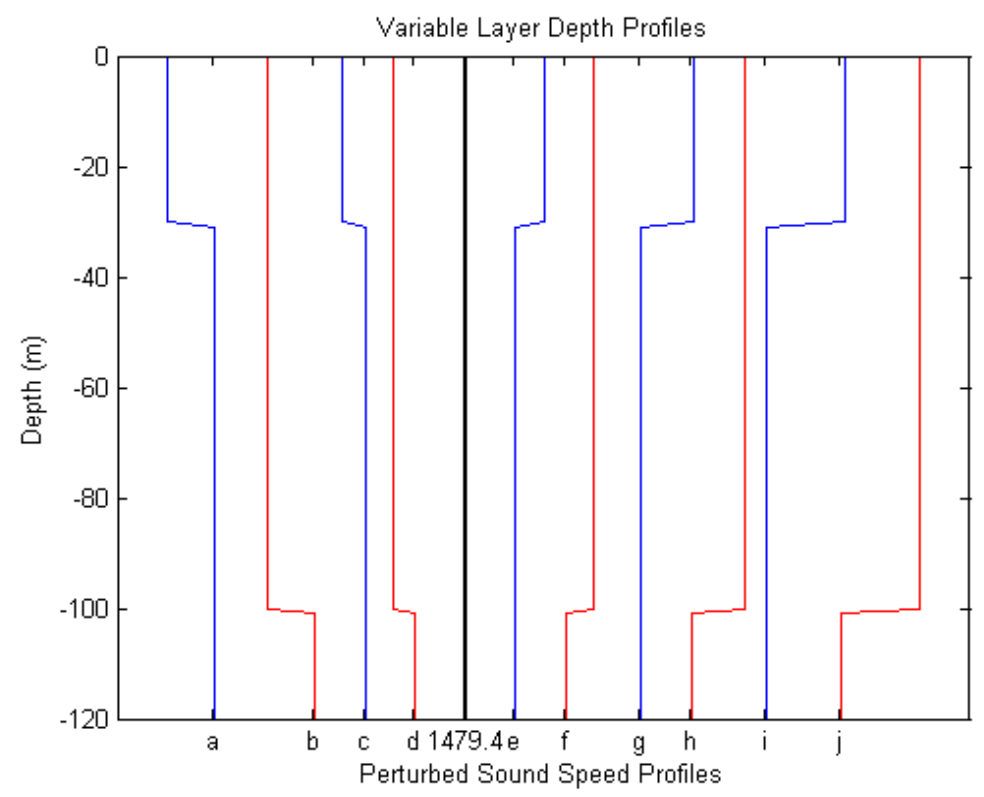

Figure 71. These sound speed profiles represent $5 \mathrm{~m} / \mathrm{s}$ perturbations at depths of $30 \mathrm{~m}$ and $100 \mathrm{~m}$ from a NEST I mean isovelocity profile at $1479.4 \mathrm{~m} / \mathrm{s}$. Corresponding table shows detailed profile information. 
The perturbed profiles described above lead to significant changes in transmission loss. We define "significant change" here as $\pm 6 \mathrm{~dB}$, which is commonly recognized as a level of significant improvement or degradation in sonar performance. Figure 72 and Figure 73 show the LB for a subset of significant grazing angles. Similar to previous examples, we see that the ray theory method does not show deviations at small angles like the wavenumber perturbation method. This reemphasizes the fact that the ray theory method is not appropriate for use in modal propagation regimes, especially because the low order (low angle) modes have the highest energy and generally dominate acoustic propagation. Therefore, the ray theory method may fail to show any change.
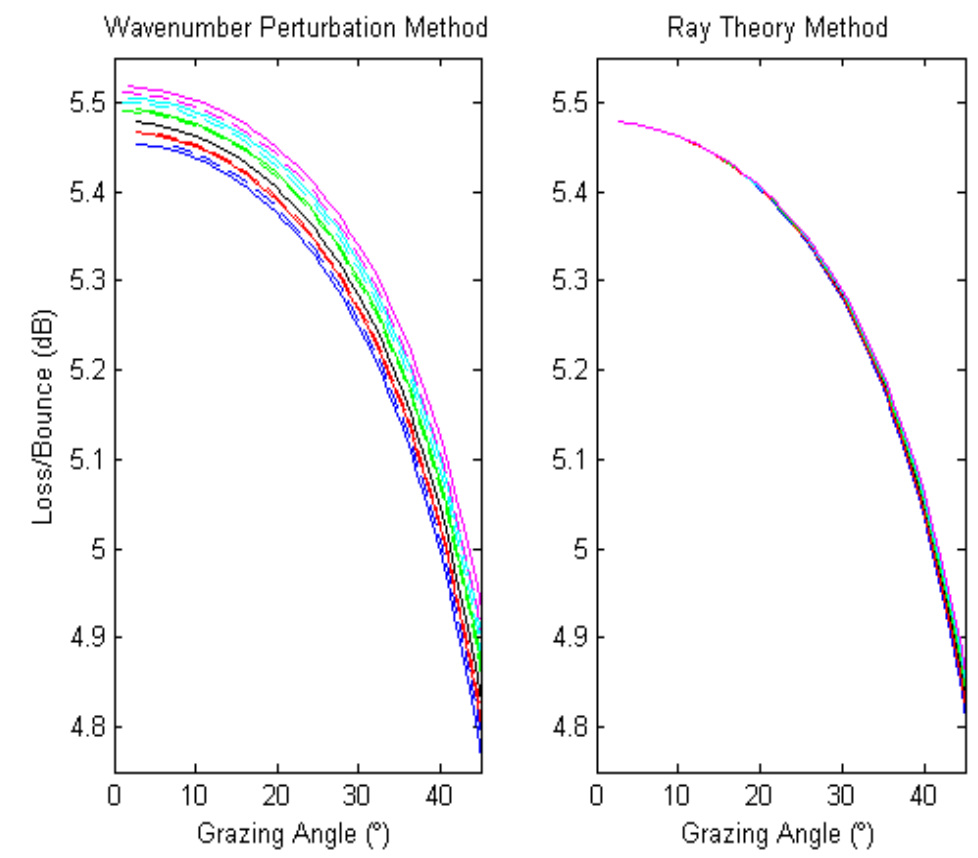

Figure 72. Comparison of loss/bounce (dB/bounce) between the wavenumber perturbation and ray theory methods for profiles a $-\mathrm{j}$. Close-up of grazing angles $0-45^{\circ}$. 

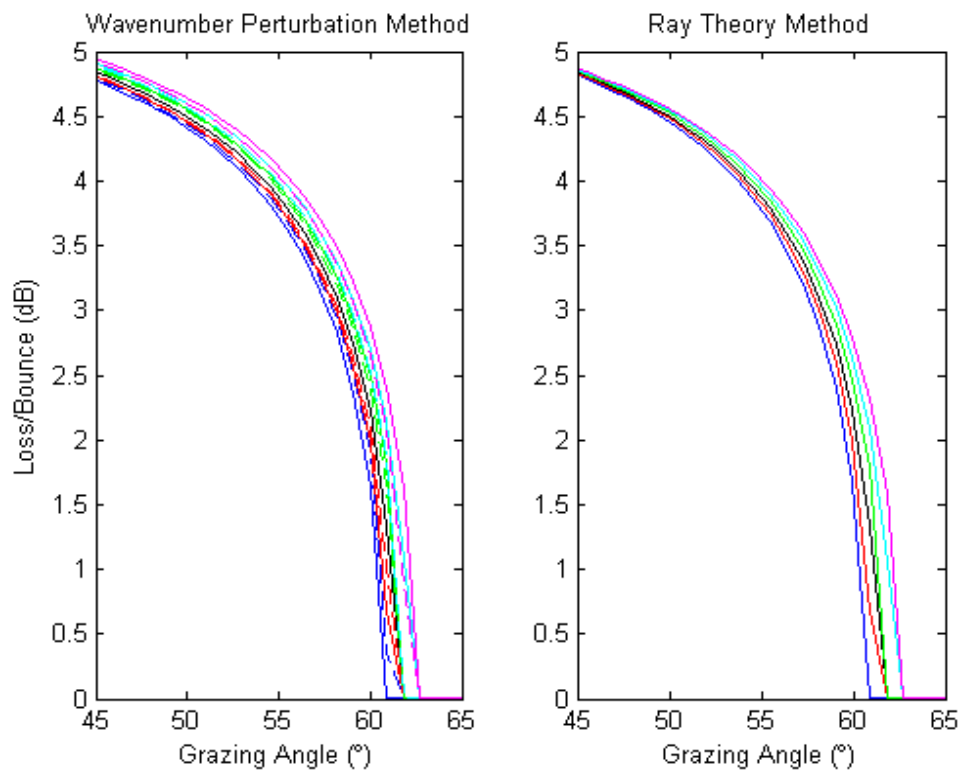

Figure 73. Comparison of loss/bounce ( $\mathrm{dB} /$ bounce) between the wavenumber perturbation and ray theory methods for profiles a $-\mathrm{j}$. Close-up of propagating angles $45-65^{\circ}$.

To simplify our comparison, we will look at the differences in LB and TL of each profile at a grazing angle of $60^{\circ}$. The differences in LB at this angle are approximately $0.25 \mathrm{~dB} /$ bounce for each $5 \mathrm{~m} / \mathrm{s}$ perturbation at $30 \mathrm{~m}$. The wavenumber perturbation and ray theory methods are found to be in good agreement with a difference of only $0.02 \mathrm{~dB} /$ bounce. For grazing angles between the critical angle and the angle past which there is (almost) total transmission, the ray theory method converges with the wavenumber perturbation method and identifies a region where the ray theory method may provide good estimates when ocean EOF modes are not available. For $5 \mathrm{~m} / \mathrm{s}$ perturbations at $100 \mathrm{~m}$, there is a difference of $0.15 \mathrm{~dB} /$ bounce using the wavenumber perturbation method. The magnitude of deviations for the deep perturbation profiles are less than those profiles with shallow perturbations of the same magnitude. This is due to the ratio of perturbation depth to water depth $\left(\frac{D}{H}\right)$ in the $\Delta k_{1 m}$ integral (Eq. 3.22). When 
the perturbation depth is shallow, the ratio is small, subtracting only a small fraction from the value of the sinc function. As the perturbation depth approaches the water depth, the ratio approaches one and the maximum value of the term is subtracted from the sinc function, minimizing the change in the horizontal wavenumber. Therefore, for perturbations of the same sign and magnitude, shallower perturbations have a greater effect on changes to the loss/bounce. Additionally, the greater the magnitude of the perturbation, the larger the difference in loss/bounce is. However, positive and negative perturbations of the same magnitude most often do not have an equal magnitude change.

Transmission loss from $9 \mathrm{~km}$ to $10 \mathrm{~km}$ is shown for the wavenumber perturbation method and the ray theory method for each of the perturbation profiles (Figure 74 and Figure 75). As with LB, greater magnitude perturbations result in greater magnitude deviations from the isovelocity TL. For each $5 \mathrm{~m} / \mathrm{s}$ perturbation at $30 \mathrm{~m}$, the mean change in transmission loss due to bottom attenuation is $5.89 \mathrm{~dB}$ for the wavenumber perturbation method and $6.11 \mathrm{~dB}$ for the ray theory method, a difference of only $0.22 \mathrm{~dB}$. While at $100 \mathrm{~m}$, the wavenumber perturbation method estimates changes in TL of $3.25 \mathrm{~dB}$ per $5 \mathrm{~m} / \mathrm{s}$ perturbation. These results suggest that changes of greater than $\pm 5 \mathrm{~m} / \mathrm{s}$ can cause a significant change in TL depending on depth. Our comparison of LB and TL indicates that the magnitude, sign and perturbation depth are all important when estimating the effects of sound speed perturbations in the water column. 


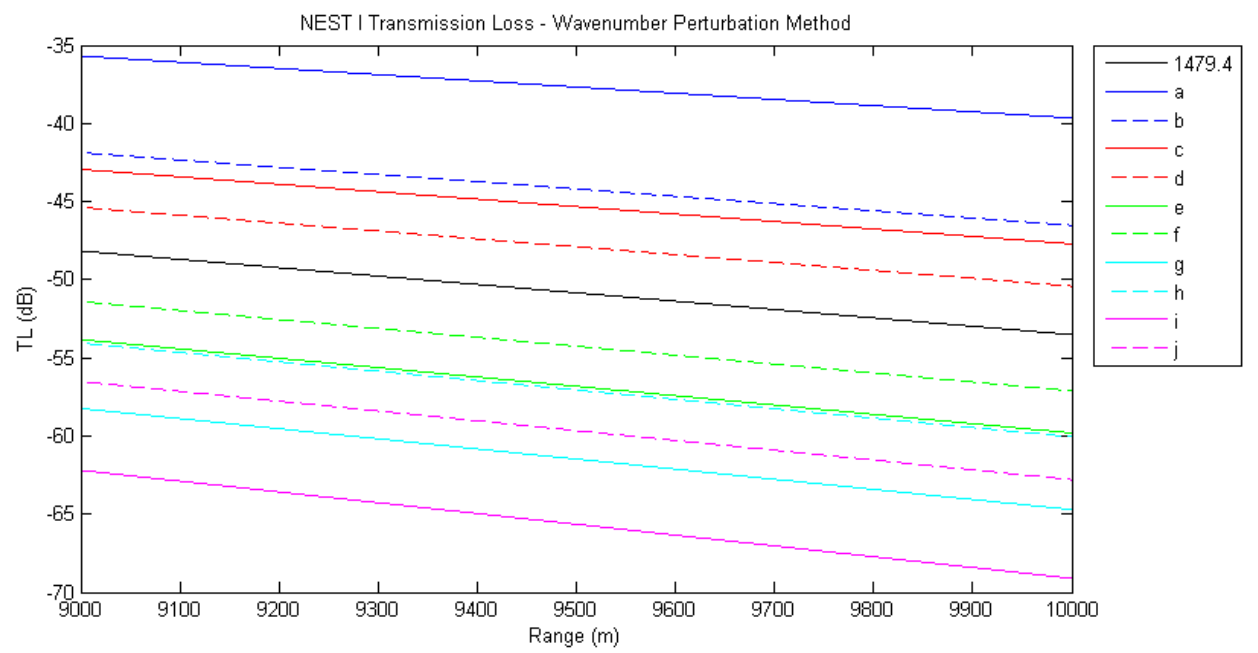

Figure 74. Transmission loss $(\mathrm{dB})$ at $9-10 \mathrm{~km}$ range for each perturbation profile a-j using the wavenumber perturbation method.

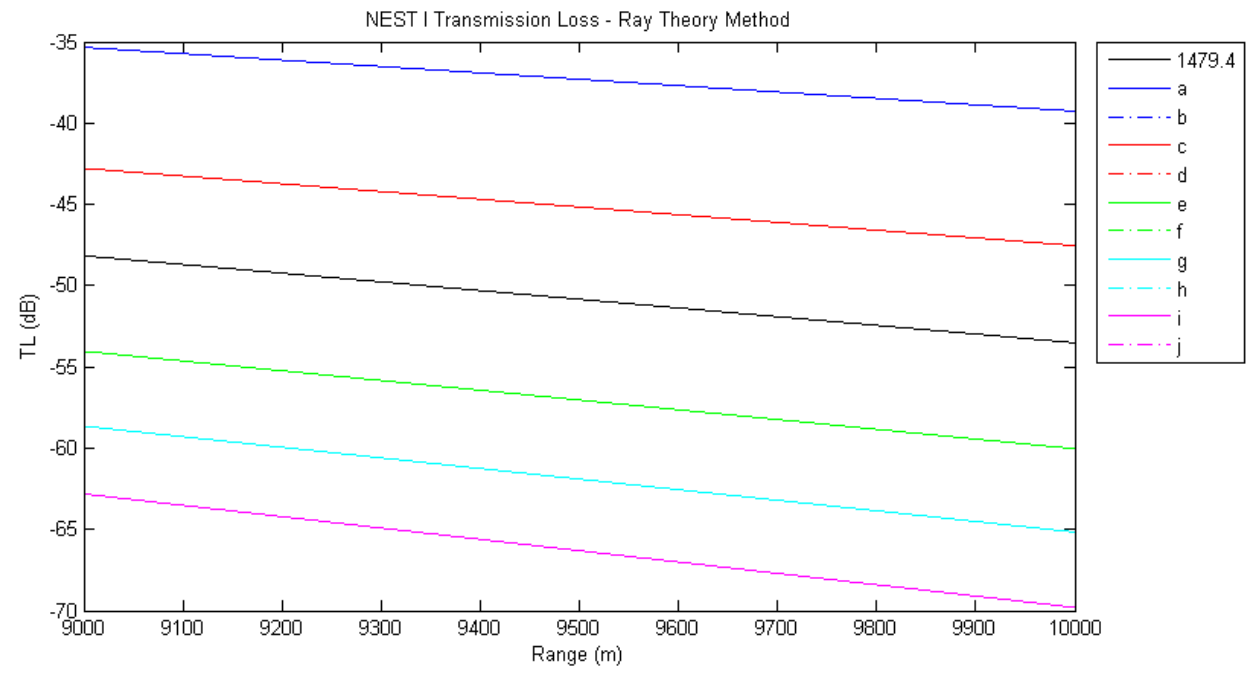

Figure 75. Transmission loss $(\mathrm{dB})$ at $9-10 \mathrm{~km}$ range for each perturbation profile a-j using the ray theory method.

The comparison between the wavenumber perturbation and ray theory methods using simple examples within the range of the NEST data highlights three important points. First, at angles below critical, the ray theory method does not predict changes in LB. At small angles the ratio $\left(\frac{k_{1 h}}{k_{2}}\right)$ is very close to 1 , resulting in a perturbed grazing 
angle of $0^{\circ}$ and no change in LB from the isovelocity condition. Grazing angles between $0^{\circ}$ and $\Theta_{\mathrm{c}}$ define an important regime where there is (almost) total internal reflection with very small loss to attenuation in the seafloor. In this regime, sound energy is only lost due to attenuation because there is no transmission into the seafloor. Therefore, the use of the wavenumber perturbation method is necessary to estimate changes at small angles.

Next, our comparison has shown that depth, sign, and magnitude of the sound speed perturbation are all critical characteristics when determining the effect of the perturbation on loss/bounce and transmission loss. Perturbations of equal magnitude and opposite sign do not result in equal change in LB. Additionally, shallower perturbations, both positive and negative have a greater effect than deeper perturbations of the same sign and magnitude. While statistical variance can provide the sign and magnitude of maximum variability at a particular depth, we will see from the experimental results that it is the sum of the acoustic modal contributions which are vital to accurately predicting TL.

Finally, there is one set of grazing angles for which the ray theory method may provide a good approximation for estimating loss/bounce and predicting transmission loss. For grazing angles between $\Theta_{c}$ and approximately $60^{\circ}$, the ray theory method converges with the wavenumber perturbation method. When either the ocean EOF modes or the acoustic normal modes are unknown, the ray theory method will provide a good first order estimate. 


\subsection{Experimental Results}

The wavenumber perturbation method was applied to experimental results from NEST I and II. Previous analysis of Scanfish profiles provided ocean sound speed EOF modes for each set of Scanfish profiles. To create a "representative" perturbation profile, the maximum variation of each EOF mode was identified and the depth and magnitude of that variation determined the sound speed perturbation from the mean sound speed, i.e. we scaled the EOF mode by the maximum point (Figure 76). For example, these EOF modes created the following sound speed perturbations: $+3.43 \mathrm{~m} / \mathrm{s}$ at $96 \mathrm{~m}$ (mode 1 ), $+4.42 \mathrm{~m} / \mathrm{s}$ at $104 \mathrm{~m}$ (mode 2$),-4.75 \mathrm{~m} / \mathrm{s}$ at $20 \mathrm{~m}$ (mode 3 ) which resulted in the sound speed perturbation profiles shown in Figure 77. The LB results were incoherently summed, assuming independent acoustic modes, to determine the combined effect of the modal perturbations (Eq. 3.28). When multiple acoustic modes contribute non-zero LB, the result is a much greater magnitude change than any of the previous single mode examples.

$$
L B_{\text {tot }}=\sqrt{L B_{1}^{2}+L B_{2}^{2}+L B_{3}^{2}}
$$



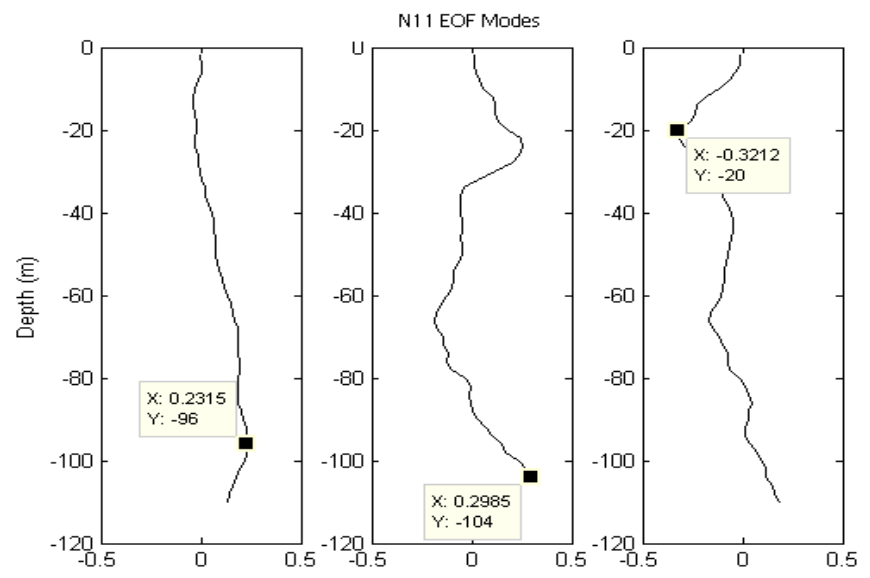

Figure 76. N11 EOF Modes 1-3 from the empirical orthogonal function analysis of ocean sound speed profiles. Data tags show the maximum variation and depth from each of the first three modes. These data points were used to create the corresponding perturbation profiles.



Figure 77. Sound speed profiles created from EOF mode perturbations for N11.

Using the method described above, perturbation profiles based on EOF modes one through three were created for each of the NEST scans. During NEST I, the water column showed increased variability along the main and bottom thermoclines. The set of modes for each NEST I scan included perturbations within both of these depth regions. Table 5 provides a summary of the results estimated using the LB model for each of the NEST I scans. Several of the single mode contributions estimate OdB/bounce LB 
because the associated perturbation profiles had positive perturbations resulting in upward refracting profiles, which shield sound from the bottom. All of the remaining profiles which contribute non-zero LB are downward refracting, with one exception. N14 mode 3, although an upward refracting profile, does contribute a non-zero LB of $5.47 \mathrm{~dB} /$ bounce. It is presumed that this is the only upward refracting profile which contributed a non-zero LB because it is a very shallow perturbation of $8 \mathrm{~m}$ with a larger modal angle. Additional estimates were calculated with a variety of perturbation depths and magnitudes for each mode.

Table 5. Summary of perturbation results showing individual mode loss/bounce (dB) estimates and total loss/bounce of incoherently summed acoustic modal contributions.

\begin{tabular}{|c|c|c|c|c|c|c|}
\hline \multirow{2}{*}{ Scan } & \multicolumn{7}{|c|}{ Loss/Bounce (dB/bounce) } \\
\cline { 2 - 7 } & Isovelocity & Mode 1 & Mode 2 & Mode 3 & Total & Change \\
\hline N11 & 5.4787 & 0.0000 & 0.0000 & 5.4907 & 5.4907 & 0.0120 \\
\hline N12 & 5.4825 & 0.0000 & 0.0000 & 0.0000 & 0.0000 & -5.4825 \\
\hline N13 & 5.4762 & 0.0000 & 5.4765 & 5.4753 & 7.7441 & 2.2679 \\
\hline N14 & 5.4721 & 0.0000 & 0.0000 & 5.4726 & 5.4726 & 0.0005 \\
\hline N15 & 5.4734 & 0.0000 & 0.0000 & 5.4738 & 5.4738 & 0.0004 \\
\hline
\end{tabular}

N12, which had the greatest sound speed variance during NEST I, showed the greatest $\Delta \mathrm{LB}(-5.48 \mathrm{~dB} /$ bounce) because positive perturbations were created by all three EOF modes. Each of the other scans had at least one EOF mode, usually mode 3, which was downward refracting. N11, N14, and N15 each had only a single contribution from mode 3 and showed a small (near-zero) change in LB. N13 was the only scan with two downward refracting perturbation profiles, which resulted in the greatest $\mathrm{LB}_{\text {tot }}$ (7.74dB/bounce). The combined contribution of these two modes resulted in a $\Delta \mathrm{LB}$ of $+2.27 \mathrm{~dB} /$ bounce. Although N12 showed the most statistical variance and greatest $\Delta \mathrm{LB}$, 
it is obvious that variance alone cannot predict the magnitude of change in LB because the sign and depth of each modal perturbation are also important factors in determining the effect of sound speed perturbations on bottom interaction and thus, changing transmission loss.

Both simple statistical analyses of the oceanographic data and the EOF modes from NEST II show that the sound speed variability was primarily contained within the main thermocline. Unlike the NEST I EOF modes, the perturbations for all NEST II EOF modes ranged over depths of $18-40 \mathrm{~m}$ only. Table 6 summarizes the results of the LB model for NEST II. N23, which was not the most variable scan, statistically, showed the greatest $\Delta \mathrm{LB}(-5.52 \mathrm{~dB} /$ bounce $)$ because the incoherent sum of the modal contributions was $0 \mathrm{db} /$ bounce. $\mathrm{N} 21$ and $\mathrm{N} 25$ had the greatest statistical variance but both showed little change when evaluated for LB. Perhaps this is because the variability for these scans was driven by internal wave induced vertical movement and not changes in the background sound speed perturbations. Similar to NEST I, it seems statistical analysis alone does not provide a completely accurate picture of which sound speed perturbations will cause the greatest change in acoustic propagation.

Table 6. Summary of perturbation results showing individual mode loss/bounce (dB) estimates and total loss/bounce of summed acoustic modal contributions.

\begin{tabular}{|c|c|c|c|c|c|c|}
\hline & \multicolumn{7}{|c|}{ Loss/Bounce (dB/bounce) } \\
\cline { 2 - 7 } Scan & Isovelocity & Mode 1 & Mode 2 & Mode 3 & Total & Change \\
\hline N21 & 5.5109 & 0.0000 & 0.0000 & 5.5113 & 5.5113 & 0.0004 \\
\hline N22 & 5.5139 & 0.0000 & 0.0000 & 5.5144 & 5.5144 & 0.0005 \\
\hline N23 & 5.5182 & 0.0000 & 0.0000 & 0.0000 & 0.0000 & -5.5182 \\
\hline N24 & 5.5187 & 0.0000 & 5.5189 & 0.0000 & 5.5189 & 0.0002 \\
\hline N25 & 5.5187 & 0.0000 & 0.0000 & 5.5191 & 5.5191 & 0.0004 \\
\hline
\end{tabular}


Generally, all of the NEST Scanfish profiles are upward refracting due to the influence of warm slope water near the bottom. The NEST experiments thus provide a unique data set with which to test our methods, because, in shallow water, upward refracting summer profiles are not typical. To illustrate our methods, a set of EOF modes for a typical shallow water environment with a warm surface layer over a cool bottom layer might look similar to those shown in (Figure 78). In this example, all three of the EOF modes contribute to the $\mathrm{LB}_{\text {tot }}$, resulting in a much greater difference than a single EOF mode contribution. The $\mathrm{LB}_{\text {tot }}$ of the first three modes is $9.56 \mathrm{~dB} /$ bounce, an increase of $4.04 \mathrm{~dB} /$ bounce over that of a single mode. The difference in orders of magnitude of LB between the single mode contribution and the summed contribution of modes highlights need to look at all the significant propagating modes of the water column.



Figure 78. Example EOF modes of a typical shallow water environment with a warm surface layer and cool bottom layer.

Using the LB model results, we can predict changes in transmission loss for a given distance (Eq. 3.25). For a range of $10 \mathrm{~km}$, small angle modes will interact with the bottom approximately twice. We can use our estimated $\triangle \mathrm{LB}$ to predict the change in TL 
$(\Delta \mathrm{TL})$. To create a baseline TL, we estimate the TL of the isovelocity mean profile of each NEST scan as a result of the corresponding LB (Eq. 3.29).

$$
T L_{\text {baseline }}=-2 * L B_{\text {iso }}
$$

Although we will use the Range-dependent Acoustic Model (RAM) for our TL

comparisons, the $\mathrm{TL}_{\text {baseline }}$ provides a better initial TL because RAM TL is a result of the pressure field for all angles of propagation versus only the small angles which we will consider here. Table 7 shows the $\mathrm{TL}_{\text {baseline, }}, \Delta \mathrm{TL}$, and predicted $\mathrm{TL}\left(\mathrm{TL}_{\text {pred }}\right)$ for each NEST scan.

Table 7. Predicted change in transmission loss $(\mathrm{dB})$ for each NEST scan based on loss/bounce (dB) estimates.

\begin{tabular}{|c|c|c|c|}
\hline Scan & $\begin{array}{c}\text { TLbaseline } \\
(\mathbf{d B})\end{array}$ & $\boldsymbol{\Delta T L}(\mathrm{dB})$ & $\begin{array}{c}\text { TLpred } \\
(\mathrm{dB})\end{array}$ \\
\hline $\mathrm{N} 11$ & -10.96 & -10.98 & -21.94 \\
\hline $\mathrm{N} 12$ & -10.97 & 0.00 & -10.97 \\
\hline $\mathrm{N} 13$ & -10.95 & -15.48 & -26.43 \\
\hline $\mathrm{N} 14$ & -10.94 & -10.95 & -21.89 \\
\hline $\mathrm{N} 15$ & -10.95 & -10.95 & -21.89 \\
\hline $\mathrm{N} 21$ & -11.02 & -11.02 & -22.04 \\
\hline $\mathrm{N} 22$ & -11.03 & -11.03 & -22.06 \\
\hline $\mathrm{N} 23$ & -11.04 & 0.00 & -11.04 \\
\hline $\mathrm{N} 24$ & -11.04 & -11.04 & -22.08 \\
\hline $\mathrm{N} 25$ & -11.04 & -11.04 & -22.08 \\
\hline
\end{tabular}

To compare $\mathrm{TL}_{\text {pred }}$ with a similar RAM calculated $\mathrm{TL}$, the RAM pressure field for each EOF modal perturbation profile was depth integrated for source and receiver positions. Transmission loss was then calculated from the incoherent sum of the pressure fields (Eq. 3.30).

$$
T L_{\text {calc }}=20 * \log \sqrt{P_{m 1}^{2}+P_{m 2}^{2}+P_{m 3}^{2}}
$$


From Table 7, we expect TL changes of OdB for scans with three upward refracting profiles, approximately $-11 \mathrm{~dB}$ for scans with two upward refracting profiles, and approximately $-15 \mathrm{~dB}$ for N13, which has only one upward refracting mode. A summary of $\mathrm{TL}_{\mathrm{calc}}$ and the difference between it and $\mathrm{TL}_{\text {pred }}$ is provided in Table 8 . For 6 out of 10 NEST scans, there is excellent $(0.09 \mathrm{~dB})$ to good (approximately $4 \mathrm{~dB})$ agreement between $\mathrm{TL}_{\text {pred }}$ and $\mathrm{TL}_{\text {calc }}$, with a maximum deviation of $-4.79 \mathrm{~dB}$. For N12, N13, N22 and N24, the difference between the predicted TL and calculated TL is larger. During each of these scans, dynamic oceanographic features such as internal waves and shelfbreak eddies were present within the region of interest. Because our model is set up to estimate LB and predict TL for changes to the background sound speed, it is possible that variability from these other features was more dominant during these four scans than the background variability. Therefore, we would not expect this model, in its current state, to adequately predict the changes in transmission loss.

Table 8. Calculated transmission loss $(\mathrm{dB})$ from depth integrated RAM pressure fields vs. LB model predicted transmission loss $(\mathrm{dB})$.

\begin{tabular}{|c|c|c|c|c|}
\hline Scan & $\begin{array}{c}\text { TLbaseline } \\
\text { (dB) }\end{array}$ & $\begin{array}{c}\text { TLpred } \\
\text { (dB) }\end{array}$ & $\begin{array}{c}\text { TLcalc } \\
\text { (dB) }\end{array}$ & $\begin{array}{c}\text { TLcalc- TLpred } \\
\text { (dB) }\end{array}$ \\
\hline N11 & -10.96 & -21.94 & -21.85 & 0.09 \\
\hline N12 & -10.97 & -10.97 & -28.22 & -17.25 \\
\hline N13 & -10.95 & -26.43 & -36.09 & -9.66 \\
\hline N14 & -10.94 & -21.89 & -20.76 & 1.13 \\
\hline N15 & -10.95 & -21.89 & -22.47 & -0.58 \\
\hline N21 & -11.02 & -22.04 & -25.65 & -3.61 \\
\hline N22 & -11.03 & -22.06 & -7.44 & 14.62 \\
\hline N23 & -11.04 & -11.04 & -14.66 & -3.62 \\
\hline N24 & -11.04 & -22.08 & -10.83 & 11.25 \\
\hline N25 & -11.04 & -22.08 & -26.87 & -4.79 \\
\hline
\end{tabular}




\section{Chapter 4: Conclusions}

\subsection{Summary}

The main purpose of this study was to evaluate the variability of the New England shelfbreak, specifically during the NEST experiments, and determine the effects of the ocean variability on acoustic propagation. To quantify these effects, a method was presented which translated sound speed perturbations into horizontal wavenumber perturbations and then estimated the change in transmission loss due to bottom attenuation. Detailed environmental analyses were conducted including a review of the climatology, statistical analysis of the collected data, and qualitative analysis of the mesoscale satellite imagery. A crude constant gradient profile method identified key parameters of the sound speed profiles. Initially, we believed that the dominant features of the region were the mixed layer, the Cold Pool, the shelfbreak front, and the internal waves, and that the characteristics of these features were the critical parameters of the environment. The key parameters from the constant gradient profiles identified most of these features. Surprisingly, variability of the mixed layer depth did not appear to be a significant factor in this area. Five critical characteristics of the NEST area which specifically describe the five layer water column were identified and simple vertical

models were developed to easily perturb each feature. Two methods, ray theory and wavenumber perturbation, were used to induce sound speed perturbations. The wavenumber perturbation method introduced the sound speed perturbations indirectly through a change in the horizontal wavenumber while the ray theory method incorporated the sound speed perturbation directly and relied upon ray tracing techniques to account 
for the resulting change in the grazing angle. The loss/bounce model presented was used to estimate changes in loss/bounce and to predict transmission loss based on the perturbed grazing angle. While the wavenumber perturbation method appeared to provide excellent results at all angles, the ray theory method failed to show changes at small angles. However, for grazing angles above critical, where there is partial reflection and partial transmission, the ray theory method may provide a suitable alternative when ocean EOF modes are not available and the acoustic normal mode assumptions within the LB model are not acceptable. For the experimental results, the LB model used the wavenumber perturbation method. Overall, the LB model predicted transmission loss due to the EOF modal perturbations to within $4 \mathrm{~dB}$ at $10 \mathrm{~km}$, and was evaluated as a good model for predicting transmission loss in areas of the ocean where strong fronts and internal waves are not dominant and there is weak range dependence in the water column.

\subsection{Environment}

Comprehensive climatology is a unique benefit of the New England shelf region. While the experimental data showed a highly complex environment very different from the simple structure of the climatology, the variability of collected data fell within the variance of the climatology. Therefore, the range of water column characteristics was not atypical for this region. However, based on climatology alone, it would have been nearly impossible to predict the horizontal or vertical structure of the water column during either of the NEST experiments. Mesoscale satellite imagery allowed for a detailed qualitative analysis of the horizontal structure post-experiment, which provided insights to how the 
mesoscale structure affected the acoustic environment of the region of interest. Several mesoscale features were identified which directly or indirectly impacted the water column structure of both experiments. The inter-annual variability was the result of mesoscale features associated with the Gulf Stream current. In NEST I, cold shelf water was entrained in a warm slope eddy pulling the Cold Pool far offshore and creating a thick, stable sound channel. In NEST II, a very large Gulf Stream meander pushed warm water into the shelfbreak, preventing all but a thin layer of shelf water to flow offshore, while very large amounts of shelf water were flowing offshore to the east in a $200 \mathrm{~km}$ wide entrainment between the warm meander and the cold cyclonic eddy. The result was a thin Cold Pool, thick warm bottom layer, and a wide, highly variable frontal transition zone within the NEST area. Despite the repeated emphasis on insitu observations, satellite imagery, where available, can provide invaluable indications of water column structure prior to an experiment and aide in both the pre-planning and post experiment analysis.

Vertical variability along the main and bottom thermoclines was a result of internal waves being generated at the shelfbreak and propagating shoreward. Internal wave effects were identified in both the Scanfish data and mooring data for each experiment. Internal wave characteristics calculated from these data agree well with previous studies of internal waves on the New England shelf. Internal waves are a major source of variability within this region and are difficult to predict. However, certain features can still be exploited. For example, the extensive Cold Pool during NEST I created a thick, stable sound channel. Although variability in the temperature and sound 
speed fields was only obvious along the water layer boundaries due to the temperature and sound speed contrasts, the vertical variability of the internal waves affected the entire water column. Because of the thickness of the Cold Pool, vertical variability had less of an impact on acoustic transmissions within the layer than on those near either boundary.

Overall, the major contributors to ocean variability for the NEST experiments were the Cold Pool, the shelfbreak front, and the internal waves. The movement and extent of the Cold Pool, as well as the position of the foot of the front was driven by the mesoscale and contributed some of the variability along the main and bottom thermoclines. The location of the foot of the front also determined the vertical extent of the cold pool which reached, horizontally, to the offshore edge of the region of interest during both experiments. The internal waves contributed additional variability within the water column. Although internal wave characteristics were calculated from the data and discussed, future work is necessary to include internal wave variability into the loss/bounce model. The ocean sound speed EOF modes which were used for sound speed perturbations primarily captured the variability of the background sound speed field along the main and bottom thermoclines. Previous studies have detailed the characteristics of frontal waves and their presence along the shelfbreak in the MAB (Gawarkiewicz, 1991). However, we were unable to resolve the movement of the Cold Pool, which is believed to have been another major source of variability during NEST. In the future, a longer experiment in this area may be able to resolve this feature and adequately describe its effect on the sound speed field. 


\subsection{Acoustics}

It is well known that ocean variability leads to changes in acoustic propagation. Many sophisticated models are available which input range and depth dependent environmental parameters to provide predictions of transmission loss and other acoustic measures. In the absence of these sophisticated models or abundant data, how can we evaluate the variability and predict change? In areas where range dependence is relatively weak, is there a simple way to predict changes in transmission loss? The LB model provides a quick and simple approach to predicting changes in transmission loss.

The two methods used for inputs to the LB model were the ray theory and wavenumber perturbation methods. The ray theory method used the sound speed perturbation as a direct input into Snell's Law and calculated the resulting change in the grazing angle. At very small angles when the horizontal wavenumber is almost equal to the medium wavenumber, the ray theory method does not predict changes in loss/bounce. At grazing angles above the critical angle, where there is partial reflection and transmission, this method produced results similar to the wavenumber perturbation method. This second method assumed the shape of the acoustic normal modes and a rigid bottom boundary. The sound speed perturbation was integrated into the change in the horizontal wavenumber which affected the modal angle of incidence. Ocean EOF modes were used to determine the sound speed perturbations used in the integration. This method provided results for all grazing angles and was used for the experimental results. 
Predicted transmission loss for the NEST scans compared well with the calculated transmission loss from the integrated RAM pressure fields. Transmission loss predictions were within $4 \mathrm{~dB}$ at $10 \mathrm{~km}$. This model is expected to perform well in many areas of the ocean where range dependence is weak and the effects of fronts or internal waves are limited to their immediate vicinity.

Statistical analyses of both Scanfish surveys and mooring data provided mean and variance of the water column. However, these values alone do not provide an accurate description of the variability, and certainly do not provide specific detail about which sound speed perturbations cause the greatest change in transmission loss. EOF analysis decomposes the sound speed field into a vertical mean sound speed and a set of vertical modes which provide greater detail about a convenient way to identify the depth, sign, and magnitude of perturbations. Sound speed EOF modes were used to create the sound speed perturbations input into the LB model. The depths of maximum variation in the EOF modes corresponded with the depths of maximum statistical variance and the perturbations created were similar in magnitude to the greatest standard deviations of sound speed. However, the NEST scans with the greatest variance were not necessarily the scans with the largest changes in transmission loss. Therefore, the detailed ocean EOF modes are important for providing greater detail for the sound speed perturbations and improving the accuracy of the predictions.

The decomposition of the ocean sound speed field into EOF modes and the use of acoustic normal modes in the wavenumber perturbation method are critical for accurately 
estimating the effect of changes to the background sound speed field on loss/bounce and transmission loss. The number of positively perturbed, downward refracting, profiles from the EOF modes was a key factor in the magnitude of the predicted transmission loss. So although, the statistical variance closely resembled the EOF perturbations, using the ray theory method with statistical perturbations would not have given reliable transmission loss predictions because the combined effect of the modal contributions is critical.

A partial source of the discrepancies in predicted transmission loss could be the acoustic modal approximation used by the LB model in this study. At our test frequency of $800 \mathrm{~Hz}$, there are certainly more than three propagating acoustic modes. However, we took advantage of the common rule of thumb in shallow water to truncate the modal solution at the first three modes. Thus, the LB model described provides a low-mode approximation. Use of the complete modal solution may further improve the accuracy of the TL predictions.

The loss/bounce estimate for each acoustic mode was incoherently summed to calculate a total loss/bounce. The incoherent summation represents the so-called adiabatic approximation assuming that there is no mode-mode interaction and that each of the acoustic modes independently contributes to the loss/bounce. This is a basic assumption that was made in order to create a simplified method. In highly range dependent environments, propagation is often affected by mode-coupling. As previously stated, the LB model is not expected to perform well in such an area because the 
incoherent sum of the modal effects ignores this complication. The incoherent sum is perhaps an oversimplification. Also, an improved solution will need to find the mode solution at a specific source depth for each of the excited modes. Then by determining the weight of each mode based on the excitation, one could use a weighted average for the total loss/bounce. This would improve our "low acoustic mode" approximation.

It is impossible to overlook the added complications of internal wave induced variability on changes in acoustic propagation. In addition to discrepancies from the lowmode approximation, some of the predicted TL discrepancies are likely due to internal wave effects. These effects are not limited to the vertical variability of the temperature and sound speed fields, as discussed previously. Mode-coupling and ducting through internal waves can significantly change available propagation paths and have drastic impacts on bottom interaction. The LB model was developed to predict changes in TL due to perturbations of the background sound speed field and not vertical perturbations due to internal waves which create range dependence. In a region of high internal wave activity, such as the NEST area, it is reasonable that changes due to the background sound speed variability would not capture the total change in transmission loss.

Despite the assumptions and simplifications within LB model, initial evaluation of the model using experimental data shows that it is a good tool for estimating changes in loss/bounce and transmission loss. While the NEST area is influenced by a strong front and internal waves, the LB model predicted the transmission loss changes due to the background sound speed field. Discrepancies are likely due to these range dependent 
features. For the small subset of grazing angles where ducting by internal waves is likely to occur, and mode-coupling effects due to strong range dependence, the model is not expected to provide adequate results. However, in other shallow water areas, away from dominant range dependent features, the LB model will be a useful tool for predicting changes in transmission loss.

\subsection{Future Work}

While the LB model demonstrated reasonable results for predicting transmission loss due to sound speed perturbations for NEST I and II, use of the model was limited to these two experiments. To more fully evaluate the LB model for use as a simple tool, a variety of shallow water environments should be used, specifically including areas without strong internal waves or fronts. The LB model does well at estimating the effects of perturbations which result in downward refraction, so it is expected that in typical shallow water environments, where a warm bottom layer is not prevalent, the model will perform quite well.

The loss/bounce contribution of upward refracting perturbation profiles was depth dependent. The depth of the perturbation determined whether or not there was a non-zero contribution from the acoustic mode and appears to be dependent on background sound speed, depth of the perturbation, and acoustic modal angle. Because non-zero contributions are so important to the total loss/bounce, identifying a relationship between these factors may result in an easy way to predict the impact of upward refracting perturbation profiles. 
The LB model was not evaluated for additional acoustic frequencies. Because the acoustic wavelength determines the acoustic significance of layers within the water column, some frequency dependence may be found. For initial evaluation, $800 \mathrm{~Hz}$ was a good choice because it is near the limits of both ray theory and normal mode methods. Because of the low-mode approximation, the LB model should continue to work well with lower frequencies. However, it is not expected to perform well at higher frequencies, with more acoustic modes. Thus, either the low-mode approximation will be inadequate or the complete modal solution will be too cumbersome.

The wavenumber perturbation method assumed the structure of the acoustic normal modes including the vertical eigenvalues and eigenfunctions. This assumption was based on a "rigid bottom" waveguide, and although useful, this simplification could be masking additional attenuation effects of the lossy bottom. Future work should include the adaptation of the model to a layered water column with a fluid seafloor.

The overall performance of the LB model on the NEST experimental data was excellent. While discrepancies were noted, several possibilities have been identified and ideas for follow on work presented. With a few adaptations, this model can provide a simple alternative to more complex propagation models. The EOF analysis provides the detailed environmental information necessary for accurate sound speed perturbations and the LB model provides an estimate of the change in transmission loss due to bottom attenuation, the greatest sink of sound energy in the shallow ocean. 


\section{Bibliography}

Abbot, P., Dyer, I., \& Emerson, C. (2006). Acoustic Propagation Uncertainty in the Shallow East China Sea. Oceanic Engineering, IEEE Journal of, 31(2), 368-383.

Apel, J. R., \& Jackson, C. R. (2002). An Atlas of Internal Solitary-like Waves and their Properties. Rockville, MD: Global Ocean Associates.

Beardsley, R. C., \& Flagg, C. N. (1976). The water structure, mean currents, and shelf/slope water front on the New England continental shelf. Mem Soc. R. Sci. Liege, 6(X), 16.

Clay, C. S., \& Medwin, H. (1977). Acoustical Oceanography: Principles and Applications. New York: John Wiley \& Sons, Inc.

Colling, A. (1989). Ocean Circulation. Boston: The Open University.

Colosi, J. A., Beardsley, R. C., Lynch, J. F., Gawarkiewicz, G. G., Chiu, C. S., \& Scotti, A. (2001). Observations of nonlinear internal waves on the outer New England continental shelf during the summer Shelfbreak Primer study. Journal of Geophysical Research, 106(C5), 9587-9601.

Csanady, G. T. (1979). The Birth and Death of a Warm Core Ring. Journal of Geophysical Research, 84(C2), 4.

Dosso, S. E. (2008). Quantifying ocean acoustic sensitivity to environmental uncertaintyslash variability. The Journal of the Acoustical Society of America, 123(5), 3433.

Garfield, N., III, \& Evans, D. L. (1987). Shelf Water Entrainment by Gulf Stream WarmCore Rings. Journal of Geophysical Research, 92(C12), 13003-13012.

Garrison, T. (2005). Oceanography An Invitation to Marine Science (5th ed.). Belmont: Brooks/Cole - Thomson Learning.

Gawarkiewicz, G. G. (1991). Linear Stability Models of Shelfbreak Fronts. Journal of Physical Oceanography, 21, 471-488.

Gawarkiewicz, G. G., Bahr, F. L., Beardsley, R. C., \& Brink, K. H. (2001). Interaction of a Slope Eddy with the Shelfbreak Front in the Middle Atlantic Bight. Journal of Physical Oceanography, 31, 2783-2796.

Hamilton, E. L. (1972). Compressional-Wave Attenuation in Marine Sediments. Geophysics, 37(4), 620-646.

Jackson, C. R. (2004). An Atlas of Internal Solitary-like Waves and their Properties (Second ed.). Alexandria, VA: Global Ocean Associates.

Jensen, F. B., Kuperman, W. A., Porter, M. B., \& Schmidt, H. (1994). Computational Ocean Acoustics. New York: American Institute of Physics.

Joyce, T. M. (1984). Velocity and Hydrographic Structure of a Gulf Stream Warm-Core Ring. Journal of Physical Oceanography, 14, 936-947.

Linder, C. A., \& Gawarkiewicz, G. G. (1998). A climatology of the shelfbreak front in the Middle Atlantic Bight. Journal of Geophysical Research, 103(C9), 1840518423.

Linder, C. A., Gawarkiewicz, G. G., \& Taylor, M. (2006). Climatological Estimation of Environmental Uncertainty Over the Middle Atlantic Bight Shelf and Slope. Oceanic Engineering, IEEE Journal of, 31(2), 308-324. 
Lynch, J. F., Lin, Y.-T., Duda, T. F., Newhall, A. E., \& Gawarkiewicz, G. G. (2009). Acoustic Ducting, Shadowing, Refraction and Dispersion by Curved Non-Linear Internal Waves in Shallow Water. The Journal of the Acoustical Society of America (In Press).

Mountain, D. G. (2003). Variability in the properties of Shelf Water in the Middle Atlantic Bight, 1977-1999. Journal of Geophysical Research, 108(C1), 11.

Potty, G. R., Miller, J. H., \& Lynch, J. F. (2003). Inversion for sediment geoacoustic properties at the New England Bight. The Journal of the Acoustical Society of America, 114(4), 1874-1887.

Potty, G. R., Miller, J. H., Lynch, J. F., \& Smith, K. B. (2000). Tomographic inversion for sediment parameters in shallow water. The Journal of the Acoustical Society of America, 108(3), 973-986.

Rutgers, T. S. U. o. N. J. (2009). COOL Data Real-time and Archived Ocean Data, from http://rucool.marine.rutgers.edu/index.php/COOL-Data/COOL-Data.html

Shearman, R. K., \& Lentz, S. J. (2004). Observations of tidal variability on the New England shelf. Journal of Geophysical Research, 109(C06010), 16.

Tang, D. J., Moum, J., Lynch, J. F., Abbot, P., Chapman, R., Dahl, P. H., et al. (2006). Shallow Water '06 - A Joint Acoustic Propagation/Nonlinear Internal Wave Physics Experiment.

Urick, R. J. (1983). Principles of Underwater Sound (3rd ed.). New York: McGraw-Hill, Inc. 